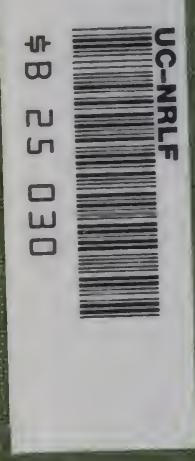

A HANDY BOOK OF HORTICULTURE

\title{
F.C.HAYES
}




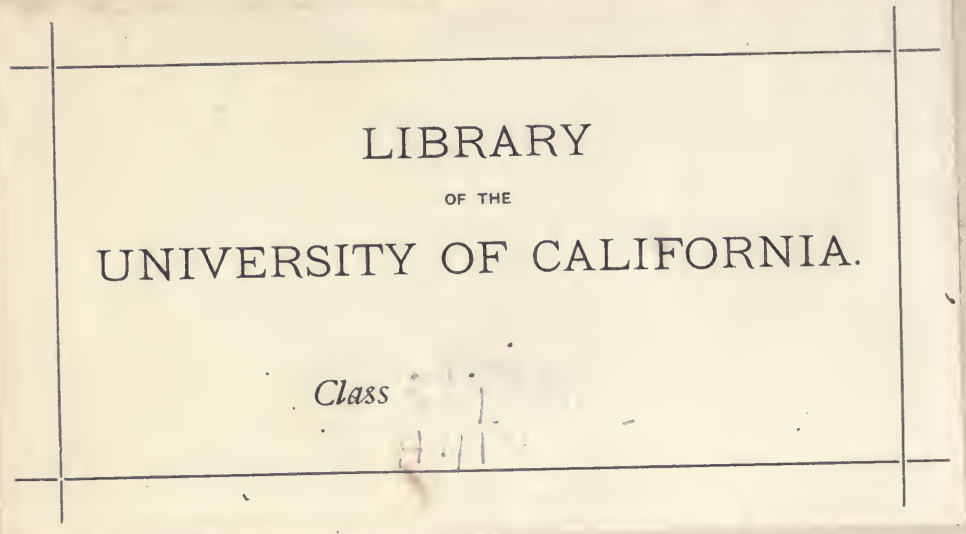


, 

A HANDY BOOK OF HORTICULTURE 
First Edition, . November 1900.

Reprinted,. . . January 1901. 



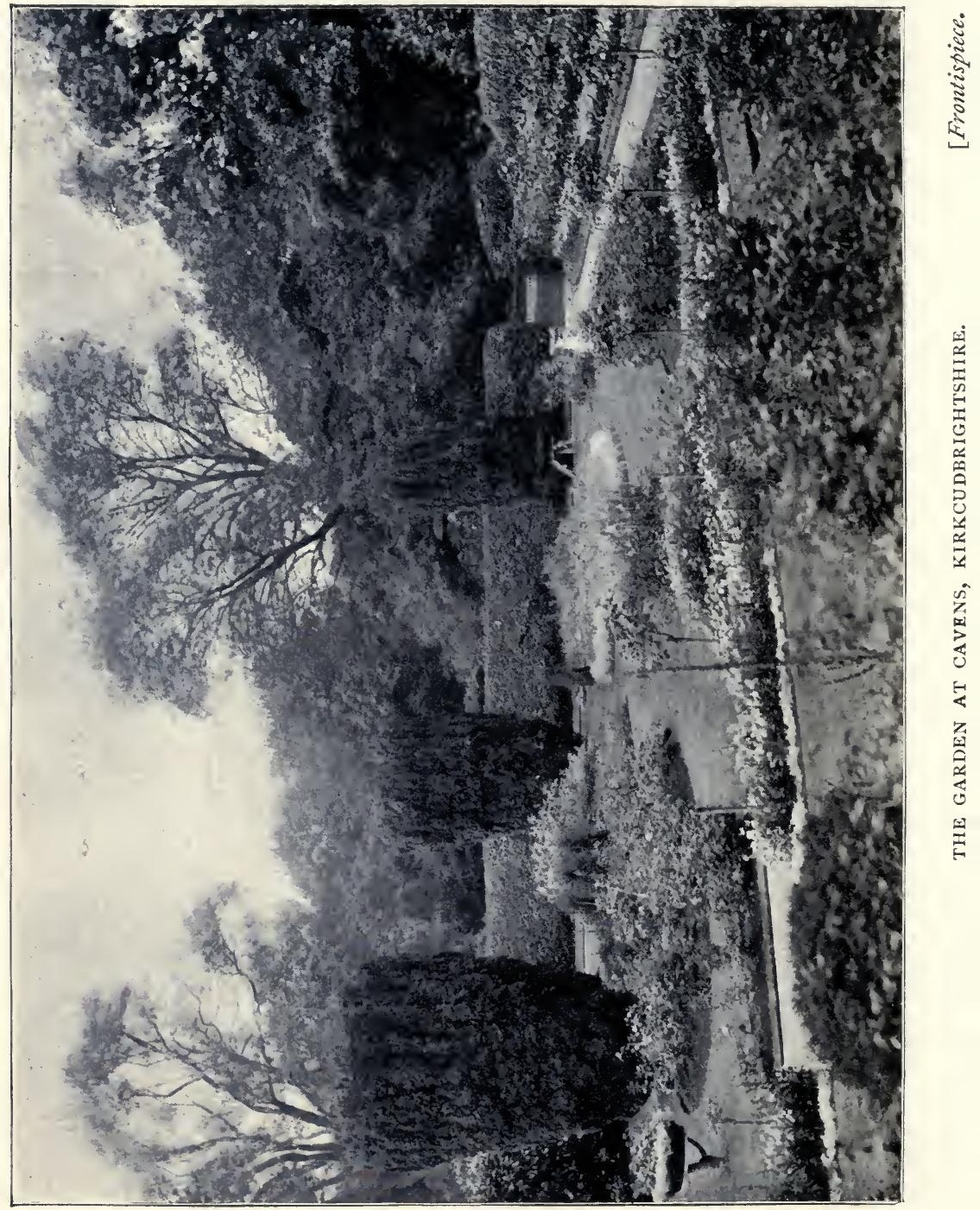




\section{A HANDY BOOK OF HORTICULTURE}

AN INTRODUCTION TO THE THEORY

AND PRACTICE OF GARDENING

By F. C. H A Y E S, M.A.

RECTOR OF RAHENY

LECTURER IN PRACTICAL HORTICULTURE IN ALEXANDRA COLLEGE, DUBLIN

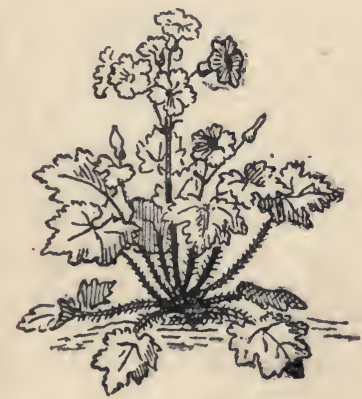

WITH ILLUSTRATIONS

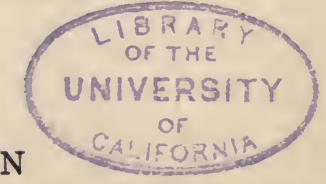

LON D O N

JOHN MURRAY, ALBEMARLE STREET

I 901 


\section{GENERAL}

'God Almighty first planted a Garden; and, indeed, it is the purest of human pleasures; it is the greatest refreshment to the spirits of man.'

-LORd Bacon. 


\section{P R E F A C E}

MANY useful and attractive books on gardening have of late years appeared-from the great standard authority, Mr W. Robinson's “English Flower Garden," now in its Seventh Edition, to Miss Jekyll's charming "Home and Garden." The bookstalls, too, are well furnished every week with capital journals of horticulture. But the books on the one hand are, as a rule, too large and too advanced for amateurs and gardeners on a small scale-for the class I mean of fairly intelligent young men who are placed in sole charge of small gardens, who have little natural aptitude for gardening and no training, and who look in vain to their employers for teaching or suggestions of any kind; and on the other hand, the gardening newspapers are, I find, too fragmentary to be of real help to them. There is, in fact, from many quarters a distinct demand for a simple 
book on horticulture-a book, for instance, such as a country gentleman who is anxious to encourage his tenants, and to interest them in their cottage gardens, could put into their hands-and it has been to meet such requirements as these, that I have endeavoured to compile a Handy-book of Horticulture, which-shall be at the same time simple and practical.

There is, besides, a large and increasing number of teachers and pupils in horticultural classes, of which I can speak from experience, who are in want of a suitable text-book on the subject, and I have been encouraged in my work by the knowledge that the new State Department of Agriculture and Technical Instruction for Ireland has decided to promote the study of this Elementary Horticulture.

It is now more than ten years since I was invited by the Council of the Alexandra College, Dublin, to undertake a lectureship in practical horticulture-at that time a new departure in education here; and ever since, I have cast about in vain for a suitable manual, sufficiently elementary, to place each session in the hands of a class of beginners, who, as a rule, have seldom previously given a thought to gardening. 
The reader will observe that in this book no attempt has been made to write a scientific treatise on gardening; it is merely intended as an introduction which when read, and in some measure carried out in practice, may help to prepare the way for much better books.

In giving lists of plants, I have not attempted to make them complete, but have for the most part confined myself to the mention of the names of a few that I have found to be the best and most suitable flowers and varieties. In fact, the limits and scope of this little book have made it desirable to restrict my work to selection, rather than to aim at completeness. But, indeed, the most popular varieties of to-day soon become obsolete; and, besides, all good gardeners should themselves observe and select those variations most pleasing and most suitable in all ways to their own use and their environment. What wearisome monotony would result from all liking the same flowers or using the same lists of "best varieties."

I am anxious to acknowledge, very wạrmly, my obligations to $\mathrm{Mr}$ Hallam Murray, and to the many personal friends who have given me their valuable assistance in various ways, as well as to others, not a 
few, from whose books I have for years obtained help, which from its variety and comprehensiveness, it is not easy to specify.

I shall be grateful for any corrections or suggestions which may from time to time be sent me.

$$
\text { F. C. H. }
$$

THE RECTORY, RaHeny, October 1900. 


\section{O N T E N T S}

\section{PART I}

\section{GENERAL PRINCIPLES}

CHAP.

PAGE

I. PRINCIPLES AND PRACTICE OF GARDENING • . I

II. THE SOIL, ITS NATURE AND PREPARATION $\quad$ - 9

III. THE FOOD OF PLANTS-MANURING • . $\quad$ I4

IV. HALF-HARDY PLANTS AND GREENHOUSE CULTURE • 17

V. HOT-BEDS AND COLD FRAMES . . . 26

VI. THE GARDENER'S NATURAL ENEMIES • . • 3 I

VII. SEEDS AND THEIR TREATMENT • . • . $\quad 38$

VIII. BUDDING, GRAFTING, INARCHING, LAYERING, AND STRIKING 40

\section{PART II}

\section{DEPARTMENTS}

I. THE SPRING GARDEN $\quad$ - $\quad$ - $\quad$ - 47

1I. SUMMER AND AUTUMN FLOWERS • • • • 55

III. HERBACEOUS AND ROCK BORDER COMBINED • • 69

IV. ALPINE BORDERS . $\quad$ - . $\quad$. 73

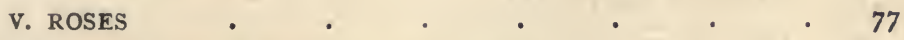

VI. FERNS-THEIR NATURE AND CLASSES . $\quad$. 82 
CHAP.

VII. CONSTRUCTION OF FERNERIES

VIII. CLIMBERS

IX. LAWN SHRUBS

X. SHRUBS AND AUTUMN TINTS

100

XI. TREATMENT OF LAWNS

IOg

XII. CULTURE OF VEGETABLES • • • • • $\quad$ • 16

114

XIII. GROWING FRUIT AND PRUNING TREES

\section{PART III}

\section{TYPES OF HARDY FLOWERS}

I. HEARTSEASE, VIOLAS, AND VIOLETS ․ $\quad$ I 39

II. SCILLAS AND GENTIANS • $\quad$ - $\quad$ • $\quad$ I $\quad$ I43

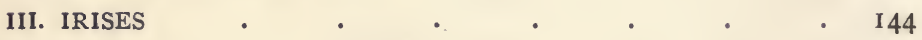

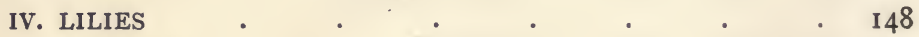

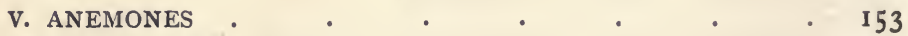

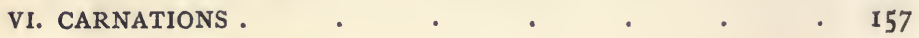

VII. CHRYSANTHEMUMS . . . . . . . . I60

VIII. CYCLAMENS AND TUBEROUS BEGONIAS • $\quad$ • $\quad$ - 66

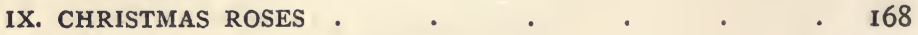

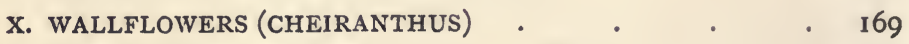

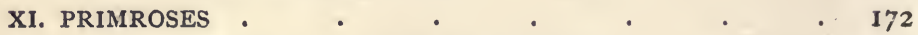

XII. ANNUALS, BIENNIALS, AND PERENNIALS • • • $\quad$ - 176

XIII. FRAGRANT PLANTS $\quad$ - $\quad$ - $\quad$. $\quad$ - $\quad$ I79

XIV. CORDYLINE AUSTRALIS . . . . . . 182

XV. WATER-LII,IES (NYMPHAA) . . . 184 


\section{PART IV}

KALENDAR FOR MONTHS

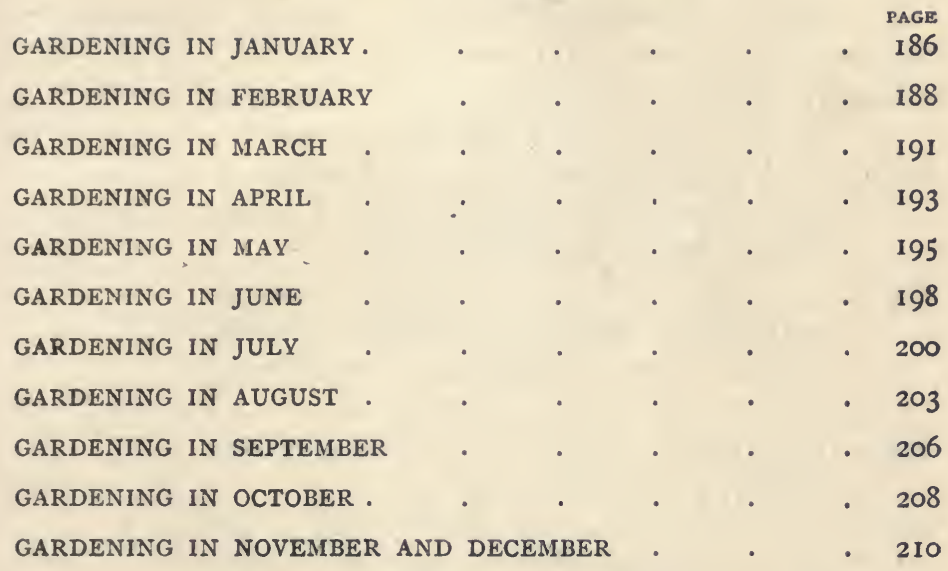

A SHORT LIST OF REFERENCE BOOKS ON GARDENING FOR

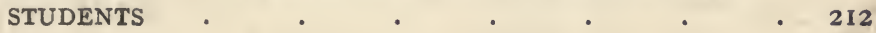

SPECIMEN EXAMINATION PAPERS • • • . 213

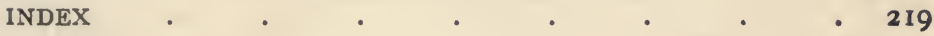


THE GARDEN AT CAVENS, KIRKCUDBRIGHTSHIRE Frontispiece GROUPS OF RODGERSIA AND BAMBOO. From a Photograph by GREENWOOD PIM, M.A. . . . Facing page 4 THE GARDEN AT EDGE HALI, CHESHIRE . . . "

GUNNERA MANICATA, AND THE WATER-LILY POND IN THE TRINITY COLLEGE BOTANIC GARDENS • 60

A GROUP OF SINGLE WHITE PEONIES GROWING IN MRS LAWRENSON'S GARDEN. From a Photograph by GREENWOOD PIM, M.A. . . . ",

WISTARIA SINENSIS AND YUCCAS ON NORTH BORDER OF TRINITY COLLEGE BOTANIC GARDENS, DUBLIN. From a Photograph by GREENWOOD PIM, M.A. • • • • • • • • CORDYLINE AUSTRALIS, GROWING AT THE RECTORY,

RAHENY, CO. DUBLIN . . . . .

CORTADERIA JUBATA-A BEAUTIFUL SPECIES OF

PAMPAS GRASS GROWING IN MR W. E. GAMBLE-

TON'S GARDEN, BELGROVE, QUEENSTOWN WATER LILIES, GROWING IN MR S. ARNOTT'S GARDEN, CARSETHORNE, DUMFRIES, N.B.

\section{DIAGRAMS}

From Drawings by AlICE JACOB.

PRIMULA SINENSIS

METHODS OF PREPARING THE SOIL

Title page PROCESS OF BUDDING . GALBREATH BUDDER GRAFTING LAYERING CHRYSANTHEMUM "TAKING THE BUD" Do. do. Do. do. page 13 " 4 I " 42 , 43 , 45 , 164 , 165 ,, 166 


\section{PART I \\ CHAPTER I

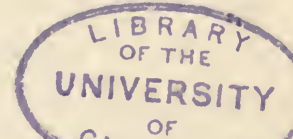 \\ OF

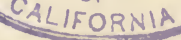

PRINCIPLES AND PRACTICE OF GARDENING

FVERY man and woman should have some hobby, some by-work, on hand-the old Greeks called it a par-ergon-and there are few hobbies which have so many advantages and such trifling drawbacks as horticulture. One excellent thing is-that it lasts. When we grow old we are as fond of our plants as when we were young, and better able to manage them, for we have come to learn their nature and habits, and, like other old friends, we understand them and love them more every year.

Then again, our garden tends to foster in us a love for nature, and to educate the eye and the mind to observe all that is beautiful and lovely around uscolour, and form, and contrast. Flowers-Mr Ruskin tells us-only flourish rightly in the garden of some one who loves them.

And surely there is an especial attraction for many 
strong people in the opportunity which gardening affords them of measuring their strength against those forces of Nature which are most hostile to the science of horticulture.

It is wonderful how much recreation, in its literal sense, is brought about by all this; the worries and anxieties of the great busy world are forgotten in the new interests of our little world of nature.

There is another point that should not be overlooked. Our work is likely to be a source of at least as much help and gratification to others as to ourselves. Some of our friends, whose own knowledge is very limited, or who think they have no time or ability for such work, can yet find a real pleasure in their investigation of other people's gardens, just as they would enjoy a private view in a friend's studio; and when these people cannot come to us by reason of the distance, or because they are sick, what joy the receipt of a box of violets by post gives, and the thought which has suggested the gift is welcomed no less than the fragrance.

That which specially marks all work connected with a garden is that there is much more practice than theory connected with it; and so, by using our hands and eyes continually, we come to know things almost by intuition. The important matter is that we take means to increase this knowledge by reading other people's-experience, and asking questions of those who know more than we do. Carlyle defined genius as 
the power of taking infinite pains about little things; and it is certainly true that successful gardening implies the use of almost infinite trouble and care and method about a host of apparently trifling details, the neglect of any one of which may mean failure.

It is a good rule to exclude rubbish from your garden-to be satisfied with no plant, or tree, or seed that you have reason to know is only second or third rate. It is mere waste of time to sow inferior seed of any sort; the very best degenerates only too soon from causes over which we have no control.

It is a pity to take up work by fits and starts; far. better to devote a little time regularly, and it is surprising how each month and season will find its own special business, and how naturally, after a while, we bring ourselves to fall in with the kalendar.

Another thing of importance is that we should be content with one or two branches of work-that we should aim at being specialists rather than general practitioners, and that our choice should be made to depend upon our circumstances. If, for example, a stovehouse should be found ready to your hand, you will find it a very interesting branch of gardening, though you should never have dreamed of setting up one for yourselves-at least for many a day.

If there is a greenhouse in which the temperature can be regularly kept up to $50^{\circ}$ through winter, there are few more attractive corners in a garden than such a place, and you will do well to set to work on that 
4 PRINCIPLES AND PRACTICE OF GARDENING [CH.

particular branch of the art, so that you may make the most of it. While, if there is no glass available, that very fact seems to indicate that you should, at all events at first, confine your attention to an herbaceous border, and to the picturesque arrangement of your grass and evergreens; and so far from this being beneath notice, I should say the amateur who deserved most praise was one who had managed to transform a bare, ugly enclosure-whether a big piece of ground in the country or a small patch of garden in the city-and turned it into something on which the eye might rest with satisfaction. There is no excuse for ugliness while it is possible by a simple and natural disposition of a few flat rocks to break the monotony of garden walls, and to contrive a footpath which shall wend its way between the jutting stones, and in some such way do duty for the vulgar, conventional, commonplace, rectangular gravel walk. So soon as the Ivy, Clematis, and Virginian Creeper have covered the walls, and some clumps of Rodgersia and Scolopendrium ferns have been planted between the strata of rock, your unpretending garden need not fear comparison with many a more favoured nook.

And now for some details :-

Composts.-As the artist must have his store of pigments from which he can produce the various colours that lend such a charm to his pictures, so the gardener will have a special department in which are stored the 


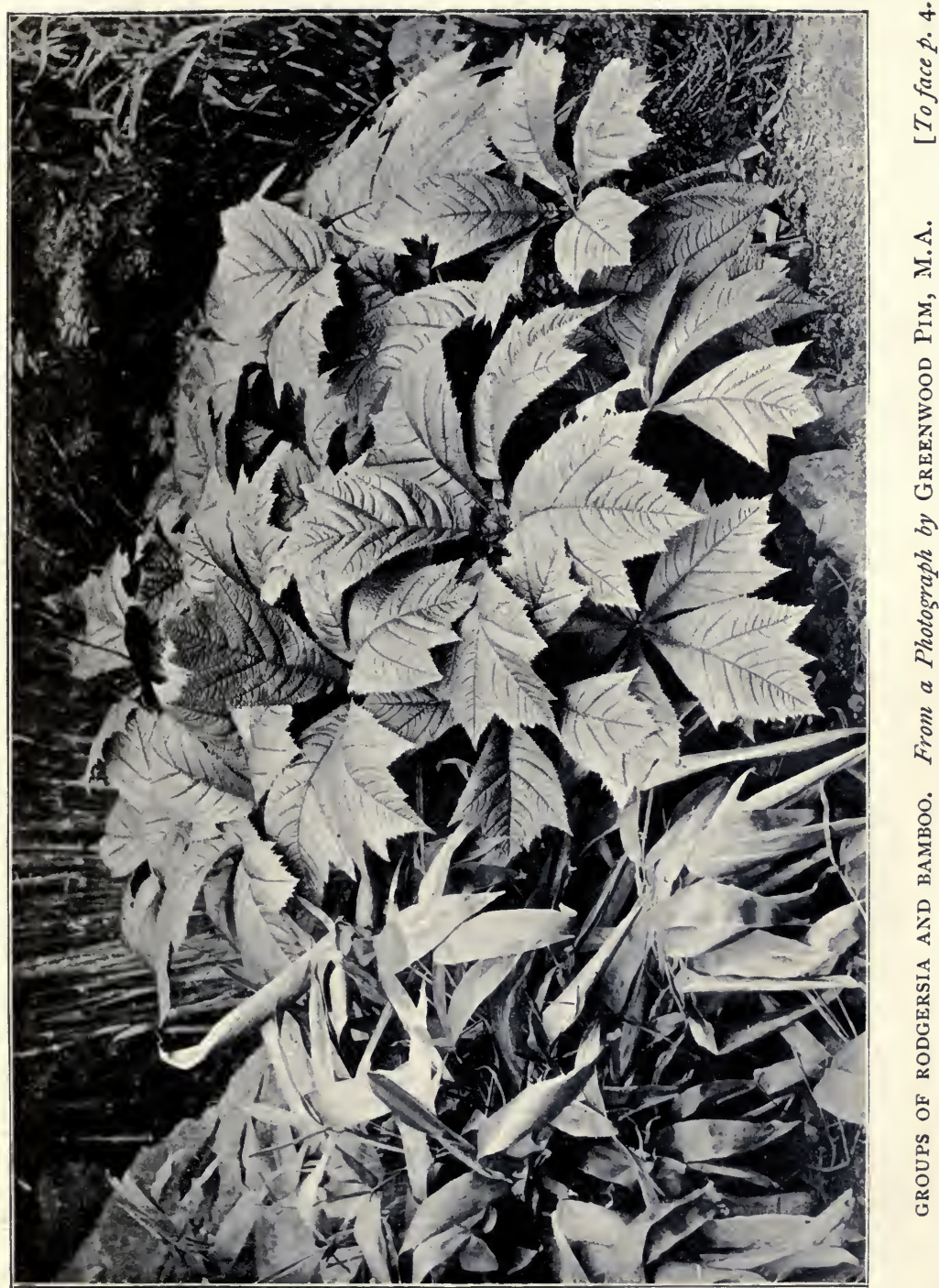


(1) 
raw material of his composts, and where lie concealed the real secrets of his art.

In a secluded corner of the garden some sort of rough shed should shelter one small heap of cowhouse manure, a second of sods taken from an old pasture, and yet another of leaf-mould two years old; a wooden box with coarse Reigate (or other gritty) sand, a second containing cocoanut fibre, a third, with a half barrow or so of peaty mould, and a can of soot. From such a store almost any sort of compost suitable for any sort of plant can be made up on the shortest notice. For example, if the supply of Dutch roots has arrived and you require to pot Hyacinths, or Daffodils, or Tulips, or if you wish to pot off such soft-wooded plants as seedlings Cinerarias, or Chinese Primulas into their first pots, the mixture would be something of this kind :Turfy loam, two parts; leaf mould, one part; sand, one part, adding a sprinkling of soot and cocoanut fibre; or if you are potting Fuchsias, or other such hard-wooded plants, you should use one-third loam, one-third sand, one-third peat; while for Heaths, Rhododendrons, and Azalias, two-thirds peat and one-third sand is best; adding for Ferns some of the rotted sods and leaf mould.

If broken pot-sherds have accumulated, and you have more than you are likely to require for drainage, they make an exceedingly good substitute for sand when ground into fine grit on a flat stone. It is much better for taking the place of Reigate sand than the fine loamy sand so often used. 
Potting.-Perhaps one of the very best tests of an experienced amateur is to be found in his method of potting. I am sure failures result more frequently from ignorance and carelessness in the potting shed than in almost any other department of work. In the first place, care should be taken that the old pots have been well cleaned, and scoured inside and out before being again used. Dirt and moss clog the pores of the earthenware, and hinder the free transmission of air and moisture to the roots of the plant; besides, if old fibres remain and adhere to the inside, the new young roots get entangled, and for soft-wooded plants make it difficult to repot without violent treatment. Then it is a safe rule to "pot small," the smaller the pot (within limits) the more vigorous the plant-indeed it never really thrives until the young roots have got well through the soil, but they should be shifted before they get turned too much by coming in contact with the pot. There should be a liberal drainage of broken pot-sherds at the bottom, with a thin layer of old moss over it. Next, fill in with the coarser part of the compost, finishing with the finer-and the stuff is all the better if it has not been run through a fine riddle. In potting soft-wooded plants they are best merely shaken down and gently pressed; with hard-wooded you can scarcely be too firm. When the operation is completed, a good watering consolidates the soil and the roots of the plant, and if the pots are clean, one may come to know by the outside appearance, or by a rap of the gardener's knuckle, when more water should be given. 
A potting bench standing nearly 4 feet high (with a block to raise oneself, if necessary) should be fixed in a convenient position in the shed, so placed that all materials may be within easy reach, and that no time need be lost in searching for them.

Labels.-Let me impress upon my readers the advantage of labels. No one should depend on memory for the name of a plant, unless it be a familiar old friend. I have found stout zinc or corrugated iron, cut into strips 9 inches in length and $I$ in breadth, pointed at end (with smaller sizes for pots), to be lasting, neat, and distinct. A mixture of white lead and drying oil should be very thinly rubbed in on one side with the top of the first finger, and the name written with a soft lead pencil, while the paint is fresh; it will then last for years, while those made of wood, if they are not oak, very soon decay and disappear. Similar labels, only cut into other shapes, may be attached to roses and fruit trees by means of a piece of lead garden wire. It will be always well to prepare the labels beforehand, so as to have them ready for use when wanted. If not done at the proper time this important work may be forgotten until too late, when the names are sure to have been lost or obliterated.

Dress.-Ladies will find a tanned skin (to be had in any leather shop for a few shillings, and deftly adjusted with shoulder straps and strings or belt) a great comfort in work, and a protection to their dress, which by this 
method need not be changed every time an hour has to be spent in the garden, besides which it will keep one's knees from damp and mud when busily at work stooping over borders.

Tools.-Very few and simple are the tools an amateur will find necessary. A well-made spade, not too heavy, a digging fork, a rake, a hoe, a strong (second-hand) mason's trowel-which will last a life-time, a pair of shears, a handy knife with large and small blades, a small handsaw, a pair of pruning gloves, a really good pair of pruning scissors, and a garden line.

Hard Names.-Let no beginner feel discouraged by what might be called "the nomenclature of horticulture." At first the long Latin or Greek word is unintelligible, but after a while the meaning of the name will dawn upon us, and we shall discover its appropriateness to the plant; it then becomes easy to remember. Take a familiar example: the name commonly given to one of the newer Virginian creepers (Vitis inconstans) is "Ampelopsis Veitchii" - opsis meaning in Greek the appearance; ampelos, a vine; and Veitchii conveys the fact that it was first introduced by Mr Veitch of Chelsea-not so very difficult a derivation; and when all has been said, it will be allowed that we gardeners are much more fortunate in this, as in other respects, than our next-door friends and neighbours, the Botanists.

Observation and Investigation.-One thing more 
those who love flowers will much observe them-their own and their neighbours'; nothing but constant observation can ever make us familiar with the habits and wants of our plants, their capacities of adapting themselves to circumstances, and their fitness or otherwise for their position in life. To those who do not know better it may seem strange enough that sane, intelligent, and industrious folk should often be found wandering round and round their garden, gazing with an interest perfectly fresh and apparently new at objects they have seen before scores of times. These people have neither telescopes nor microscopes, yet they are making observations, and seeing things with their own eyes which outsiders could not see even with the help of a lens of very high power. Such habits of observation go to form the very soul of a gardener, and their results may be seen continually in all sorts of unexpected arrangements and pleasant surprises.

\section{CHAPTER II}

THE SOIL, ITS NATURE AND PREPARATION

OUR garden soil has been very fitly compared to our cook's larder. The similarity is threefold-each must be kept sweet by the action of the air, kept clean by the activity of the owner, and, above all things, well furnished.

The rcturn the soil will make to the cultivator depends more than we suspect on what the cultivator can do for the soil. 
The soil of the garden is, as I have said, the larder which holds the food for the crops; it has indeed a double use-it gives anchorage to the roots, and it holds the materials for the support of their growth.

It is not an uncommon error to suppose that our plants feed on the soil of the garden just as, I daresay, some people think that bees feed on the flowers of the garden; as a fact, bees take the honey, but they leave the flowers intact. Crops take what is to them the honey, and the earth remains to have itself refilled with new food for future crops, and the cultivator's office is to see how he shall best render the soil of his garden fit for receiving and holding the food of his plants.

Now there are two extremes of soil which are equally unfit to support vegetable life, and that for opposite reasons.

The two extremes are sand and clay. Neither in its purity is in the least capable of supporting or growing a plant. Sand is like a sieve, all nutritive matter runs out of it directly, while clay is like a metal pot, or a swamp, sealed against air, and with no means of outlet, and there can therefore be no sweetening process and no growth in it.

The ideal garden soil is loam-that is, a composition of sand and clay in varying proportions.

Before we can decide, therefore, on the proper treatment for our garden, we must satisfy ourselves as to which sort of loam our garden is composed of. In a rough way, most eople can guess the quality and composition of their 
garden soil, but if we wish to be accurate, any one may ascertain this for himself by a simple experiment.

Let him take a trowelful of soil out of the garden, dissolve it in water, boil it ; in a little time the sand, which is the heavier, will be on the bottom. When the water evaporates he can measure the sand and the clay respectively.

In this way it will be found that in the soil taken, e.g. from :-

Garden A., sand is present to the extent of over So per cent. ; this is sandy soil.

Garden B., sand is found to be between 60 and 80 per cent.; this is sandy loam.

Garden C. contains from 40 to 60 per cent. of sand; this is typical loam.

Garden D. contains only from 20 to 40 per cent of sand; this is clayey loam.

Where there is less than 20 per cent. of sand it is clay pure and simple.

In a garden where the soil contains less than 40 per cent. of sand, the gardener's object will be to add as much gritty matter as will bring it nearer the standard or typical loam, to stir and pulverise it so that it may become sufficiently porous to admit air and sun; and, on the other hand, where there is too large a proportion of sand, enough to render it too porous-i.e. containing a larger amount than 60 per cent., under these conditions it cannot hold moisture for the roots and nutriment for the crops; then there must be added heavier material of the nature of clay, and this must be well mixed with it by digging and trenching. 
In some soils, from the nature of the ground and of the subsoil, one of the first essentials is a thorough draining-i.e. some method of filtering away underneath the surface all superfluous water.

It would be hard to exaggerate the importance of draining wet soils. Land on which water constantly lies becomes a cold swamp in which only bog-plants will thrive. It is cold for the simple reason that the sun's rays which fall on it are wasted, employed as they are not in warming the soil, but in evaporating the water which ought not to be there at all.

But it is not only that wet land is cold; earth full of water is hermetically sealed against all healthy atmospheric influences. Not until the water drains away does the air take its place-I 5 lbs. pressure upon every square inch of the surface; it then becomes moist, warm air, the most important of all agents in promoting plant growth.

Having dealt, then, with the nature and use of the soil, it only remains to add something regarding its preparation. By this I mean the art of making the most of it with a view to the production of large and healthy crops. It is evident that the deeper the soil the greater will be the space in which roots can grow and the larger the capacity for containing food for them. A shallow earthenware pan, e.g. will suffice for young seedlings during the first few weeks of their life, but if they are to thrive they must then be removed into a deeper pot, and finally be distributed into larger ones, or else they will soon become dwarfed and cramped. It is precisely 
so with the land; where the soil is shallow and has a hard surface the roots are necessarily confined to a very small feeding ground. They cannot penetrate down, nor can the moisture from beneath pass up to them in dry weather, neither can the surplus water in wet weather pass away; under these conditions only a small part of the land is utilised and a great deal is left waste.
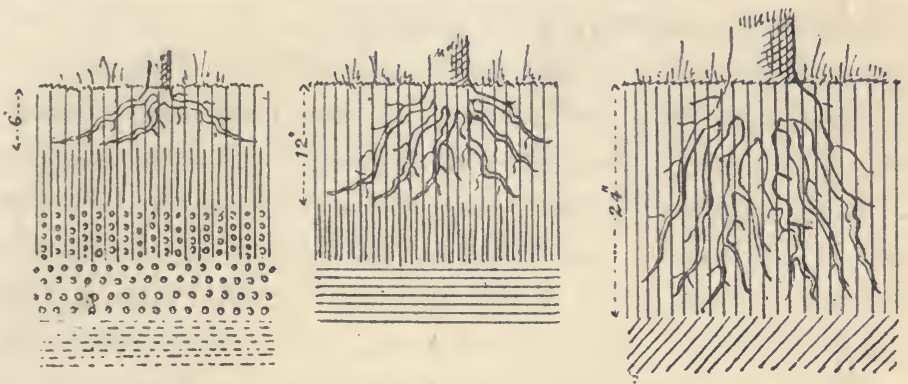

The three diagrams are meant to illustrate the three recognised methods of preparing the ground-first by ploughing, which is practically limited to the upper 6 inches of the surface. By digging, there is a further depth of another 6 inches gained; the food-holding soil is proportionately deepened, the useless subsoil recovered, and by this means the store for food is just doubled, and the capacity of growth for trees and crops in the same proportion increased. By trenching again, the soil may be made good to a still greater extent. Trenching means the moving of all the soil to the depth of about 2 feet, and by a judicious mixing of the upper and lower strata bringing the whole avail- 
able soil into cultivation. In this way, as is shown, in the diagram, the food-store is again doubled, the root area further extended, and just in proportion as the roots extend below can the stems and branches flourish above. With a free and healthy root-action in such deep fertile soil, the growth of the plant becomes more active and the produce much better, at least so far as the tiller of the land can secure it; for of course at best he can only improve, he cannot change, the nature of the soil.

It should be borne in mind, however, that inexperienced workers may do more harm than good by vicious methods of trenching, ${ }^{*}$ and there is perhaps no process in horticulture which so much needs the help of an expert as the art of using the spade judiciously. In this department half an hour's practice on the ground is worth more than a whole chapter's instruction on paper.

\section{CHAPTER III}

\section{THE FOOD OF PLANTS-MANURING}

WE have endeavoured to explain the nature and the use of the soil as the anchorage and storehouse of our plants. It remains to add a word or two as to the

* For instance, when the subsoil is of a clayey nature, great harm would be done by bringing up such raw material to the surface at once, but great benefit would accrue by incorporating with the bottom spit, manure, or even sand or road-grit. 
nature of the food with which we should provide them. The oldest record in the world in its opening page, after describing the creation of the earth itself, suggests the exact treatment which it requires. Adam was directed to "replenish the earth, and subdue it." The soil was not to be left to itself; it must be reclaimed and then replenished. Here briefly is to be found the whole secret of plant life and soil culture. All growing plants will greedily and constantly draw upon the soil for the nourishment stored in it, and it is the gardener's duty to see that the store is never exhausted; his part is "to replenish the earth." But that this rule which Nature suggests is not seldom broken we may often see.

We may observe the signs of exhaustion whenever we enter a garden or orchard where the bush fruits are stunted and the vegetables are lean and thin. These plants tell the same tale as the neglected children one meets in the slums, and we know well enough the cause is the same, starvation-empty larders.

The remedy of course is simple enough-it is food; but even then there is the danger of supplying unsuitable food.

The staple food of all trees and plants is nitrogen, phosphorus, and potash in certain proportions. Most of the other necessary ingredients which go to make up manure are already in the soil in the requisite quantities. Plants also take up and solidify a large quantity of carbon from the air in the form of carbon dioxide $\left(=\mathrm{CO}_{2}\right)$ which is as much their food as the earth salts soluble in water. 
Such essential elements are found naturally combined in our farm-yards and stables. One ton of farm-yard manure should contain these chemical fertilisers in about the proportion of from 9 to 15 lbs. of nitrogen, 9 to $15 \mathrm{lbs}$. of potash, and 4 to $9 \mathrm{lbs}$. of phosphorus. Such manure, when it can be had, should be used at the rate of from 10 to 12 cart-loads to every quarter of an acre.

Then again, in some remote corner of every garden, if possible out of sight, there ought to be a compost heap, on which can be thrown animal and vegetable refuse, sweepings of the avenue and road, charred wood fibre, decayed short grass and soft weeds, half-rotted leaves, cleanings of fowl houses, occasionally sprinkled with lime and covered with soil; on this may be thrown soap-suds and all sorts of slops from the house. When turned over now and then, and sprinkled with soot, it becomes a rich store-house for garden use. The covering it over with soil deodorises the heap, so that it need not be in the least offensive. It may then be used for digging into the ground, or for mulching or top-dressing fruit plantations. Such manure heaps are of great service at small cost; they are the reserve commissariat of the garden.

In many public and private stables peat-moss litter is now used for bedding horses. After lying some weeks in the stall it becomes mixed and saturated with the stable manure. A surface dressing of this stuff is peculiarly useful for fruit trees; it not only attracts the roots to 
the surface, but its rich juices percolate down into the soil with every fall of rain.

Old gardens which have become sour and over-fed with vegetable matter will get much benefit from a dressing of lime every few years. The lime should be brought fresh from the kiln, distributed in heaps over the border, covered with soil, and when slacked worked into the ground. This should be done some time before sowing or planting. Chemical manures, such as nitrate of soda, bone flour, and guano, are excellent stimulants, as well for plants in pots as in the borders. They, too, should be applied early in the year before active growth sets in, and are best given in liquid form, or as top-dressing in showery weather. For greenhouses, Cannell's or Carter's or Icthemic (fish) guano mixtures are the safest to use.*

I know of nothing better, however, as a top-dressing for flowers, vegetables, and fruit trees than the scraping of the fowl-house mixed with five or six times its bulk of fresh earth, and kept in a dry heap in the potting-shed ready for use.

\section{CHAPTER IV}

\section{HALF-HARDY PLANTS AND GREENHOUSE CULTURE}

MR PUNCH'S advice to those about to marry might very well be offered to another class in the community-those

* Bassic slag is an excellent artificial manure, but, like others, it must largely depend on the nature of the soil it is used on. 
about to build a greenhouse-“Don't." Only a very few should be encouraged to undertake such a task-those who have had experience in the culture of plants, and who, moreover, have some spare time each day to devote to the small details which such ownership involves.

It should be remembered that plants grown in a greenhouse are, in many respects, like birds confined within a cage. Canaries, for example, are at the mercy of their owners; if neglected, they pine and die, or worse, it may be, starve and linger on, much to the discredit of their keepers, while a jackdaw or gull, as a rule, though confined within the garden, runs no such risks, as these birds can forage for themselves even when the morning visit has been omitted. This is one reason why a herbaceous garden is much to be preferred to a greenhouse for the majority of amateurs: once it is made, weeded, and top-dressed occasionally, it may, without much harm, be left to itself for weeks together.

There are those, however, who will find a greenhouse a constant source of pleasure both to themselves and to their friends, and, like many another occupation, its difficulties are easily overcome by those who love such work.

A well-designed greenhouse, say 20 feet by 12 feet, will often afford more enjoyment, and produce more satisfactory results than a large and costly conservatory. Years ago I remember building a house about 6 feet square for tea roses in a garden where they could not be grown in the open, and now, as I write, the vision of 
some of the blooms, and even their peculiar aroma, comes to me like a whiff of spring.

It is a mistake (to which architects are peculiarly liable) to build your house with a high roof; you should have barely room to stand in it with your hat (a low crowned one) on. Every additional inch makes against the well-being of the plants. Then there should be good ventilation, both overhead and below, if possible at opposite points of the compass, so that some of the ventilators may be open whichever way the wind blows. A tiled floor, or one made of wooden laths, will permit of watering and syringing being carried on without mess, and there should be a water tank inside, if possible, so that the temperature of the water may be not much lower than that of the house, for there is nothing that so effectually checks root growth as the application of icy cold water.

Under ordinary conditions, the matter of greatest importance is the stove. I have known a very simple device to answer the purpose, but by far the best, and in the end the most economical, is a high-pressure boiler, which supplies hot-water pipes. A judicious mixture of cinders (or coke broken small) and a little breeze (coke slack) mixed with some slack from the coal cellar will keep the boiler fire alive for weeks at a stretch, the great point being to aim at keeping the night temperature to $50^{\circ}$, and the day not more than $10^{\circ}$ higher.

Unless one can have a satisfactory stove, I can see little benefit in giving oneself the trouble of keeping half-hardy plants at all. What is the advantage of 
a greenhouse which only lures good plants to their destruction on some frosty night? And I know not what is to be gained by storing ugly pots with leafless tenants all through winter only to have them beautiful when all the plants outside are vigorous. If it is worth spending money in building a house, it is surely worth just a little more in fitting it for its special purpose, which is to grow these things well, as they ought to be grown, and to be able to enjoy their beauty during the long, bleak, wintry months.

It is desirable that the house should not be crowded with stages. A bed running along one side, front or rear, makes it easy to plant such things as are meant to adorn the walls or roof, and this bed should be amply and well filled with nourishing food for years to come, chiefly rotted sods from an old pasture, mixed with broken bones, charcoal, or charred wood ashes and burnt earth. One Rose, a Maréchal Niel, or Fortune's Yellow, thus planted and trained over a portion of the roof, might be made to bear the cost of the winter's fire. A few wire baskets hung judiciously above the stage will lend themselves to the requirements of straggling plants, such as the Ivy-leaf Geraniums, Blue Lobelia, Moneywort, or some of the better sorts of Nasturtium.

Of course, each house will be furnished according to the taste and ability of the owner, but one rule I would suggest for all -it is, that they only admit good things into their greenhouse, that they endeavour as far as possible to exclude rubbish; and this rule holds good for seeds as well 
as plants. There is no more trouble in growing the best things of their kind than the worst, and there is very little more cost. Mr Cannell, of Swanley, Kent, will send his catalogue to those who write for it, and it is in itself an inspiration.

When once an amateur has selected a few dozen of the Swanley plants, and they have been well treated, very soon they will multiply and increase his store, so that not only his own house will be filled with really good plants, but he will have a great deal from which he may enrich his neighbours.

Again, the importance of shading must not be overlooked. It is wonderful what a difference shading will make in the greenhouse; it promotes an equable temperature, and saves a world of time and trouble in the matter of watering. There are some houses in which it is most convenient to tack some lengths of tiffany (sold in the seed shops) along the inside of the roof which looks south. This can be removed in autumn, and folded up for next year's use. But the method I prefer is to prepare to the consistency of cream a mixture made up of sour buttermilk (or hot water mixed with powdered alum or size) with fine-ground whiting and a square of blacking, or if a blue or green shade be preferred, a handful of blue or green paint. This, artistically patted on the glass with a whitewash brush, will last until the autumn rains wash it away. It should be done on a fine morning, so that it may be dry before rain or the fall of the dew. If the greenhouse is low, as all greenhouses should be, a small 
platform of some sort will make a ladder unnecessary, and the brush may be tied to a handle 3 or 4 feet in length. It will be sufficient to muff the south roof and the ends of the greenhouse, and the stuff should not be applied thick, rather after the manner and substance of the tiffany itself.

The uses of a greenhouse are as various as the seasons of the year.

It may be a mere winter shelter for bedding plants, or a resort for the healthy growing of specimens to be promoted to the sitting-room or the porch, as they are required; or it may be the ultimate destination of those soft-wooded things which are raised in the hot-bed and cold frame, and only brought into the greenhouse when it is no longer safe to keep them outside. For all these objects it is of the greatest importance that a low, equable temperature be maintained, with good ventilation, and without draughts-not too dry, and yet not damp. In late spring and summer, floor and stages should be judiciously syringed in the evening. In winter and early spring carefully moisten in the early part of the day, except in frosty weather, and then under such conditions the plants will not suffer much when transferred to less favourable positions.

There is no reason, however, why the greenhouse should not be so arranged as to be gay with flowering plants all the year round.

Cacti are grown without much difficulty. Perhaps 
the best plan is to stow away the pots in a frame under a south wall for August and September-giving no water -then carry back to the greenhouse and keep dry till the end of March; from April to July giving plenty of water. They seldom need repotting.

When Zonal Pelargoniums are properly managed they will be one of the chief features of the house all through winter and spring. There should be two or three sets of them potted respectively in anticipation-say, in March, July, and September-in good, rich soil, not allowed to get too dry, and all the strong shoots nipped in, so as to throw the strength into the flower trusses. Those I have found best are Henry Jacoby, Countess of Derby, Athlete, Plutarch, Niphetos, Queen of the Belgians, Lizzie Constable, Surprise de Nain, Antoine Barton, Aurora Borealis, Raspail, Juliet, Paul Campelle.

Chinese Primulas (Primula Sinensis) are, perhaps, amongst the most popular of all winter and early spring greenhouse plants; they are now grown with all the tints of the rainbow-white, rose, magenta, and carmine, crimson and spotted, double and single. If sowings have been made in succession between March and May, while there has been bottom heat in the frame, or young plants obtained from nurserymen, they will be sure to bloom from November to Easter. The proper compost for them is, three parts good old rotten sods broken with the hand, one part old cow-dung and leaf-mould mixed, and 
as much coarse Reigate sand as will keep the whole open. The young plants should be potted firmly, plunged, and kept close in the cold frame, and shaded from bright sunshine. When they have filled the small pots with roots they may be shifted into 5 -inch pots, with good drainage, potted rather deep, and some sand round the neck to prevent damping. Return them to the frame, keeping them plunged, and near the glass, giving plenty of air, and seeing that the flower-buds are nipped off until well on in September. The longer the plants are kept in the cold frame the better, but they should be moved into the greenhouse before frost. While the flowering stems are growing up manure water once or twice a week will give vigour both to leaf and flower.

Long ago, when the bedding plants were turned out to summer quarters, for the better part of the season the greenhouse used to be absolutely devoid of interest. The tuberous-rooted Begonias have brought about a wonderful revolution, and with as little skill as is required to raise early potatoes bare stages may now be filled with dazzling blooms. These bulbs may be grown from seed as readily as Chinese Primulas or Cinerarias, and they have this advantage over all other flowering plants, that they last year after year, the roots increasing in size like Cyclamens.

It often happens that from varying circumstancesfrom change of ownership most frequently-large greenhouses have become disused. Sometimes it becomes a question whether they should not be pulled down. 
In such a case, where one could be sure that both owner and gardener have their wits about them, I may suggest another alternative as a practical way of turning a ruin into a profitable investment.

It is very simple and very practical; all it needs is some industry and skill. At the outset, I propose that every available space around should have a rose planted in fresh, rich, well-prepared ground, so well prepared that it may feed the trees for some years. There are half-a-dozen roses which are only in perfection with such protection :-Maréchal Niel, Climbing Devoniensis, Madame Lambard, Niphetos, Cloth of Gold, Reve d'Or, Fortune's Yellow, Lamarque, Catherine Mermet, The Bride, Souvenir d'un Amie, and Allen Richardson. These will produce a profusion of early buds each spring, which may easily be sold in the flower market at a good price.

I would then cover the floor surface of the houses with a rich compost, made up of earth from the field, grit from the roadside, and well rotted manure. A few score, to begin with, of early flowering Chrysanthemums will not cost much as a first outlay. Even in the border they will produce more blossoms than any other flower, and with the protection of glass they will bloom up to Christmas. La Vierge, Madame Desgrange, Lady Fitzwigram, Harvest Home, Mytchett White, Mytchett Beauty, Crimson Précocite, Geo. Wermig are amongst the best.

Then again, at any time in summer a thousand Tulips can be had from "Van Tubergen, jun., Haarlem, Holland," for seventeen shillings, and if they are thickly planted 
between the rows of Chrysanthemums, they will be ready to mature their buds when the time comes for the Chrysanthemums to be cut down. These also have a ready sale.

Long before this, strong, young autumn - grown plants of Tomatoes will have been waiting ready in their pots to be planted through the house, wherever there is a vacant space, during the early months of the year, and they will have borne their fruit and found an early market at a time when most of our neighbours are beginning to think of potting theirs.

\section{CHAPTER V}

HOT BEDS AND COLD FRAMES

ALL garden plants which are not perfectly hardy need in various degrees the protection of glass, and the proper management of half-hardy plants in their earlier stages is that which chiefly taxes the resources of the amateur gardener.

Without the aid of the cap-glass and the cold frame and the artificial heat of the hot bed, one's greenhouse can be, after all, little better than an empty show. It should indeed be looked upon as the ultimate destiny of our exotics, but for the early part of their existence it is a most unsuitable quarter. 
The early spring is the season for raising plants from seed, and propagating cuttings, for the furnishing later on of our borders and glasshouses.

But these weeks of spring are almost always cold and bleak, and seeds will not germinate, nor cuttings strike root without a warm, shady, and moist atmosphere, produced by artificial heat of some sort-without an atmosphere which is different alike from the cold blast of the open and the glare and draughts of the stages of the greenhousè.

A shallow melon or cucumber-frame, into which a hot-water pipe from a neighbouring boiler can be introduced beneath the peat mould or cocoanut fibre, or some such contrivance on a small scale within the greenhouse itself, when practicable, is perhaps the ideal arrangement for a propagating pit; but where this cannot be had, then a hot bed must be rigged up, and this requires some skill and knowledge, for the necessary heat may spend itself as quickly as it came, and cause no small disappointment; indeed, there should generally be a second hot bed in succession.

A good-sized load, therefore, of fresh stable manure should be obtained, and turned every third day for more than a week, with a good sprinkling of water applied when the weather is dry, then built into the proper shape, alternating each layer with an equal thickness of the grass rakings and leaves of the previous autumn. When built, and the frame in its place, 6 or 8 inches of turf-mould, or sandy loam, or cocoanut fibre should be 
thrown over it, into which the seed-boxes and pans can be plunged.

The treatment of such a hot bed requires, as I have said, a good measure of skill, and beginners would need the help of some nurseryman or gardening friend, not merely as to the method of sowing their seeds, but as to their after culture, and more especially as to the details of watering and the regulation of temperature, light, and air.

Until the first violent heat has spent itself, neither cuttings, nor bulbs, nor seeds must be allowed into the frame.

The most convenient things in which to sow seed or propagate cuttings are shallow earthenware pans, or raisin boxes with holes pierced below - drainage of cinders or potsherds to the depth of an inch, over that 2 or 3 inches of coarser compost, and some finer stuff on the surface. When the pan has been filled to within an inch of the top, water freely with a rose, let it stand for an hour or two, then sow thinly, cover lightly, and plunge into the mould on the hot bed.

As weeks pass and the heat becomes less, another hot bed may take the place of the first, in which to keep up the vigorous growth of the young seedlings and cuttings, many of which by that time shall have been transferred to other boxes (pricked out) or thumb-pots, still plunged in the warm compost, and in this way their tender roots protected from blasts and variations of temperature, until after a while they are strong enough 
to be brought back to the original spent hot bed, and so by degrees rendered hardy enough for the cold frame in which they shall be prepared for their ultimate destination of greenhouse or border.

It is more than likely that some of my readers may before now have looked with curious eyes on a group of very moderate-sized pots of Mignonette in the window or on the counter of a London flower-shop, or in Covent Garden Market itself, and may have wondered how the nursery-gardeners contrive to produce such well-grown plants, dwarf, healthy, floriferous, and without a leaf turned.

Every step in the production of a pot of Mignonette is simple enough. What is chiefly needed is careful attention to details as to soil, temperature, repotting, a vigorous, steady advance from stage to stage in growth, and, more important than all, the avoiding of checks and sudden changes; it is, as I have already said, on such things ultimate success depends. This most common and well-known and readily-grown of all garden flowers may thus be taken as an illustration of how any soft-wooded plant may be managed from start to finish. Any one who will take sufficient pains, and who has acquired the requisite knowledge to grow such a perfect plant of Mignonette as I have described, may grow almost any ordinary greenhouse flower - the Chinese Primula, Tuberous-rooted Begonia, Gloxinia, the Cineraria, Calceolaria, and the Cyclamen. Something depends upon the quality of the compost that is used; one half should 
be fresh fibrous mould from the field or rotted sods from an old pasture, the other half made up of leaf mould and coarse Reigate sand. A small heap of this mixture made now will serve constantly for potting purposes all through the season.

In the growing of Mignonette there ought to be no transplanting: half-a-dozen thumb-pots should be filled with the compost and a few seeds dropped into each, afterwards plunging the little pots into the warm frame, and in less than three weeks there will be some goodsized plants in each pot, which may be reduced to two or three, according to their vigour, and after ten days more these will be ready for their shift. Select some clean 5 -inch pots, invert a piece of crock, add some moss, then stuff the lower half with very rich cow-dung; fill in with compost, and, having scooped a hole with the forefingers, press the contents of the thumb-pot into the space, and make the clay in the pot as firm as possible, tapping down all round with the trowel handle. Water all with a rose, and put back into the frame.* In a few weeks' time the pots will have become full of roots, and the stems will be 6 or $S$ inches long and vigorous. Pick away the leading buds, and bend and twist down the stems round the inside edge, carefully staking them down to the soil with wire hooks or hairpins. Water

* While in the frame the tap root is very liable to grow vigorously, and soon forces its way from the pot into the bed below, then when the plant is removed the tap root is snapped and the result is failure. It is therefore necessary to place a piece of glass or slate under each pot against which the root will grow and spread itself out. 
twice a week with liquid manure, and syringe the leaves frequently. They may afterwards be moved into the greenhouse, where soon they will come into blossom, each pot being furnished with flowering spikes, which will last in bloom for weeks. By making a sowing every month there can be a succession kept up through the season.

Chinese Primulas are better all sown in one large deep pot, well drained with sherds, and filled only twothirds, pressed down thoroughly, and watered once for all before scattering the seeds, then tying thin paper or gauze over it until the seeds have germinated and well rooted themselves. Begonia seed is so very minute it should be thinly scattered and lightly covered. Cyclamens are very slow in germinating, and one fears they are often lost through sheer impatience.

As a rule all these things prefer the equable temperature first of the warm frame, then of the cold one, to the draughts and drought and hot sunlight of the average greenhouse, and the longer their promotion is deferred the more likely are they to attain to a healthy maturity.

\section{CHAPTER VI}

THE GARDENER'S NATURAL ENEMIES

AN American writer, Chas. Dudley Warner, in "My Summer in a Garden," once said that he would like to be a gardener, but on one condition only, that he 
could have a hinge in his back. One sometimes feels the need of two or three such devices where weeds have to be pulled up, gooseberry caterpillars to be picked one by one, slugs and wireworms gathered and destroyed, and all the thousand and one other enemies, visible and invisible, met and vanquished.

Luckily, one of the attributes of a true gardener is that his powers of detection become abnormally heightened and his eye trained by habit to observe beauties, and dangers and defects, which to the unpractised eye do not exist.

Weeds are the most obvious of enemies; they probably grew in the Garden of Eden, at all events they have flourished ever since. It has been well said of them by $\mathrm{Mr}$ Wright that "it is not only the mineral support of crops, or what may be termed their solid food, that weeds steal ; they devour the liquids also, the rains and all the rich nourishment for plants which the drops collect in their passage through the air. Depriving the earth of its life-giving moisture and the food it contains is often a very serious matter, and, in dry, poor soils, positively ruinous."

Some soft annuals like chickweed and groundsel only require the hoe, and if it be used before seeding time it is a simple remedy. The very worst of our weeds is couch grass; another is the white Convolvulus, one of the loveliest of native flowers, but with a persistently running root, every inch of which quickly forms 
a new plant. The only cure is to fill the ground with some crop which will soon be replaced by another, and in this way will allow several opportunities of picking out the roots during the season.

Dandelion and other deep-rooted weeds growing on walks and in grass may be killed by applying some drops of vitriol when the crown has been cut.

Labour may be saved in scuffling garden walks by using a weed-killing mixture which claims to keep a path clear of weeds for eighteen months.

In some of our gardens one of our worst enemies is the small white or black slug. These creatures bury themselves in the ground or hide under decaying leaves, coming out after dark to make a clean sweep of young seedlings on their first appearance. I have known them during one winter to devour a large group of Christmas Roses. Their bane is quicklime, but that cannot always be used with safety. A sliced Swede turnip left in their haunts will often attract them in great numbers. Each night or early morning the slices should be turned up, examined, and the slugs picked into a flower-pot containing some lime or salt I have been told that a circle of zinc with copper wire running round the top has been found a destructive agent against any slugs that venture to trespass over it.

Where mice are troublesome peas should be moistened with paraffin and then dusted with red-lead powder before being sown.

Small birds will watch for the first sign of germination in cabbage and turnip seeds, so that it is necessary at the 
time of sowing to stretch a square of netting on a few pegs over the bed, which should not be moved until the seeds are well over ground.

In fighting our garden enemies of all sorts it is well to act promptly, e.g. where the gooseberry caterpillar makes his first appearance, just as the fruit is being formed, there must not be a day's delay in applying the finger and thumb remedy-easy work that day, but hopeless when a week has passed.

Wireworms are the brown centipede grubs of a beetle which I have known to destroy a whole field of potatoes. They are a pest to be reckoned with in the garden, but, as a rule, they only give trouble in fresh soil which has come in from the field. Gas lime is perhaps the best remedy. It should be spread on the ground in the proportion of I cwt. to every 60 square yards, and allowed to remain during the winter, and afterwards dug into the soil; I stone of coarse salt to the same space dug in during the late autumn has been found to kill the larvæ.

Wireworm may be discovered sometimes in the earlier stages of his depredations in some particular part of a flower-bed, and it may be possible to arrest his progress without sacrificing the crop all round by the use of such drastic measures as applications of salt or gas lime. It is worth while in such cases to try and trap the larvæ by inserting a few scooped potatoes stuffed with pieces of sweet plum cake amongst the roots, and examining them each morning for a few days. Perhaps the simplest and 
most effective plan is to dust the infected area with some strong ground mustard occasionally.

Mildew* and Fungus are the fruitful sources of evil in our gardens; they are in fact minute parasitic plants which feed on the sap of those plants and trees which have been neglected and starved. The true remedy is to bring about a healthy root action, prune and thin the branches, and so allow a free passage of the air through them.

The simplest remedy is to smother the tree with soot, let it rest there for some days, and then wash it off.

A good remedy for all fungoid growth and for red spider is to syringe with a mixture of $6 \mathrm{oz}$. of soft soap, 3 gal. of boiling water, and a handful of sulphur-flower thrown in and stirred well.

Greenfly is almost certainly an indication that the Rose or other plant affected is not in vigorous health-the Aphis does not relish healthy sap. Drought, or when, under glass, neglect of watering, is most frequently the cause; the remedy is tobacco smoke, or its equivalents, or fir-tree oil applied with warm water, or Bentley's Quassia mixture, which is perhaps the best of all applications for greenfly, red spider, scale insects, or mildew. There is a useful brush sometimes used, made in the form of scissors or sheep

* This will be found an excellent remedy, especially for mildew on roses : -2 lbs. quicklime, 2 lbs. flour of sulphur, boiled in I quart of water in an EARTHEN jar for Io minutes, stirring all the time. Give it time to settle, and pour off the liquid. Use a glassful to a gallon of water. 
shears; with a pressure of the thumb and fingers the brushes are brought together and drawn gently along the stem infected with greenfly. Two or three applications of the brush will remove all the aphides without injuring the shoot.

Somebody has made the shocking calculation that in five generations an aphis might be the progenitor of nearly six thousand millions of descendants, so that in every Rose garden it is wise to cut him off before his prime. It may nterest my readers to learn the result of another entomologist's observations on the greenfly. "Insects in general," he informs us, "come from an egg, then turn to a caterpillar, which does nothing but eat, then to a chrysalis, which does nothing but sleep, then to a perfect butterfly, which does nothing but increase its kind. But the aphis proceeds altogether on another system. The young ones are born exactly like the old ones, but less. They stick their beak through the rind, and begin drawing up sap when only a day old, and go on quietly sucking away for seven or eight days; and then, without love, courtship, or matrimony, each individual begins bringing forth young ones, and continues to do so for months, at the rate of from twelve to eighteen daily."

We have the satisfaction, however, of knowing that the aphis finds no food, and does not look for it, on a Rose which is in good health; he will not taste the sap which is pure and good. If situation and soil and oversight have been looked to, it can only be the accident of weather that can favour the fly. 
The process of "scrunching" the Rose grub is to some people disagreeable, but it is inevitable.

The cause of Canker in apple-trees and secretion of gum in plum-trees is most frequently fungus. When such symptoms appear the branches should be cleaned and pruned, the subsoil roots cut back, and fresh soil thrown in, with a liberal supply of liquid manure.

The Potato disease, too, has been proved to be a fungus growth, and the system of spraying the potato crop for the prevention of disease has had most satisfactory results both in the farm and garden.

The spraying mixture most frequently used both in France and in the United Kingdom is that known as the Bordeaux Mixture; for $\frac{1}{4}$ acre the quantities are: copper-sulphate $5 \mathrm{lbs}$., lime $5 \mathrm{lbs}$., and water 25 gallons. There is another called the Burgundy Mixture, consisting of copper-sulphate and soda, which adheres better to the leaves, if applied as soon as prepared and not given time to deteriorate, and it also runs more freely through the nozzles of the sprayer.

It should be first applied some little time before the disease usually makes its appearance in the neighbourhood. This in early districts would be during the first week in June. But even after the first traces of the fungus are observed a dressing will have excellent results. Within three or four weeks much of the stuff will have been washed off by the rain, and much additional 
foliage will have been developed, so that a second, and even a third dressing may be desirable at times.

However, in late districts, if the crop is well developed, one good dressing will be enough, especially if the weather after the spraying has been fairly dry.

The experiments carried on by the Irish Land Commissioners seem to show that the best results follow spraying applied from underneath upwards; the disease is first developed on the under surface of the leaves. It should, if possible, be conducted only in fine weather, when the foliage is dry.

\section{CHAPTER VII}

\section{SEEDS AND THEIR TREATMENT}

THERE is perhaps no department in the garden which is the source of so much vexation to amateurs as the sowing and growing of seed-the fault lies sometimes in the seed, but oftener in the sower.

As I have said before, it is the worst economy to buy cheap and inferior seed. The first cost is the smallest part of the business; it cannot be compared with the time and trouble of the sowing and growing-far better to do without than to waste time in growing rubbish, or sowing what will not grow.

Germination is the first development of the seed. What is needed for germination is warmth and moisture 
and oxygen; when any one of these is absent there can be no growth.

Where buried too deep, therefore, they have moisture, but no heat or air. When too near the surface they have too much of these, but too little moisture. Moreover, seeds germinate best when light is excluded.

In sowing seeds, then, they must be covered to exclude light, deep enough to find moisture - not so deep as to hinder the air reaching them-for warm, moist air is exactly what they require. It is of the greatest importance that the ground should be properly prepared for the seed; the soil ought to be fine and loose, should not be beaten hard and smooth. If it be flattened down when damp it will shrink as it dries, and there will be cracks through which the moisture will escape, carrying the heat with it. The essentials for germination and growth are: a well worked soil preparatory to sowing, and a frequent stirring with the hoe or trowel afterwards in spring and early summer.

As a rule, annuals only need to be well covered, but they should be really covered, and in such a way that they will not be disturbed by watering. Vegetable seeds should be covered in proportion to their size-cabbage and turnips not more than half an inch; onions, parsnips, and carrots, I inch ; spinach and beet, 2 inches ; peas, 3 ; beans, 4 ; and in summer rather deeper than in early spring. And here let me once for all sound a note of warning. It is no uncommon thing to hear bitter complaints from one's friends as to the failure of their seeds-the failure 
has been most likely in themselves. They have been, for example, anxious to have a good bed of Mignonette or Nemophila, and they have, accordingly, taken unusual pains to prepare the ground for it, made the soil fine and loose-as we have before explained it should beand yet it has failed. The reason is very often this : they have scattered the Mignonette on this well-prepared soil, but without having previously given it a thorough drenching from the rose of the water-pot, and so the seed has fallen upon the open and porous earth, and the next rain has carried both the seed and the finer part of the soil down through the open spaces of the freshly prepared earth never to come up again, and it has, probably, also washed away the thin covering from the remaining grains of seed with an equally sad result. Before sowing seed in pots, boxes, or in the border it is, therefore, always well to make good use of the watering-pot, so as to consolidate the soil and drainage previous to intrusting our seeds to its keeping.

\section{CHAPTER VIII}

BUDDING, GRAFTING,* INARCHING, LAYERING, AND STRIKING

THE propagation of plants otherwise than by seed is effected by various processes of more or less difficulty; * These operations are only necessary when plants cannot as readily and as well be grown from layers or cuttings. 
they can only be very imperfectly described here ; indeed, the processes must be illustrated by actual experiment before they can be properly understood. Those which chiefly concern the amateur gardener are the operations known as budding, grafting, inarching, layering, and striking cuttings.

Budding is the insertion of a bud (2) cut away from the plant which it is desired to propagate, (I) along with a portion of its bark, into the bark of another plant, (3) to which it is bound (4) gently but firmly. Every well matured growth bud (not blossom bud) contains the rudiments of a plant of the like kind, and a bud can be transferred from one plant into another of a different variety, but of the same

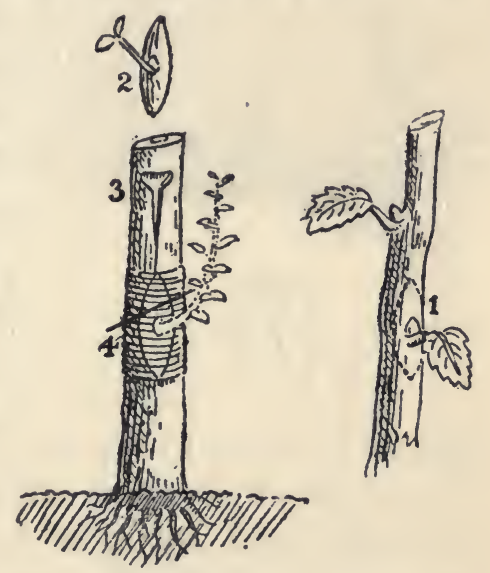
species, e.g. Rose buds transferred to Dog Briars will grow, but they will not grow in any plant differing in its nature from a Rose. Apple buds may be inserted into a Crab tree, but not into a Plum, nor a Plum into a Pear. Budding must be done after midsummer-July or September, when the trees are in full growth, the buds well formed, and the sap active. No time must be lost in the process, or the sap will evaporate from both stock and bud. The chief points 
to be observed are these: the sap must be active, the root action healthy, the incision must be cleanly made, and the binding not too tight.

The Galbreath Budder is a recent ingenious invention, which claims to make the transfer of buds from their old to their new limbs safe and easy.

The tool consists of two handles like those of a

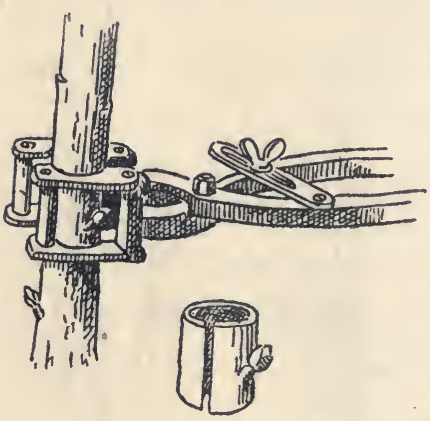
pruning scissors, working on a pivot, and to the end of each a pair of concave blades is screwed, so that when the handles are drawn together and turned round, an incision is made round the bark of the branch above and below the bud, and the complete ring of the bark cut from the branch, as shown in the annexed figure.

The branch to which the bud is to be transferred is similarly treated, the space from which its bark is taken corresponding exactly to the ring of bark with the new bud which it is to receive.

Grafting is the process by which most hardy kinds of fruit trees are propagated. Seedling fruit trees are generally good for nothing, and should be grafted when young with choicer proved sorts. Healthy old trees are often practically worthless, but may by this simple process be converted in a very few years into fruitful and vigorous 
modern bushes, producing the very best quality of fruit. The operation must be performed in spring, when the sap is active. The tree to be grafted is called the "stock," the new young sorts "scions." The scions should be portions of the previous season's growth, selected from healthy and well-known parents. The stock should be in a state of vegetation, somewhat in advance of the graft, otherwise the flow of sap will be insufficient to supply the wants of the scion. To secure this, therefore, the grafts or scions should be taken off from the trees some weeks before they are wanted, and kept fresh in moist earth under a north wall while the stock is advancing. During winter grafts may be conveyed long distances, if carefully packed in damp moss. From the beginning of March to the middle of April is the best grafting season, earlier or later, according as climate and other circumstances suggest.

When the grafts and stock $(a, b, c)$ have been fitted together, $(e)$ and

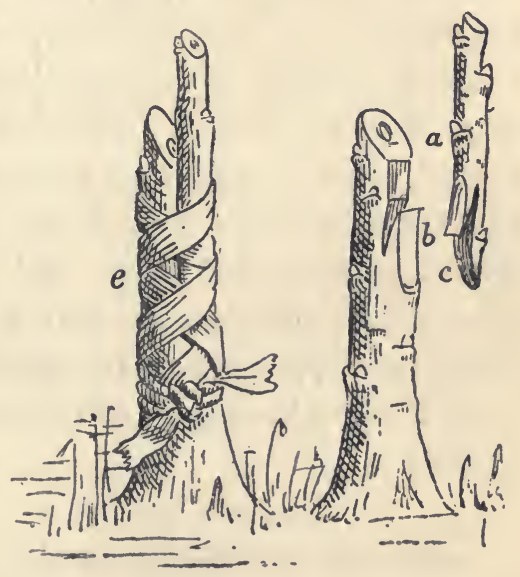
tied firmly with baste, they must be covered with a plaster composed "of clay. and stable manure, of the consistency of putty, rolled closely round the point of juncture. Whenever this gets dry and 
cracks, it should be again smoothed over so as to exclude the air.

Inarching is only another method of grafting, except that in this case the graft is usually a growing plant brought in its pot, close to the side of the stock on which it is to be worked. A slice a few inches in length is cut away from each, and the cut parts made to fit together, and then bound tightly with some damp moss over it. After a few weeks they will have united. The young graft may then be severed from its own stem, and the old stock cut away above the junction.

Young gardeners often grow orange trees from pips; the chances are they will never bear fruit. In this case, a simple method of inarching will produce happy results. When a firm, healthy cutting has been taken from an orange or lemon that bears good fruit, it may be placed in a bottle of water standing by the stock, and the upper end spliced as described above; the moisture from the bottle will support the cutting until the union has been completed; the upper part of the seedling tree may then be cut away, and the lower end of the cutting nipped off with a scissors.

Layering consists in making a slit or tongue from the lower side of the branch of a plant, close beyond a joint, while still attached to the parent, bending it (sce diagram) so that the branch is brought down to the ground, fixing it with a forked peg, and covering it round 
with sandy loam. Almost all sorts of trees and shrubs carnations and other plants, may be easily rooted in this way. A niche made underneath a trailing branch, and a stone placed on it in the autumn, will often root an evergreen or flowering shrub, which is not easily propagated otherwise. Carnations treated in this way in July take only a few weeks to

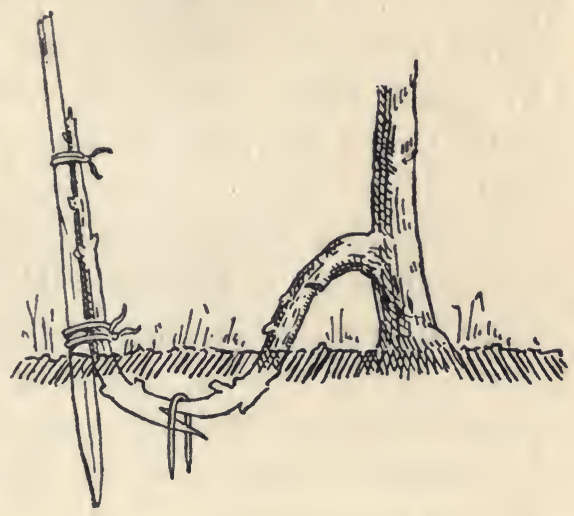
root, but woody plants are naturally very much slower.

In the case of Cuttings the production of roots is the result of the deposit of cellular tissue at the base, and the formation of a lip called a "callus," from which roots spring. There is a great variety in the selection and treatment of cuttings ; in some cases soft green shoots are used, in others the shoots must be half ripened, and sometimes fully matured. Then again, some will root if cut or broken off anywhere, and stuck into wet earth and sand in a warm place. Others need to be cut with great care, just below a joint. This indeed should be the rule. As to position, many cuttings grow freely if they are planted in the open border reserved for such things, shaded from a southern sun. The less hardy things must be covered with a bell 
46 BUDDING, GRAFTING, INARCHING, ETC. [CH. vIII.

glass, and must be in a close warm atmosphere with bottom heat, and must be rooted in pure gritty silver sand. Spring is the fittest time for taking cuttings. Those of fruit trees and shrubs are best made as soon as the leaves have fallen. The callus just then seems to form quickly; while the earth is still warm, it promotes the growth of the roots.

In preparing cuttings of bush fruits all the buds should be carefully taken away, except the four at the top, which will go to form the branches, otherwise the lower buds will become sucker growths, and leave the tree useless. The cutting should be sufficiently long, 12 or 15 inches, so as to allow at least 8 inches of a stem over ground, between the root and the branches. 


\section{PART II}

\section{CHAPTER I}

\section{THE SPRING GARDEN}

$\mathrm{F}^{\mathrm{F}}$ all the varied groups of plants in an English flower garden, by far the most attractive and seasonable are Dutch bulbs, as they are commonly termed; they certainly claim at least one chapter for themselves.

This class of flowers has advantages which are almost self-evident. So far from being, as some people imagine, troublesome and costly, the culture of spring bulbs is, perhaps, the simplest and cheapest thing in the world when once the secret has been learnt. The first thing to be said for them is that they are perfectly hardy, and that our climate suits them exactly. The severest winter has no terror for bulbs. Some of the most beautiful and delicately tinted are those that burst into bloom almost before the snow has gone, and so it is that from the very first dawn of spring into the bright days of summer we are indebted to our spring bulbs for most of our enjoyment of the garden. 
There is another thing in their favour. When once we have judiciously planted our bulbs we may let them alone for some time. With, perhaps, the exception of Tulips, they may be left to themselves for years. When one thinks of all the tending and shifting so many favourite flowers require in a twelvemonth, we can see at once what an advantage the bulbs have over great numbers of their neighbours. In another chapter I shall explain a method for the planting out of bulbs among summer surface-growing annuals in patches of rockwork, so that when in the early winter the ground has been cleared of débris and made trim with top-dressing, there remains nothing more to be done but to watch for the heralds of spring as one by one they rise from their summer and autumn sleep, and then as the weeks go by each brings to us a new enjoyment, a new accession of glory and beauty in our unpretending garden, which may compare with some of Nature's fields of flowers in more sunny lands.

But while the more rare and costly bulbs belong of right to the garden proper, I like to think of them as growing more and more at home amongst us, and as time goes on becoming naturalised.

The truth is, where bulbs, such as Daffodils and Tulips, thrive, they multiply exceedingly, and often the crux is how best to dispose of them. The solution is easy enough where there is a lawn, or a grassy bank, or any spare corners, or space under a spreading lime or elm. These are spots intended by Nature for groups 
of Snowdrops, or patches of Crocus, the hardiest of our early spring flowers, or broad bands of Daffodils, or the Poet's Narcissus. While contrasting with them all, and helping in a wonderful way to brighten the effect, different sorts of Squills may be distributed amongst them.*

Bulbs should be bought early, and it is well to send one's orders as soon as possible after the catalogues are received, as the merchants act upon the principle of "first come, first served"; besides, it is good to have borders filled in the early autumn, so as to insure strong matured blooms in their season. In ordering bulbs, it is well to bear in mind that some are best fitted for potting purposes and others for bedding. Without pretending to supply an exhaustive list of well-known bulbous plants, I shall endeavour to suggest a few of the less familiar as well as some of the common sorts, which even an inexperienced amateur may easily grow.

When bulbs are to be planted in grass, it is easy to dibble them into holes made by a crowbar, but the better plan is to raise the sod from each patch, loosen the soil, drop in the bulb, shaking round them a shovelful of sand, and then covering with the grass sod as before.

The most attractive harbinger of spring is the Iris

* Amongst bulbs which are peculiarly suitable for grass are the Colchicums, which send up their rank foliage in Spring, but reserve all the beauty of their bloom for autumn. Colchicums are for the most part a newly found class, and when more extensively grown they will add to the autumn attractions of the garden many of the mysterious charms of the spring. 
reticulata; it is strange how seldom one sees it in gardens, and yet my experience of it has been that it increased more freely and grew more vigorously than almost any other bulb, and when last removed, it was found that from having been a small clump of half a dozen, it had become almost half a hundred. On the other hand, I have known of a large bed suddenly dying out, owing no doubt to the ravages of a grub. It may be the same grub which is often so fatal to the Narcissus.

Perhaps the most persistently constant spring bloomer is the Iris stylosa. Its flowering season is from November to April. It thrives in poor soil, and is all the better for the intrusion of the roots of stronger plants beneath, or the piling on of stones above the surface. The flower has no stem, it grows on the elongated style (hence its name), which is often 9 or Io inches long, and the seed pod will be found almost under ground. The white variety is very beautiful.

The old-fashioned single and double Snowdrop is one of the best known of our spring flowers, and the colder the season the more satisfactory seems its growth.

Not so many years ago few people imagined what a very numerous and widely extended family the Snowdrop is ; only one sort was then grown-Galanthus Nivalis.

It was in the winter of $1854-5$, I think, in the trenches before Sevastopol, that the large Crimean Snowdrop was 
found by our troops; roots resembling small onions were scattered over the trenches, and in a few weeks these developed into a veritable garden of spring flowers. It is, however, in Greece that a greater variety of these plants is found than elsewhere. Some blossom there in September and October.

A peaty soil suits them best, but a mixture of loam sand and peat-mould would be an ideal soil for them.

Their near relations, the Snowflakes, are also very attractive and free-growing plants.

Somewhat after the Snowdrops the Lent Hellebores enliven the spring garden. As cut flowers they are not as satisfactory as the Christmas Rose, but, if properly treated, they will retain their freshness for ten days. Miss Jekyll suggests that "before being put into water their outer skin should be scraped off, or the stalks slit up 3 or 4 inches, then plunged in water for some hours up to the very flowers, and they may then be arranged in their vases, though they have an inclination to droop, and need support from some sprays of Jasmine or Berberis."

The Narcissus, of all spring flowers, are the hardiest and best; they vary so much in form and colour and in their season of bloom, that a most perfect spring garden might be made of them alone. They like best the fresh, virgin soil or any well-drained fibrous sandy loam, whether, in pots or borders, they rather resent manure, and should 
be planted between July and October.* They are most effective when boldly grouped, and in situations and soil that suits them increase so fast, that they may be lifted every third or fourth year.

The Narcissus includes the numerous family of Daffodils, which may be classed into three or four groups:- Golden, such as Ard Righ and Emperor, and the dwarf varieties, Nanus, Minor, and Minimus; Bicolors, as Empress and Horsfieldi, which it is not easy to distinguish; and the White, Moschatus and Cernuus. Star Daffodil ( $N$. incomparabilis), of which Sir Watkin is the most remarkable, contains fully a hundred kinds.

In some soils the beautiful Cernuns grows freely, but the grandest and hardiest of all are Emperor, Empress, and Horsfieldi. When dividing a group it is a good plan to replant the best bulbs in some fresh ground and naturalise the remainder on a grassy bank.

The more delicate kinds, such as Bulbocodium and Tazetta, require a sheltered border and peaty loam.

The best doubles are Telemonius plenus, Capax, and Double Cernuus.

There can be no question that a well raised sloping border, 3 or 4 feet high at the back, or a fresh grassy

* The period of planting must altogether depend on circumstances ; after the bloom is over they should have ample time to grow and mature the bulbs before being stirred, but if the season is wet, and they are allowed to remain late in the ground and then moved, it will be found that the new fibrous roots will have begun their growth, and the result will be to weaken the plant and retard the bloom. 
bank, is a far more suitable position for the Daffodils than the level border; and for this, amongst other reasons that in such an elevated position the bulbs can dry and ripen and mature their growth throughout the summer and autumn.

Late flowering Tulips come on in quick succession to the Daffodils, and ought certainly to be grown as extensively. Beds of Tulips may be carpeted to great advantage with such things as Violas, Aubretias, Ajuga, and Primroses.

All the late Tulips come from the Gesneriana stock. The parent itself is the most splendid of all; it has an immense bright red flower on a tall stem, is sweetscented, and lasts six or eight weeks in bloom. Few things can equal the brilliancy of a group of Griegi, which is dwarf, and of a vermilion red colour. Then there is Bouton d'Or and Golden Eagle, Retroflexa, Silvestris, and Vitellina, and the Parrot Tulips with their curiously cut petals, and the large double Yellow Rose and the early double White Swan and La Candeur.

Anemones (fulgens) and the Blue Wood (Apeninna), as well as our native White, should be grown extensively in every Spring garden (see part iii. chapter v.).

A quaint, old-world tribe are the Fritillaria (Snake's Head), very graceful and unusual in their habit. The Crown Imperial is the most distinguished and best known member of this family, but, in dimensions, head and shoulders over all the others. 
The Dogtooth Violets have a quaint charm of their own.

Another hidden treasure is the Trillium, a Canadian bulb, which thrives in a peaty soil, or on a deep bed of leaf mould, and when it first shows itself it comes up after the manner of a shamrock, with tripartite leaf and corolla ; the flower is, for the most part, white; and resembles a diminutive Magnolia. Mrs Ewing has done much to bring this unique plant into notice in her pathetic little story of "The Trinity Flower."

The Sanguinaria Canadensis is also a Canadian plant; the name is derived from the fact that when the root is broken it drops a red sap like blood; the pure white flowers (not unlike the Snowdrop) start overground long before the leaf is formed.

The Sisyrinchium (Rush Lily) is a lovely little perennial with grass-like leaves; it flowers early in the year, and is well suited for a rock garden, and easily grown in a light peaty soil or sandy loam.

Hyacinths, planted with a due regard to the proper massing of their various shades of colour, are a distinct gain to the Spring garden. The pot bulbs of the previous year often serve very well for the border, but sound, fresh bulbs can be had very cheap, and will prove more satisfactory. When planted 6 inches deep they will bloom somewhat later, but are less liable to be injured by frost. 


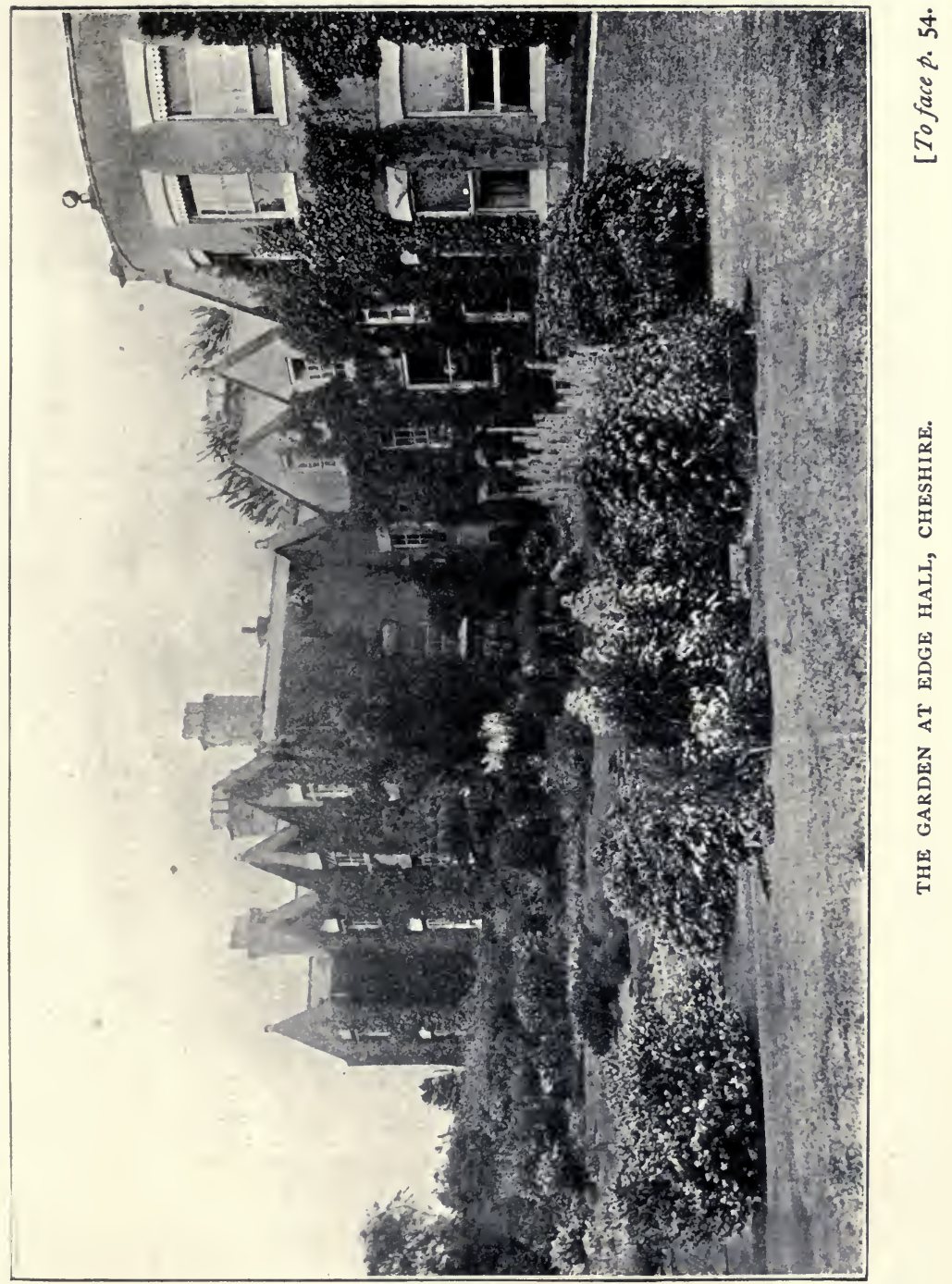


LIBRARy P
OF THE

UNIVERSITY

OF 


\section{CHAPTER II}

\section{SUMMER AND AUTUMN FLOWERS}

THIS chapter must be largely supplemental. The more important and better known of our garden flowers are treated either in their own departments, or else in chapters specially devoted to themselves. There are many others, however, which equally deserve recognition, and in their case the difficulty is to know how and where to draw the line. I propose in this chapter to notice in alphabetical order some of the more familiar herbaceous flowers not elsewhere alluded to, which should certainly find a place, if possible, in every garden. Those of my readers who want fuller information I would refer to Mr Robinson's "English Flower Garden."

The Alströmeria (Peruvian Lily).-There are several varieties of this attractive, lily-like perennial with spotted flowers of varied shades of red and yellow. They have fleshy, tuberous roots, which resent excessive moisture. They should be procured in pots, and once planted never disturbed. Perhaps the best plan is to sow the seed in the beds where they are to remain. Aurea, chilenses, and pelegrina are amongst the most suitable for our climate.

The Antirrhinum (Snapdragon) is amongst the best known of garden plants. There are tall, medium, and dwarf varieties. The last-named are most effective when 
grouped in separate colours in the border. Suttons' Yellow Prince, White Queen, and Crimson King, when treated in this way, are very striking.

Aquilegia (Columbine) has been brought to great perfection of late years in our borders. Suttons' crimson and gold hybrids are lovely. They must be treated as biennials, sown in boxes in spring, and planted out in autumn. The more permanent sorts are chrysantha (golden) and the blue and white Rocky Mountain carulea and alpina.

Alyssum (Rock Madwort) is a showy rock-work border plant, very easily grown in light soil, which should be frequently renewed by cuttings. It is one of the most satisfactory of yellow spring flowers, and contrasts well with patches of Candytuft and Aubretia.

Aster (Michaelmas Daisy). - A very large family of autumn-blooming composites, not to be confounded with the annual China Asters. When every other flower has faded these continue to bloom in spite of rain and storm. They are most effective when planted amongst shrubs which give support to their great stems, and room below for their greedy roots. When grown in borders it is well to fix a strong pea-stake in the centre of the group, into which the stems may grow up. Almost all the Starworts have been brought from North America.

Aubretia (Purple Rock Cress).-One of the most 
effective and useful of our garden Alpine plants, excellent for walls and edgings, where it will spread out over the path in beautiful patches, alternating well with similar groups of yellow Alyssum and herbaceous Candytuft. Purpurea is the oldest variety, and from its habit most suitable for growing over stones on the rock garden. Campbelli is fine, with large, deep violet-purple flowers, and Leichtlini, a bright reddish crimson. Short sideshoots, pulled from the old plants in June or July, planted firmly in sandy loam, and occasionally watered, will root freely, and be fit for putting out some months later, or the seed may be sown on old walls covered with some earth in autumn or spring.

Bocconia cordata (Plume Poppy) is a handsome plant, which should be grown where there is plenty of room to develop its fine foliage.

The Campanula (Bell-flower or Hairbell) family is very large and varied in habit and character. The Alpine sorts are excellent for rock gardens, more especially pulla, isophylla, and portenschlagiana (Wall-hairbell). Persicifolia (peach-leaved) is a vigorous and beautiful species, easily propaged by division of roots. The tall Chimney Campanula (pyramidalis), both purple and white, is a beautiful thing either in the sitting-room or border, and the Canterbury Bell is one of the best of biennials.

Dianthus barbatus (Sweet William) is one of the oldest, hardiest, and most showy of perennials, and has 
been much improved of late by careful selection. The self-coloured dwarf double crimson is beautiful; it is a vigorous grower, and forms a strong tuft. Seed sown in April and planted out in Autumn will make a perfect bed the following summer.

Delphinium (Larkspur) includes a great many species ranging in shade from white to nearly crimson, from lavender to dark blue. Perennial Larkspurs are hardy, and will grow in any soil. They should be divided and replanted every three or four years in spring-time. They will bloom for months in succession if the spikes are cut away immediately after flowering. From really good seed a great variety of beautiful sorts may be obtained. Nudicaule, orange-scarlet, is best treated as a biennial. It will produce its brilliant flowers the second year after sowing. Some of the annuals-Rocket and Hyacinth flowered-should be sown in September, and again in March, in the place where they are to bloom.

Dielytra spectabilis (Bleeding Heart), now more properly called Dicentra, belongs to the Fumitory order; a very elegant plant easily grown in good soil. It bears prony-like leaves and drooping spikes of heart-shaped pink flowers in May.

Digitalis (Foxglove) is a grand border flower, with great variety of colour. Some of the large blooms are marked and coloured like a gloxinia, and most fitly one of the best sorts is named gloxinioides. 
The Doronicum (Leopard's Bane) is of the Composite order, and will thrive anywhere, sending up its golden daisy-like blooms four times a year, if closely cut in after flowering.

Erigeron (Fleabane) might be easily mistaken for a Michaelmas Daisy. It is very like the Alpine Aster with its large heads of purple flowers in the late autumn. It is easily propaged by division of the roots. Aurantiacum bears bright orange flowers as large as a crown piece. Speciosum superbum is purple.

Erinus Alpinus is a charming little Alpine for rockwork, or will grow and scatter its seed on an old wall. It has a dwarf tufted habit and pink flowers in great abundance.

Eryngium (Sea Holly) resembles thistles rather than Holly. Alpinum and amethystinum are both beautiful. Their steel-blue sheen, where grown in good bold groups, is perhaps more attractive than any other border plant, and they continue in bloom longer than most. Sea Hollies will stand almost any exposure, so long as their drainage is good and the soil deep.

Gaillardia, a most brilliant perennial, the outer zone of the flower is orange yellow, the inner brownish-red. There is also the annual Lorenziana double, with similar colouring. They all thrive best in bold groups, on wellprepared soil, light and dry, in a sunny aspect. They 
may be grown from seed or increased by cuttings in spring or autumn.

Galtonia (or Hyacinthus) candicans (Cape Hyacinth), a noble plant (bulbous) from South Africa, grows 3 or 4 feet high, with a long raceme of a score of large handsome bell-shaped white flowers. It is quite hardy and easily grown in light soil.

The Gladiolus is a very desirable plant; the bulbs are natives of South Africa, and have been extensively hybridised; one of these, Colvillei, to which The Bride belongs, is specially hardy, and bears lovely white flowers in early summer, while there are others, e.g. Lemoine's gandevensis, Brenchleyensis, whose brilliant spikes are seen to most advantage at the very end of the season. They may be planted at intervals from March to June, and so a long succession of bloom will be secured.

Gunnera (Prickly Rhubarb), a grand plant from South America; it requires plenty of space and depth to grow in, and thrives on the edge of ponds where the roots can penetrate the moist earth. When well grown $\mathrm{Mr}$ Burbidge assures us there is no hardy foliage plant which can compare with $G$. manicata.

Helianthus (Sunflower)._Like the Michaelmas Daisy, the perennial Sunflowers could be badly spared from our borders in autumn. They are rank growers, gross feeders, and profuse bloomers, and should often be divided. The 


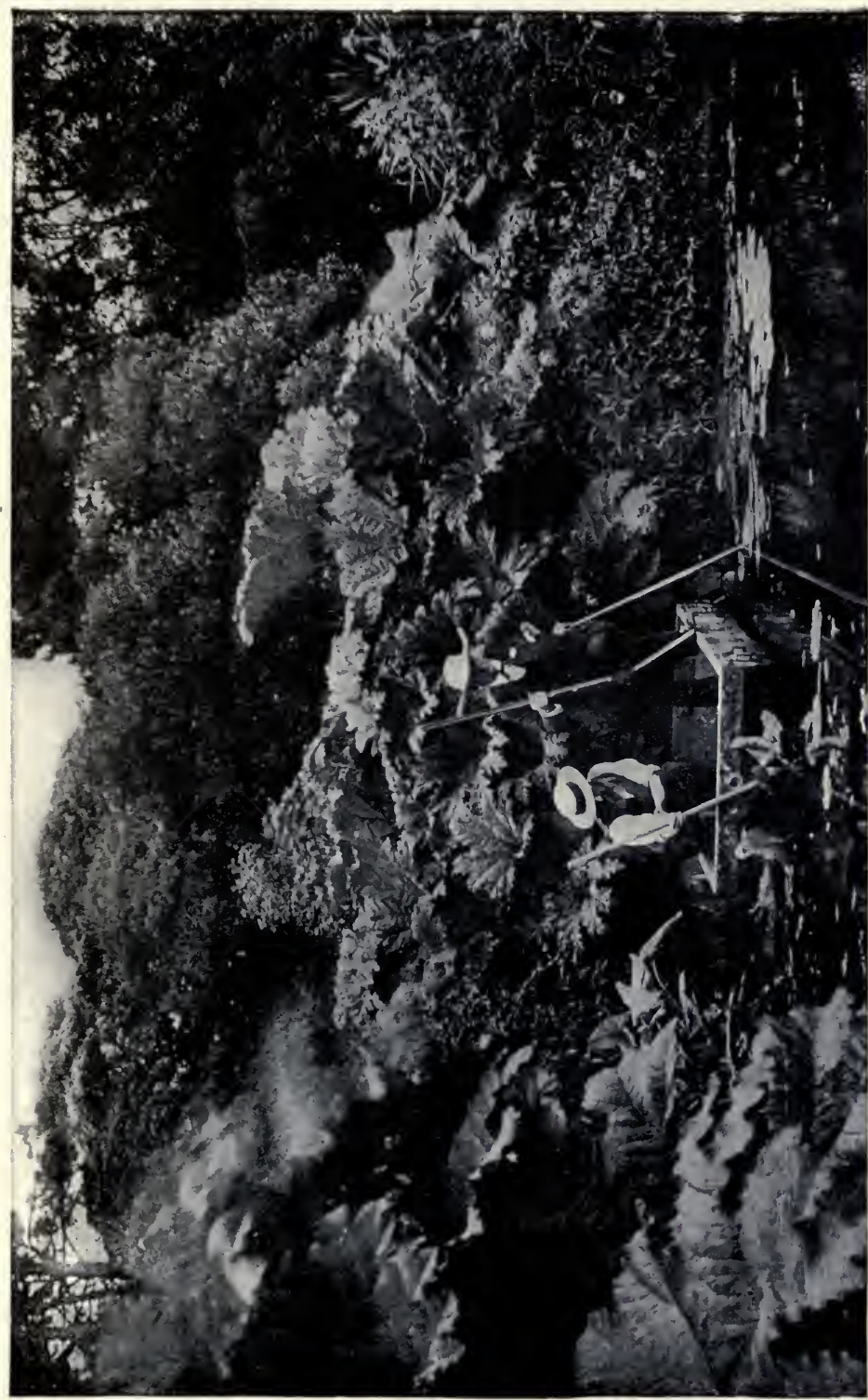


LIBRAR
OF THE

UNIVERSI

Ca OF

iforinia 
best varieties are giganteus, Maximiliani, and orgyalis. Rigidus and its varieties-better known as Harpalium rigidum (Prairie Sunflower)-is a native of Texas, and some of its varieties are amongst our most effective and brilliant autumn flowers. Miss Mellish is specially fine. The Annual Sunflower has many varieties. A mixed package of seed should be sown in March in the hot bed or in April in the open ground. They require a strong, rich soil, with a mixture of dung, and are the better for the shelter of shrubs to support their tall stems. The sulphur-coloured variety is very beautiful.

Hemerocallis (Day Lily) is a strong and useful plant in a mixed border. It is readily increased by division, is very fragrant, and its flowers useful for cutting. The best known are Dumortieri, flava, and fulva.

Kniphofia (Flame Flower), better known as Tritoma, is amongst the most striking of autumn plants. It requires no care beyond a dressing of well rotted manure. There are now more than fifty varieties of these beautiful Torch Lilies, and when well planted in bold groups in the distant parts of grass lawns or shrubberies, their effect is exceptionally fine. Burchelli is a useful and distinct plant which flowers soon after midsummer.

The Leucojum (Snowflake), a sort of connecting link between spring and summer, is a very hardy bulbous plant. Vernum (dwarf) appears shortly after the Snowdrop, of which it is a near relative; astivum, much larger, 
comes into bloom in early summer. All have white pendent flowers tipped with green.

Lobelia Cardinalis is perhaps the most conspicuously beautiful of autumn flowers. It is a bog-loving plant, and not very robust, and requires the protection of coal ashes in severe winters.

Of Lupines there are annuals, biennals, and perennials. The Tree Lupines are sweet-scented. The yellow is specially good. The flower spikes of polyphyllus are particularly effective. The annuals are varied in colour and very easily grown.

Lychnis, a brilliant, erect-growing family of plants, which thrive best in beds of peaty mould or deep sandy loam. Calcedonica, 3 feet, has dense heads of bright scarlet flowers, both single and double, in June and July; fulgens, I foot, vermilion; Haageana, I $\frac{1}{2}$ feet, scarlet; grandiflora, I foot, coppery-orange-all are large-flowered and showy, but require a little protection in winter.

Lithospermum prostratum is a dwarf evergreen with a spreading habit and lovely blue flowers of the same shade as Gentians. It is well suited for growing down the edge of a rocky bank, and thrives best in peaty loam.

Mimulus (Monkey-flower) grows well in damp places and on the margin of water. Cardinalis is a showy plant; Moschatus is the common Musk, and Harrisoni is a 


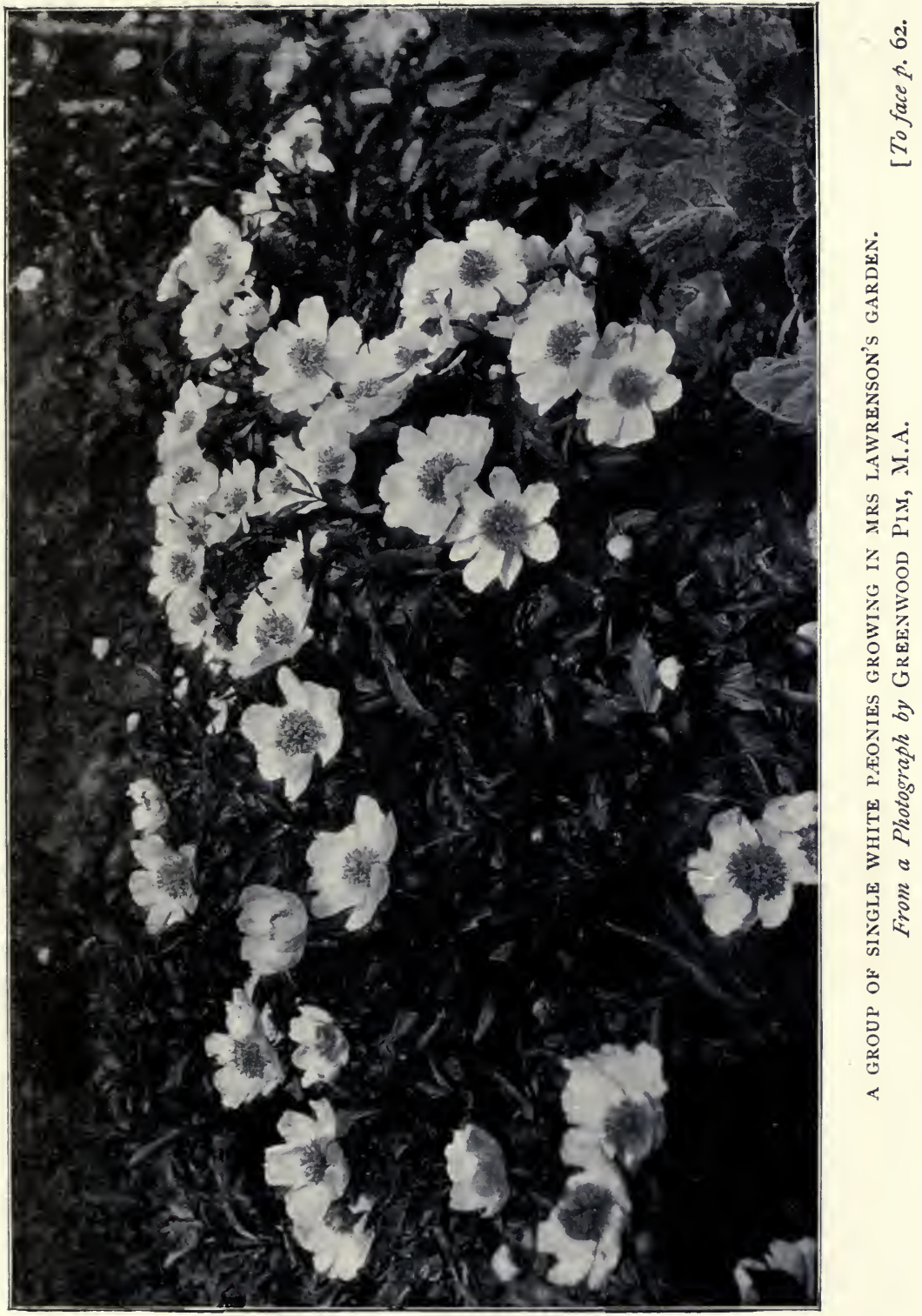



greatly improved form of it. Luteus is bright coppery red. The seeds of the Mimulus should be sprinkled on the ground without cover.

CEnothera (Evening Primrose) comes from California and Texas. The lemon tone of the flower and its continuous bloom gives it a high value, and, in spite of its name, many open their petals all day long. Fruticosa and marginata are perhaps the best of upright growth, and of the trailers taraxicifolia, a Chilian variety. Youngi is a distinct sort, and most satisfactory.

Ornithogalum (Star of Bethlehem) is a well-known bulbous plant of early summer, which in some gardens grows so freely as to become a positive nuisance. Arabicum is one of the best; nutans hardier, if not so attractive.

The Pæony is one of the most beautiful of all hardy flowers. It combines qualities of gracefulness, colouring. and fragrance as few other plants do. The Tree Pcony (Moutan) is a particularly attractive object when grown on a lawn; its blossoms and foliage are equally good; some few of them are sweet-scented. The Hybrids, both single and double, are perfectly lovely, of every shade of colour, from the purest white to brightest purple. They require good moist loam and rich manure, and should be planted in autumn or spring. They like best a shady border, but are well suited for growing at the edge of shrubberies or in grass. 
Papaver (Poppy) is an interesting garden plant of free growth and easy culture. The largest of all is orientale, bearing huge crimson-scarlet flowers. Bracteatum closely resembles it, but has leafy bracts just beneath the blossom; its colour is better and blooms larger. A few of these grouped here and there on a border, of themselves go to make a brilliant garden. Nudicaule, the Iceland Poppy, is dwarf and well suited for the rock garden; there are white, orange, and yellow varieties. There are few annuals so strikingly beautiful as the Shirley Poppy, when grown early or late in good soil and properly thinned. The yellow Welsh Poppy is, properly speaking, a Meconopsis (Poppywort); it is more easily grown than any other flower.

The Penstemons are a valuable addition to the flower border. Few plants bloom so freely and for so long a season. Of late years they have been greatly improved by careful selection. They may be grown either from seed or cuttings.

The Phlox belongs to a strangely varied family of plants. Drummondi is one of the best of our annuals, and has been brought to great perfection. Nivalis and its allies are pretty trailing evergreen rock plants. The showy Garden Phloxes have sprung from other types; the White, Scarlet, and Rosy-Salmon are beautiful and effective border flowers, easily propagated by breaking the root into pieces. 
Polygonatum (Solomon's Seal) is a graceful and hardy flower, growing 2 or 3 feet high, with arching stems and drooping white flowers; it does well in partial shade or amongst shrubs, and is very suitable for early forcing in pots.

Potentilla (Cinquefoil) belongs to an extensive family. Some of the species come from the Alps, others from the Himalayas. There are many named varieties combining every shade of colour and of all sizes. Some are well suited to the rock garden.

Pyrethrum (Single and Double), a showy border flower, and has become extremely popular. The plants should only be propagated in spring by pulling the old roots to pieces, placing them in small pots in a cold frame for some weeks, and then bedding out.

Pyrethrum uliginosum is a glorious plant growing to a height of 6 feet, with clusters of white Ox-eye Daisy flowers, admirable for cutting purposes. It comes in late in autumn, and is a welcome addition to the garden just then.

Richardia $Æ$ thiopica (Lily of the Nile) comes, strangely enough, not from North but South Africa. It was one of the earliest of the many plants brought from the Cape. With us it is usually grown under glass, but in some favoured places it has been naturalised in shallow water, and in any case the plants should spend their summer under such conditions. 
Rodgersia podophylla is a remarkably handsome plant of the Saxifrage family, with bronze foliage, perfectly hardy; it likes a peaty soil and shade.

Rudbeckia (Cone Flower) closely resembles some of the smaller perennial Sunflowers; it is well suited to shrubbery borders, and thrives in light, loamy soil.

Salvia.-Many of the sages are too tender for our winters-their home is Mexico. Those from Southern Europe are best known to us, and some very lovely. Patens is an intense azure blue, has tuberous roots, and may be taken up, stored away, and replanted in spring, like a Dahlia, or better still, it may be protected in its border with coal ashes. Splendens is a glorious scarlet flower either for indoor use or for summer bedding.

Saxifraga (Rockfoil) is the easiest to grow of all Alpines, but the kinds are most diverse in their appearance and use. Most of them are well adapted for rock work. Some of the larger species are now named megasia, and are grand border plants, with clusters of rosypink flowers; the London Prides (S. umbrosa) form one interesting section. The Mossy species are useful for carpeting the ground around taller plants.

S. sarmentosa (Wandering Jew) is often seen suspended in a cottage window, but mixes more naturally with ferns, its thread-like runners dropping gracefully from the higher levels. 
Sedum (Stone Crop) a pretty, succulent plant, easily grown on old walls, rock-work, or wherever its roots can find a hold. Its forms and habits are as diversified as those of the Saxifrages.

Sempervivum (House Leek) is very similar to the Sedums in nature and growth. The plants are neatgrowing succulents, forming rosettes of fleshy leaves close to the ground, and rapidly increasing by runner-like off-sets. They do best in sandy soil.

The Sparaxis and Ixia are very showy South African bulbous plants, of most varied and brilliant tints; they each require a light, loamy soil and a warm, sunny aspect. Sparaxis pulcherrima (Wand Flower) is immensely larger than the type, and may be grown best amongst shrubs, with the advantage of getting their shelter.

Sternbergia (Winter Daffodil).-The plants are, like Colchicums, very attractive autumn and winter bulbs, well adapted for our gardens. They require to be thoroughly ripened in summer and to have some slight protection in winter, and are therefore best located in sandy ground on a high and sheltered part of the rock garden. Colchiciflora and lutea are the best known. The bulbs must be established a year or two before they will bloom.

Schizostylis coccinea comes from South Africa, and is one of the brightest gems of the garden. It loves 
moisture in summer, and should be divided in March and replanted in bold groups every two or three years, as the roots multiply exceedingly.

Tritonia or Montbretia or Crocosmia are similar African bulbs, and require like treatment. They, too, spread very quickly.

Trollius (Globe-flower) has a ranunculus habit and vigorous growth. It varies from a pale yellow to deep gold, and blooms all through early summer. The plants grow freely on any soil, but seem to demand a cool, moist sub-soil and plenty of manure.

Verbascum (Mullein) a handsome biennial. Like the Foxglove, when once established on a border, it will shift for itself. The best are olympicum and phlomoides.

Vinca (Periwinkle) is a trailing plant too well known to need description. It is, however, such a free grower, that once established, it will need constant repression. The common blue and the variegated Vinca are useful for covering roots and spots where little else will grow. Of Vinca minor there are several varieties, one with a tiny white flower, and two with flowers like double violets. 


\section{CHAPTER III}

\section{HERBACEOUS AND ROCK BORDER COMBINED}

IT may be all very well for those possessed of large means and gardens large in proportion, to partition off certain parts of their grounds and devote them to separate uses, and one often finds satisfaction in being conducted in succession to the rose garden, the herbaceous border, the fernery, and finally to the alpines. Those who have money and leisure may very well find enjoyment in this way. I am little qualified to help them; they can get on without hand-books. They have their valuable books of reference and expert gardeners, at whose feet the writer is often glad to sit.

It occurs to me, however, that there may be many others with small means and little leisure, but a true vocation for gardening, who might get quite as much satisfaction from their very limited plot of ground, if only they could know how to lay it out to advantage, and what sorts of plants to cultivate. For such people I am inclined to advise a combination system.

The one border may be made to combine everything if it be only judiciously planned. It may seem a mere fancy, but nothing satisfies me so well as an irregular serpentine curve-a border which may start with an aspect facing due north, and, after frequent twists, find itself in a warm southern climate. There are grounds which lend themselves naturally to this suggestion. 
I have a strong prejudice in favour of a border raised 3 or 4 feet higher at the back than in the front, irregularly crowned with boulders and inverted roots of trees, so as to afford shelter and break the force of prevalent winds.

Then again, where stones, great and small, may be had, I like to work them everywhere into the border, from one end to the other, and by this means to secure an edging as far as possible removed from the stiff earthenware abominations from the potteries.

There is no edging so full of possibilities as rough stones, but I would go further, and build up separate small divisions or "pockets" on the bank, sometimes with great rocks, sometimes with small and medium stones, laid (as thick limestone flags or flat stones can so readily be) as nearly as possible as though they were lying in their own quarry, stratum upon stratum. These divisions will then render the border not unlike, in miniature, the curiously shaped little fields one often notices on some unproductive farms in mountain districts.

In raising such a bank it is well to lay every available sort of stuff under contribution-layers of rich manure where it may be had, heaps of leaf mould, and of gritty road-scrapings (taking care to pick out all roots of weeds), or the high bank of earth which often is thrown up as a mound at the edge of a ditch. I have turned to account the lime-rubbish and slates from the roof of an old house. Such material is often to be found, and folks are glad to be rid of it. 
This, then, is the foundation I would suggest for the border, and for the rest, a great deal must, if necessary, depend upon the owner's taste and skill in the building up and laying out.

Its special advantages are not far to seek; one of these is aspect. Often I have known plants to die if placed on one side of a rock, while they thrive on the opposite. A north border suits them, a south enervates.

The serpentine bed I have described affords its owner endless opportunities for making experiments and gaining experience, if he will only keep his eyes open and use his wits.

The separate divisions again afford all the advantages of the bedding system without its defects. There may be found room and scope here for the culture of all sorts of plants, the ground having been prepared beforehand with a view to the requirements of each, viz. a limestone compost for some things; a peaty mould for others; a dry corner for certain plants; a moist swamp for certain others; higher ground suitably prepared for alpines, out of reach of the stronger growths, which would choke and smother them, and yet not "high and dry," but congenial soil into which the roots may penetrate; and there should be contrived some shady nooks in retired depressions for Ferns or Pansies.

On certain of the higher levels the Christmas Rose might be planted in groups where its roots would 
have a depth of 3 or 4 feet to sound, and where it might remain undisturbed for many a year.

Similar plantations of Lilies might be placed half way up, and here and there in their neighbourhood small paddocks of the better sorts of Daffodil, growing securely beyond reach of the spade, and high above the dead level of border life. All through the heat of summer and autumn these would dry and ripen, and accordingly, instead of dying out in a few years, would multiply, often quadruple themselves. Groups of Tea Roses might appear here and there, with Ramblers becoming bushes behind the high level at the back.

Single specimens of Fern everywhere, with Mosses, and Gentians, and Saxifrages, all making themselves at home along the serried edgings of the pathway.

One great advantage of this plan is, that instead of single, separate, ineffective, isolated plants, the border will chiefly consist of groups and patches of various extent, each sort assigned to its own special quarter, and so arranged that the colours contrast and combine. Bulbs and plants which are not always in evidence should be somewhat deeply planted (and always carefully labelled), so as to allow a carpet of spring or summer flowers on the surface-Forgetme-not, Nemophila, Phacelia, Mignonette, and so forth.

Over rocks or division walls the Aubretia, Wild Thyme, and Creeping Phlox will find their way, and Dwarf Ivy will soon form festoons round the projecting roots, so 
that presently the bank through its entire length will show no traces of its origin.

Of course all this will have involved considerable trouble, but it may be easily done during one month in autumn, and it will scarcely need alteration for six or eight years to come, and in all that time a spade will seldom be permitted to intrude. A careful weeding every three months and a top-dressing of fresh rich compost every winter-these will suffice.

Changes can be made more or less radically on certain stretches of the border in any year, and transplantings may, of course, be made at any time, as the condition of the plants suggests, and it is simply wonderful how much information, occupation, and enjoyment may be found from year's end to year's end, in one unpretending border, by those who love their plants, and will patiently observe the nature and habit of each variety, as seasons and months succeed each other, and as each brings its own special work and contributes its own share of pure satisfaction.

\section{CHAPTER IV}

ALPINE BORDERS

ONE of the most attractive parts of the ideal garden of modern days is that known as the rockery or wall-garden. When judiciously planned and tolerably well-looked after, 
it gives very real pleasure and satisfaction, with comparatively little work. In one of those awkward formations of ground which one frequently observes in a garden, where some abrupt change of level would seem to make a terrace or a retaining wall necessary, the oportunity should certainly be availed of to build there a dry wall (which may be anything between an old broken-down wall and a very steep line of rockery). So much the better if it is exposed to north or east if it is meant to be a home for Alpine plants.

In Miss Jekyll's "Wood and Garden" she tells us that she has built and planted a good many hundred yards of dry walling with her own hands, and that she can speak with some confidence of the pleasure and interest of both the actual making and planting, and of the satisfactory results which follow.

I should not recommend begininers to try and build such a wall out of their own inner consciousness, and without having previously made a careful inspection in some garden where the thing had been already well done, or consulting some amateur like Miss Jekyll, who is a clever expert; and indeed it may perhaps prove most helpful if almost in her own words I try to describe the operation.

A dry wall needs but little foundation, two thin courses underground are quite sufficient. The important thing is to keep the earth well rammed and trodden behind the stones of each course and in the middle, and every two or three courses to lay some extra long stones across, so as to tie 
the wall well into the bank. The more porous and rotten the stone the more welcome as nourishment and root-hold it will be to the tiny plants, whose roots are to find their natural home in its chinks, and even if a stone or two should crumble right away in a few years' time, the rest will hold, and the space left will make a little cavity where some small fern will live happily.

As it is being built, the wall should be planted with hardy ferns. The long fibrous roots of such sorts as the Parsley may be spread out between two flat stones, with but a sprinkling of turfy mould between. The Polypodies had best be placed where their strong root-stems shall have ample opportunity of spreading themselves over the surface. The Welsh and Cornish are the best of all Polypodies, but the Limestone, the Oak, and the Beech, though not so easily naturalised, are lovely plants. Then there are the Hartstongue, Ceterach, Asplenium, and Wallrue. These last three like lime, and so a barrow of old mortar-rubbish may be thrown in where they are to be planted, so that they may have a layer of their favourite soil.

Each course should be laid fairly level as to its front top edge, the earth behind then carefully rammed into the spaces at the uneven backs of the stones, and a thin layer of earth over the whole course, where in a built wall the mortar would have been. This supplies both a "bed" for the next row of stones and soil for the plants which are to grow in the joints.

The face of the wall slopes backward on both sides 
so that a breadth of 5 feet below is contracted to 3 or 4 feet above. Each stone should be set to tip somewhat down at the back, so that every drop of rain that falls on either side of the wall may find its way naturally amongst the joints, and go to moisten the tender roots and attract them inwards.

The middle of the wall, which may be supposed to stand over 4 feet high, can be planted with Bush-Roses, Scotch Briars, Berberis, and some bushes of Sweet Verbena, Olearia, and Choisya ternata at the more sheltered end. As there are thus practically three sides available, almost every aspect is afforded, and many things which refuse to live at one side will probably thrive at the other side or above.

Early autumn is the very time to get to work on the rock garden, for alpines that are planted then at once take a firm hold, and all through winter their roots, at least, grow steadily. The names of a few of the more familiar plants which would find a congenial home on such a site will here suffice:-Dwarf Alpine kinds of Alyssum, Artimisia and Achillea, Mossy Saxifrages, Yellow Everlasting (Gnaphalium orientale), Erinus Alpinus, and the three sorts of Cheiranthus-a near relative of the wallflower-alpinus, Marshalli, and mutabilis. The Edelweiss, an unusual-looking Alpine, will grow freely from seed, and lives on for years on the rock border. . It bears interesting flowers wrapped up in woolly silvery leaves. The plant has a romantic interest for Swiss mountaineers. 


\section{CHAPTER V}

\section{ROSES}

$\mathrm{By}$ far the most effective way of growing Roses is to have them distributed through every part of the garden. Bushes of Teas in groups amongst the pockets of the rock garden look at their best, and often find there just the sort of shelter they need. Happily, the time has come, when the Rose has ceased to be looked on merely as a cut flower for the decoration of our rooms and houses. It is now cheerfully given its rightful place as one of the choicest decorative garden plants. Thanks to $\mathrm{Mr}$ Robinson, an important change has come of late years, and the beautiful Tea Roses, with the newer hybrids, have been assigned their rightful position of precedence, for the purity of their tints-both petals and leaves; for their unique fragrance; and, best of all, for their constant, persistent bloom. They are, indeed, the true perpetual Roses; the name of the others is misleading in comparison.

Amongst the Tea-scented Roses which I have proved most satisfactory, I would place first of all-Madame Falcot, Madame Lambard and Anna Olivier, Madame Hoste, Narcisse, Hon. Edith Gifford, Marie Van Houtte, Madame Berard, W. A. Richardson, Innocente Pirola, Niphetos, Devoniensis; of the Noisette class, Rêve d'Or, 
Lamarque, Maréchal Niel, and Cẹline Forestier, and many more equally good.

These Roses, I find, grow well on their own roots, and, with few exceptions, are exactly adapted for the climate of our gardens.

The ever-increasing and beautiful class of Climbing Ramblers should be allowed to grow at their own sweet will, in spots where they have room to spread without hindrance, e.g. Brunonis, the lovely Himalayan single milk-white Rose. One of Lord Penzance's new Sweet Briars will be most at home when finding its way into an old Apple or a great Holly tree, and flinging out its long wreaths of bloom on every side. A Crimson Rambler in my own garden has taken possession of a dead Laburnum, itself once very beautiful, but now supporting such lovely clusters of rosebuds and wealth of rose leaves throughout the season, as to make us forget its old beauty in its new grandeur. For some mysterious reason, this Rose does not thrive against a wall.

Madame Plantier, and Ophirie, and Bouquet d'Or, and Paul's Carmine, and Bardou Job, and Reine Olga are good types of pillar Roses, and for trellises $W m$. Allan Richardson is unequalled, while Gloire de Dijon must always take the first place, either as a dwarf or climbing Rose.

The very best Hybrid Perpetuals are amongst some of the oldest. La France comes first, but Victor Hugo is grand, and Charles Leferre, Duke of Edinbro', Victor 
Verdier, Baroness Rothschild (which has no scent), Mrs John Laing, Senateur Vaisse, Marie Beauman, General Jacqueminot, Madame Victor Verdier-these should find a place in every garden: others equally good may be found in the best catalogues.

There is no difficulty in raising one's own Roses from cuttings, and those who have good Roses seldom grudge their neighbours a few of their best sorts. A' large proportion of those put in during the month of October are likely to strike freely, and become themselves strong, healthy bushes the following autumn.

The cuttings should be prepared by clipping off side shoots and leaves; 6 or 8 inches is long enough for a cutting; see that it is cut off straight at the base, just below a knot or bud, or left as it has been slipped off the branch. Mark off a narrow piece of north border, mix sand with the mould, to the depth of 4 or 5 inches, tread it well, and water; then plunge the trowel into the mould along the whole length, drawing it out carefully, and inserting the cuttings 3 inches deep, and same distance apart; make the ground very firm with your foot, label, proceed similarly with the next line, and so on; water, cover with cap-glass, and leave them to themselves until April, when the glass may be removed, and they can be potted off, or allowed to grow on until the autumn. All the strong growers, however, will do rather better without the cap-glass, only they require to be put in 6 inches deep.

Those who prefer it may have fair results by taking 
similar cuttings early in August, and planting them firmly in sandy soil in a well-drained north border. Let them remain there till frost comes, and then cover the ground with a couple of inches of ashes, and strew some fern or straw over them. The following June they may be potted or planted out as they are wanted.

It has been already explained that July is the most satisfactory month in the year for budding, and those who wish to learn the art may readily find an instructor; any intelligent gardener or nurseryman will give a demonstration in five minutes, and it is well, after seeing him do it, to let him see you, so as to make assurance doubly sure.

Another method of propagating the Rose is by layers. Roses growing on their roots may be successfully layered in this way. About the first week in July prick up the ground round the tree, and mix up an inch or so of sharp gritty sand with the soil, provide some strong hooked pegs and short stakes, select a branch, not too sappy nor yet hard, bend the middle of the branch to the level of the ground, and where it touches make the incision, direct the knife upwards, making a clean cut up the centre of the shoot for a couple of inches. Again bend the centre of the shoot, and make the tongue of the slit to dip into the sandy soil. Fix it securely in position with a. hooked peg, supporting the upper end by tying it to a stake, then fill up the hollow made for the reception of the layer. Most of the shoots will likely be rooted in three months, when they may be cut from the parent plants 
potted, and stowed away into a cold frame for the winter.

It is thus, as I have shown, comparatively easy to propagate the Rose either by cuttings, or budding, * or layering. The after culture, however, is a matter sometimes beyond our control.

There is no use in trying to grow Roses where smoke and grime abound; it is labour in vain, and something more. And yet it is worth a little expense and trouble, in a town or suburban garden, to rig up some place where they may be grown. Six feet square of glass will hold a dozen pots of Tea Roses, with Marechal Niel growing, after the manner of a vine, on the roof. They will thrive in large pots if grown in good old broken sods and strong manure, and sometimes watered with soot water and liquid manure. After each time of blooming they may be stowed away in a corner of the garden, so as to season and harden the wood. All straggling branches should then be cut in, to induce a new growth of buds. When these appear, the plants may be again brought indoors, syringed and watered, plenty of ventilation being given, and in this way, they will blossom frequently in the course of the year.

* See page 4I. 


\section{CHAPTER VI}

\section{FERNS-THEIR NATURE AND CLASSES}

THERE are few plants so generally popular, and none so widely distributed over our earth, as Ferns. They avoid the Arctic Zone, but to all other regions they readily adapt themselves. In some countries they are equal in number to one-ninth of all the known flowering plants, to none of which they claim any relationship. In fact, they must belong to another era than ours-probably a survival of an older world, as the conditions under which they live and thrive are the very reverse of those which are conducive to the well-being of animals like ourselves. Moist steamy surroundings are their paradise, and for this reason all the hardiest Ferns known may be grown in the same high temperature as the most delicate exotic.

It may be helpful to those who love Ferns, and whose knowledge of their structure and habits is yet limited, if in this chapter I say something concerning a few of our better known Ferns, promising not to intrude very far on the domain of the botanist or the specialist, and I am not without hope that even an elementary acquaintance with their classification may help to increase the interest and pleasure of some amateurs.

If it should be asked why our British Ferns are such 
attractive objects of study and culture, I venture to say there are several reasons. The first is, that their peculiar beauty and graceful forms are alike irresistible on the mountain side and in the rock garden. Then, again, they are not numerous or difficult to find, the number of native species is probably not more than forty, and, moreover, when found they are easily cultivated, and well adapted for growing in the garden, the greenhouse, or the drawing-room.

Speaking generally, a Fern may be defined as a plant which bears leaves only and no flowers. The name of their order is Cryptogama, i.e. hidden flowers; they have organs which produce spores, but the attractive petals are absent, and the spore-cases are hidden away or take strange forms.

When we meet with a full-grown plant, and examine the under surface of its leaves, and find dust-like patches, circular, or in lines, here and there, we may conclude that plant is a Fern, for the leaves of plants which bear flowers do not bear these patches of brown dust.

Ferns, then, are flowerless plants, with roots, stems, and leaves, and the leaves generally bear on the lower surface the spores by which they ultimately reproduce themselves.

The roots are fibrous or thread-like, and these insinuate themselves between the stones or turf or wooden fibre or sandy loam which lie near them.

The stem of our native Ferns seldom rises above the surface, though in some exotics it reaches a height of 
30 feet, like a palm. I have seen the stem of our Royal Fern (Osmunda) rising more than 12 inches, after the manner of the Tree Ferns; and the Male Fern (Filixmas), when undisturbed for years, sometimes grows as high; but these cases are exceptional.

The stem is sometimes called a rhizome, when it creeps horizontally on or beneath the surface-and from it the fibrous roots strike down or adhere to the rock or branch. These rhizomes when on the surface are covered with hairs or scales; of this habit the Polypodies are the most familiar examples.

The leaves of Ferns known as fronds are something between a stem and a leaf in an ordinary plant; they are endless in their variety, some immense, others minute, some simple, others divided and sub-divided, some soon fade, others are practically evergreens.

The fronds are traversed by veins running either in parallel lines or in networks, the way in which these veins are disposed is termed their venation, and the nature of this venation indicates the divisions of the ferns into family groups. It is from these veins that the clusters of spore-cases are derived, and each separate cluster of these cases is called by botanists a sorus.

Without going into the question of the botanical classification of Ferns, it may be well to suggest that our British Ferns may be roughly classed under two groups. The first, a small family, whose spore-cases not being surrounded by a ring (annulus), are called exannulate. They are Adder's Tongue, Moonworts, Osmunda. As in 
the case of the Osmunda, these are all distinguished by the fronds being entirely leafy in the lower part of the plant and entirely fertile at the top; the leaf-like divisions (pinnce), at the apex of the fronds, being changed intc masses of spore-cases. This mode of bearing the fructification gives the plant an aspect different from those whose fructification is concealed by their position on the under surface, so that Osmunda is sometimes spoken of as the Flowering Fern.

The second and much the larger family is composed of those whose spore-cases are ringed, annulate. These may be arranged under three sub-divisions: the first (a) including Polypodies and Parsley Ferns; the second $(b)$ the Shield Fern, Lady Fern, Spleenworts, Hartstongues, Bracken, Scale Fern, Maidenhair, Bladder Fern, and the Woodsia; and finally (c) Filmy Ferns, Killarney, and Hymenophyllum.

By far the most interesting group is that of the Polypodies, of which there are five members. The Common Polypody includes about twenty varieties, and amongst the best known are Cambricum (the lovely Welsh Fern), which bears no spore-cases; Hibernicum, and Cornubiense (the Cornish). Then there is the beech (phegopteris), the alpine (alpestre, very like the Lady Fern), the oak (dryopteris), and the limestone (Robertianum).

I have ventured to sketch out, for the help of those of my readers whose knowledge of the Fern Family is limited, a very simple and yet sufficient classification with which every collector should become more or less familiar, and in 


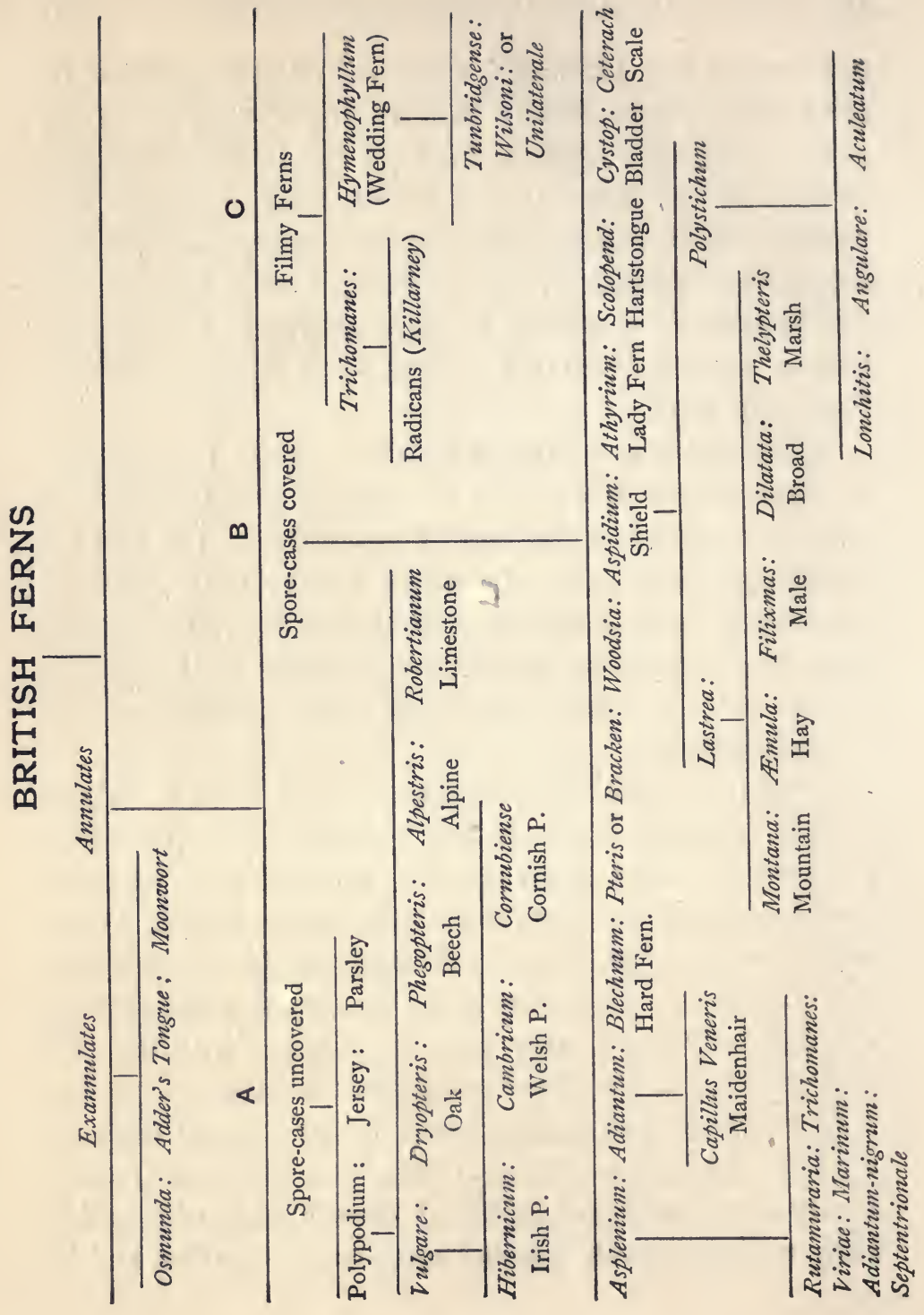


chapter vii. there will be added some practical suggestions on the construction of a fernery.

Let me add a few words as to the Ferns which are best suited for outdoor cultivation, and those kinds which may be reserved for a cool fernery under glass.

The Osmunda thrives best at the edge of water, where its roots-may reach into moisture which is not stagnant.

The Blechnum and the Lastrea Thelypteris or Marsh Fern also like a damp atmosphere, where there is good loam and fibrous peat. Here also the Oak and Beech delight to spread their matted rhizomes over the roots of over-shading trees.

The Parsley Fern will not grow for long in any place where it cannot push its roots between the crevices of flat rocks; it cares less for soil than for a cool equable moisture, but when it finds this, it becomes luxurious in its growth.

The Welsh and Cornish Polypodies, as well as the more common sorts, are perhaps the most satisfactory of all for forming beautiful groups. Their creeping stems grow upon the surface and spread themselves around blocks of wood and stone, and, being evergreens, they are in perfection when most wanted.

The Polystichums or Prickly Shield Ferns include some of the choicest of all hardy plants. The richness 
and feathery beauty of fronds give them a charm all their own. $P$. divisilobum robustum is, perhaps, the most beautiful of all Ferns in cultivation.

The Scale Fern (Ceterach officinarum) will only thrive properly on a wall or in a soil chiefly composed of old decayed lime-stone, but in such conditions its very marked character may be seen to perfection.

The Spleenworts are nearly all small evergreens, and interesting to collectors, though some are troublesome to grow in the open air.

The Prince of Wales' Plume (Struthiopteris germanica) is a beautiful, strong-growing plant, with a habit of its own; so is the Onoclea sensibilis. Both these are quite hardy, though not indigenous to Britain.

The Hartstongue (Scolopendrium) is the hardiest and best known of all our native Ferns. It has broken from the type into almost innumerable forms and varieties, all interesting, some striking and beautiful. The sports of Hartstongue are said to number from five hundred to nine hundred varieties, many of them mere "vegetable cripples" not worth cultivating. Crispum is the best of about eighty of the named varieties; its margin is frilled from the base to the point.

Of those British Ferns which are best suited to a cool house under glass, I would suggest the following amongst many. 
The Killarney Fern (Trichomanes radicans) is only found in the immediate neighbourhood of waterfalls, and in places where constant moisture is the rule and the direct rays of the sun are excluded, and so it can be successfully grown only when kept pretty close and constantly wetted overhead. It has a creeping, wiry, blacklooking stem, which clings like Ivy to a ledge of rock or peat.

Hymenophyllum Wilsoni and $\mathrm{H}$. Tunbridgense are small moss-like plants, which grow in matted tufts on the surface of damp rocks, the black, wiry, creeping stems being tangled together. They may be easily removed in flakes, with some soil or turf attached, and, if carefully fastened down in their new quarters, will grow freely in the same neighbourhood as the other Filmy Ferns.

The Todeas which belong to this group require similar treatment and atmosphere. They can stand several degrees of frost, but no sun.

The Maidenhair Fern (Adiantum capillus Veneris) is found in some rocky nooks on the south and west coasts of Ireland, as well as in the warmer parts of Europe and Asia. In a Wardian case or in a damp, warm greenhouse it grows well. The proper soil for it is a very light turfy peat, mixed with silver sand, and with lumps of sandstone pushed in amongst the roots.

For baskets the best sorts are the different varieties 
of Adiantum. Those that form underground rhizomes travel quickly to the outer edge and form a perfect wall of delicate verdure.

$A$. assimile, $A$. glaucophyllum, and $A$. lunulatum will be found the most satisfactory.

The proper time for repotting or transplanting Ferns is the month of March. A compost which will suit most of them can be made of two parts fibrous peat, one of good loam, with plenty of sand and sandstone broken small.

The more delicate sorts prefer sandy peat only.

\section{CHAPTER VII}

CONSTRUCTION OF FERNERIES

No plant perhaps has so great a power of imparting to a garden a certain charm of homeliness and personal interest as the Fern. Owing to some association of place or person from which it may have been procured, an individual Fern can possess an interest for the planter so special as to amount almost to an affection, and he will return to visit it again and again with ever fresh interest.

And yet, though it is good to have our favourite Ferns up and down through the garden, specially when we find that they thrive in it, one cannot help feeling that they are worthy of some special corner of their own; this should be, not in the full view of every passer-by, and not in the full 
glare of the sun, but rather at some unexpected turn where mounds can be thrown up and a sort of natural rock-work arranged, as if some dozen square yards of limestone quarry had been removed thither by a pre-historic earthquake.

During a half-hour's stroll in one of our well-planned public gardens a useful lesson may be learned in the construction of a fernery. A rough pencil sketch of a few groups or combinations of limestone here and there, jotted down at the moment, may often be judiciously reproduced on a smaller scale, and then, when the interstices have been filled with peat and sand and leaf-mould, Ferns will make themselves at home very soon.

And for those who desire to see Ferns at their very best, I know of few places better worth a visit than the gardens of Kew or of Glasnevin. At Glasnevin $\mathrm{Mr}$ Moore has of late years greatly extended his out-of-door fernery, and so planned the aspect and the construction of the stonework, that even half-hardy things, like the Woodwardia, live and thrive amongst their more robust neighbours.

Where it may be found, a derelict greenhouse of some sort that will afford the protection of a roof may be turned into a useful and interesting fernery. A devious path might be made in it, leading down by a flight of rock steps to the lower level. Rocks may be artistically built at each side all along the meandering central path, and nooks or pockets arranged here and there between the stones on the level of the path. Then above these foundation-rocks, terraces or walls may be built of sods of turf up to the roof, each layer or course being well 
grouted with sandstone and lime rubbish mixed with peatmould. At the darker, shadier end arches can be made of the sods of turf and the walls behind them lined with them, and in these alcoves (which are thus secured from any direct rays of the sun) Todeas and the Truchomanes radicans (Killarney Fern) and Hymenophyllum Tunbridgense may be planted, and when syringed and kept moist their rhizomes will soon run over the surface of the turf and grow as in a state of nature, and, moreover, their beautiful filmy fronds may be admired without the trouble so often experienced, of peering into dark corners under greenhouse stages in the vain hope of admiring them there.

I have found the Woodwardia radicans one of the most effective plants for furnishing a fernery at the beginning. When it grows too rank it may be easily cut back or even rooted up; but its great, healthy, overshadowing fronds give a tropical appearance even to a very plain house, and in such shelter frost has very little effect on it.

In such a house, constructed and prepared as I have endeavoured to describe, Ferns will thrive and look their best, owing to the absence of draughts and droughts and direct sunlight, and to the possibility of maintaining a constantly moist and equable atmosphere.

There is no reason why Ferns should not be successfully grown in earthenware pots and pans, and thus be moved about the fernery and into greenhouse or sitting-room, as may be found necessary. Their home, however, should be the fernery itself, and if they must leave it, the sooner 
they are back the better. Sudden changes into such dry, draughty, uncanny positions as they are likely to be exposed to are most trying, and very risky, even for strong, hardy plants; and I have no doubt that a couple of weeks sojourn in a corridor or a drawing-room is resented by all classes of the inhabitants of ferneries in very much the same way as we should resent the experiment of banishment to the uncongenial regions of Siberia.

\section{CHAPTER VIII}

\section{CLIMBERS}

OF late years a great change has come about in the treatment of hardy climbing plants. They used to be stiffly trained against walls, which tended to cramp their habit, and hindered them being seen to advantage, or being made a pleasant feature in the landscape, and all the time the great bare trunks of old trees were left to stand out in their native deformity without any attempt to clothe them with a wealth of beauty and verdure, growing hard by, yet lost for the want of their natural support. There are scores of graceful trailing plants, like the Golden or Silver Ivy or Cotoneaster, that are just fitted to garland some awkward tree stumps, and there are few things more beautiful than a trailing Clematis or Rambler Rose, suspended from the branches of some huge tree. 
An unique garden might, indeed, be made without a single formal bed, simply by a judicious arrangement in groups and clusters of Climbing Roses, Ivies, Jasmines, Clematis, and Honeysuckles. In winter there is nothing more attractive than a low wall or bank covered with Cotoneaster, Jasmine, Escalonia macrantha or Berberis stenophylla; nothing sweeter than a plant of Chimonanthus fragrans or Magnolia grown on a sheltered. space of wall, for the sake of their delicious spicy scents. Then in the spring we have a large choice; Clematis montana takes a first place for covering high walls, or anything which needs to be draped with quick-growing creepers. Wistaria Sinensis is also good where rapid growth is not expected.

Forsythia viridisissima and suspensa and Cydonia Japonica (with its newer varieties) are not creepers, but grow well over a buttress or pier; such Hybrid China monthly Roses as Fellenburg or Cramoisie will bloom late and early, while Gloire de Dijon will begin to flower in May.

In summer and autumn, however, Creepers are at their best; various Clematis in succession, Passion Flowers in sheltered districts everywhere-the white variety, Constance Elliott, is one of the loveliest of garden flowers, and as hardy as the older kind-and Rambler Roses.

The Ampelopsis and the wild types of Vine-e.g. Vitis Coignetice (comparatively new to English gardens), have a peculiar charm with their luxuriant habit and wealth of foliage. The larger-growing sorts are admirable 


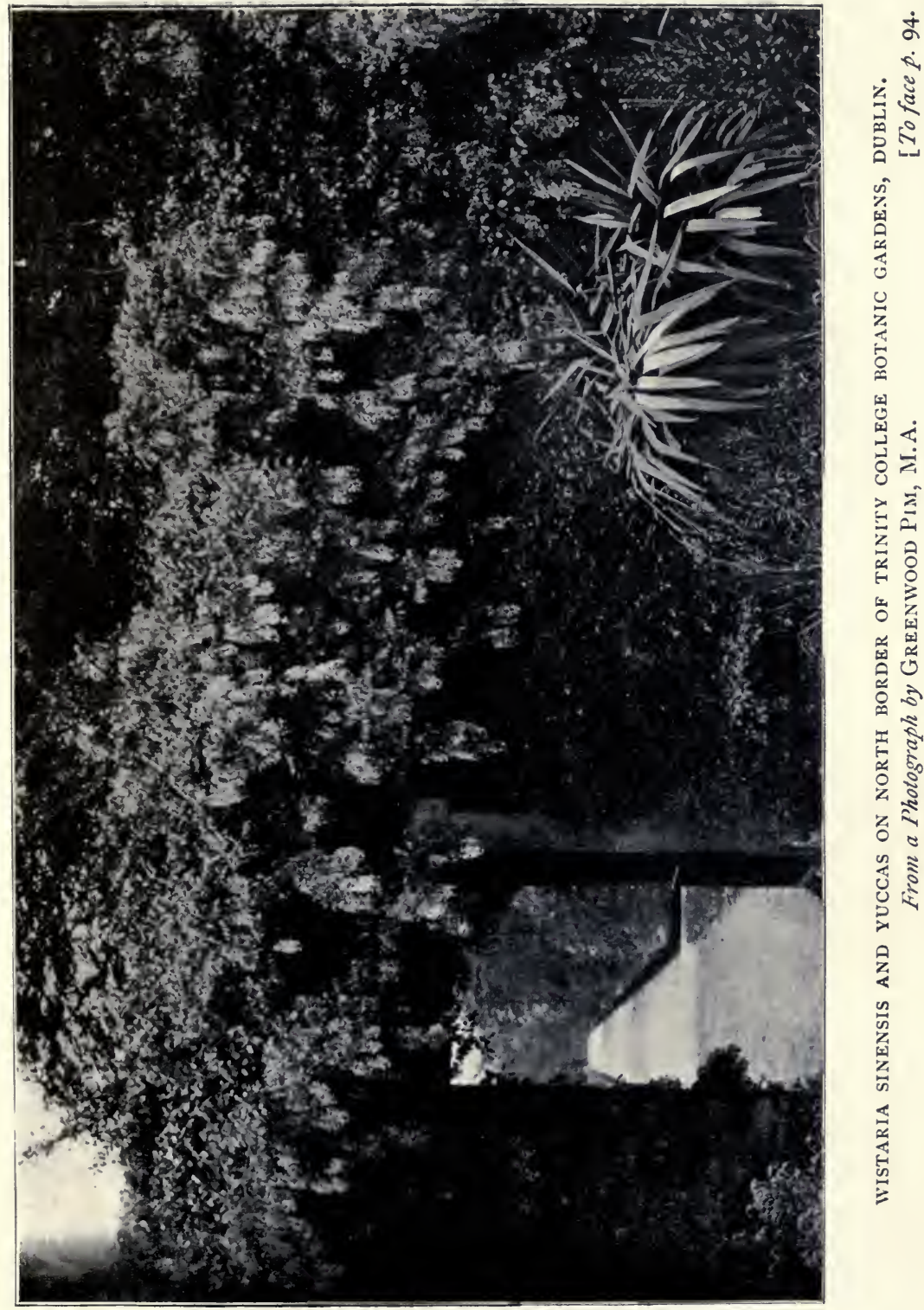


(1) 
for clambering over tall living trees and verandahs. They are moisture-loving plants, and need liberal treatment at their roots.

The Pyracanthas, though not a creeper, is a most hardy and useful ornament on a house wall, and its bright berries are in perfection up to Christmas.

In selecting some of the better-known climbers, I give first place, for convenience sake, to the Clematis.

The earliest and most attractive is Montana. It is specially fitted for being trained well up to the top of a cornice or porch, and allowed to droop down of its own accord in a graceful drapery. It is well adapted for trellis or arbour, or, in fact, for any position where rapidity of growth is desired. It is not particular as to soil, but at the beginning of spring the young shoots should be seen to, and carefully trained before they entangle themselves.

C. montana, unlike the others, must not be pruned until after it has flowered. The rest should be pruned early, and some of them cut severely back. The C. lanuginosa family bloom from May, and Jackmani and its varieties are the latest of all. Some of these blossom into winter. All are tolerably vigorous. As they blossom. very freely, rich treatment is required. Some sorts are effective as a bed, trained carefully over wire or netting.

The Tropcoolums (Nasturtium) are a large and interesting family of plants. They are only half-hardy, and the first frost cuts most of them down to the ground. They love a shaded situation. There are annual and perennial 
species. They are not particular as to soil, and grow very rapidly.

$T$. canariense is admirable for festooning trellises. It is best sown early, and hardened off before being finally placed. When planting, it is a good plan to drop a few seeds amongst the young early plants, which will grow up through the summer, and take their place when the first have begun to fade.

T. lobbianum and majus are the commonest and most free growing of all climbing annuals, and there is no limit to the uses to which they may be put.

T. speciosum (Flame Nasturtium) is a splendid climber, with brilliant vermilion flowers. It has roots like the strongest convolvulus weed, and they have a strange habit of wandering. Speciosum enjoys deep, rich, and rather moist soil, dislikes hot sun and a dry atmosphere. It would thrive in some spot on a west wall, partially screened by a deciduous tree, so that in hot weather the sun will only reach the plants for two or three hours each day. A careful division of old roots is the best way to propagate them. I have found it a good plan to grow the plants at first in pots until the roots have filled them, and then plunge into ground made light, deep, and free with peat, leaf-mould, fibrous mould, and sand, according to the nature of the soil, covering the surface in summer with leaf-mould or manure to hinder evaporation. Slugs are very fond of the young sprouts, and I suspect are often the cause of the disappointment when they fail to grow.

T. polyphyllum has tuberous roots, and is quite hardy 
in dry situations in the rock garden, but it should not be often disturbed. The flowers are a lovely golden colour, the leaves are rue-like in tone, the stems creep about, sometimes 3 or 4 feet, through the neighbouring plants like a golden snake.

T. tricolor is an interesting bulb, which may be easily grown in a pot in the greenhouse, and trained over a balloon-shaped wire frame; it is soon covered with gay flowers, and remains in bloom for weeks together.

Besides the Nasturtium, the best annual creepers are the Maurandya, Convolvulus, and Ipomoea. The Common Hop is a useful climber when rapid growth is required, and there is space to allow of its running wild over a bower, or climbing up some old fruit tree. When free from insects, both leaves and clusters are very attractive.

Aristolochia Sipho is a distinguished looking climber, with great tendrils and noble leaves. Tomentosa wears a different foliage.

The Cotoneaster microphylla is named rupestris, from its habit of creeping over rocks and like positions on sloping banks; it is smaller than the common one.

The Azara are distinct and graceful shrubs. As wall plants they flower freely. They are natives of New Zealand.

Melia azadarach is an ornamental tree, not unlike the Ailantus. I have admired it growing round the English churchyard at Nazareth, and even more vigorously in some of the Californian streets, where its shade is most welcome. 
Muhlenbeckia complexa is a graceful rapid climber, with long wiry stems and small evergreen leaves, not unlike a Maidenhair Fern. It will readily twine itself to the very top of a high stump, but requires some protection in severe winters. It may be easily propagated from the strong shoots, which are sent up from the base like suckers.

The Smilax or Green Briar has many varieties. It is a valuable evergreen climber. In Syria it covers the forest trees like our ordinary Ivy.

The Myrsiphyllum asparagoides might readily be taken for a Smilax. It is really a Lily, and very easily grown under glass. There are few things so effective for decoration of a table, and may be bought by the yard in London flower shops; it can easily be raised from seed in a hot-bed, and if planted in boxes of peaty loam, may be trained up a pillar in the greenhouse, or be supported by a wire or string fastened above. The Myrsiphyllum needs good drainage and a fair amount of water, and will be all the better if shaded from scorching sun and fed with weak liquid manure about once a week when in a state of growth.

It is scarcely necessary to describe the very best of all climbers-the Ivy-whether it be the vigorous Giant Ivy, or the glorious Golden, or the graceful tendrils of the Silver. Whether it be used to cover a bare wall or the trunk of a tree, or to form a clump by itself over an old root, which gives it some support, or as an edging for paths or beds, it is equally good; but if we wish to have the Ivy in its fullest beauty, it must be trained, or pruned, or clipped, as the case may be, every 
year in the month of April. The buds are just then beginning their growth, and all traces of the knife or shears will have disappeared within a very few weeks.*

If there were no other reason for cutting Ivy close in this way in the spring, there is this great advantage, that it avoids the nuisance of constant litter from the old leaves, which otherwise keep dropping off for the greater part of the summer; it also drives the sparrows into other quarters.

Fortunately, Ivy is one of those things which thrives under almost all conditions. There is no excuse for bare walls and unsightly corners-these have only to be furnished with a few old roots and blocks, over which our native Ivy soon climbs; they may be completely covered in one or two seasons. If a strong plant be put into some rich earth at one end of a wall, and carefully run up for Io or 12 feet, then unfastened and laid along the whole length of the base and firmly covered with soil, each bud will presently climb up, and there will soon be a sheet of green Ivy over the whole surface. Such a covering tends to make the structure on which it grows very dry; it has, in fact, most of the advantages, without the drawbacks, of the old-fashioned and unsightly weather-slating. It should, however, never be allowed to run so wild as to afford a covert for birds

* Some gardeners prefer a July clipping for these reasons:(I) It can be done more easily, the growth being young. (2) The growth which follows is small and neat, so that it is close all the winter. (3) July is a comparatively idle time for the men on the farm and in the garden. 
and vermin, or get under the slates of the roof, or intrude into the reveals of the windows, or between the bricks and stones of a wall; and no year should pass in which it is not closely shaven.

The Climbing Hydrangea (Schizophragma hydrangeoides) is a Japanese climber which fixes its roots to a wall as firmly as Ivy, and will grow freely over wood or stucco work. Its leaves are of a lovely shade, it is deciduous, and in a sunny aspect blooms freely. This vigorous climber will cover in a very few years an extensive lattice.

\section{CHAPTER IX}

\section{LAWN SHRUBS}

IT is a fact not infrequently overlooked, that a very large part of the attractiveness of a garden depends upon the selection, culture, and the judicious pruning of its shrubs; and it is the neglect of these which often spoils a garden as well as the reputation of the gardener. I do not think the utter absence of ornamental trees is quite as bad as the crude and vulgar way in which they are often treated. The care of one's trees is as much an art as the dressing of one's daughter, and quite as much justifies the taste and judgment of those who are responsible.

Ill-assorted colours and ungainly, inartistic arrange- 
ments of form are inexcusable in each case. There are those, for example, who find it very difficult to feel at home in a garden where the Yews and Hollies are closely shaven, after the manner of a well-kept box edging, or with a carefully whitewashed wall as background. And yet such things are not seldom seen, and they prepare one for further developments that will afterwards cause no surprise.

In planting shrubs it is well to place them rather close at first, and as they grow, to thin out by transplanting them into other positions. Some things look best in groups, others standing alone; a thicket of Laurestinus or of Laurels, for example, kept well pruned in, serves as an excellent screen or background, while Aucubas are much more effective growing apart. If the knife be judiciously used, an Aucuba always forms a graceful plant; the foliage is rich and varied, and the large and highly-coloured berries, which now grow so abundantly on the female plant, render the bushes all the more attractive. So that they may bear these berries freely it is necessary to have a few male plants growing in their neighbourhood.

In almost all the older grass gardens and lawns there are numbers of ancient evergreens, such as the common and variegated Hollies, Portugal Laurels, Phyllereas and Laurestinuses, for the most part over-grown, unwieldy objects, which render the planting of new shrubs impossible.

A number of these may be often taken away root 
and branch, but sometimes it is much better to cut them down to within a few inches of the ground (obliquely) towards the end of March, when they will very soon sprout and grow rapidly into handsome shrubs, but the stronger shoots will need to be nipped back with the knife now and then, to secure proportion and balance.

Some very graceful and vigorous shrubs may thus be obtained from the veriest stumps, and by pruning evergreens a little every year, they will furnish as they grow, and will gradually extend themselves, and become each season more valuable and beautiful.

In the spaces cleared by the removal of old trees some new features should be introduced-here a strong plant of Pampas Grass (Gynerium argentium)* or another big species of grass, Molinia altissima, there a Yucca, and elsewhere a group of the Dracœna (Cordyline Australis) or New Zealand Flax (Phormium tenax), while, to give a more striking character, there is nothing so effective as Fortune's Palm (Chamorops Fortunei). A sheltered sunny position suits it best, with a good screen between it and the east wind.

To associate with Yuccas and Dracœnas there are few things more effective than the Bamboos; Metake is the hardiest, gracilis one of the most graceful, palmata has large handsome leaves. The proper time for planting

* According to Dr Stapf, Chief Graminologist at Kew, Cortaderia jubata is the grass formerly known as Gynerium jubatum. See illustration, page 182 . 
Bamboos is April and May, just as they are beginning to grow freely; they then lose no time in forming their new roots.

One can see no reason why an occasional Apple-bush should not be planted in the shrubbery. What could be more attractive or beautiful, with its lovely spring bloom and clusters of rosy autumn fruit?

And it may not be out of place to observe here that the tree which provides most food and plenty in our households, and which is best fitted for thriving in our climate, is the Apple. It is essentially a western fruit-whenever the word occurs in Scripture it refers not to the apple, but to the Quince or the Citron or Orange. It was probably the Romans, and afterwards the Normans, who brought over with them to Britain some of the original trees; and in later times the monks, those great horticulturists of the Middle Ages, brought the apples to wonderful perfection, growing them amidst the quiet seclusion of their monastery gardens. It is thought that some of our favourite varieties have held their own during all these centuries.

Some of the more modern apples are well worthy of a place on the lawn. I know nothing prettier in our gardens than a well-laden Bijou or Worcestershire Pearmain, with its vermilion colouring; or the Ecklinville, or Warner's King, bending under the heavy weight of their enormous fruit. But the most attractive of all is, perhaps, the Siberian Crab. I have seen it sometimes in gardens in the west of Ireland laden with a 
great abundance of bright cherry-like festoons lighting up the landscape. Later in the year I found that they had produced very beautiful and delicious apple jelly.

Apples and Crabs are, however, only one branch of a most attractive family, which embraces Medlars and Double Cherries, Almonds, Quinces, and Plums. The Thorns (Cratagus) are another branch. There are dozens of Hawthorns as good as our own beautiful May, and some of them flower much later, and so lengthen out the early summer.

When a rapid growth of effective shrubs is needed, there are few things so satisfactory as the Golden-leaved Elder; in one summer it will grow 6 feet high, and may be cut back without injury at any time-indeed the deep colouring can often be kept up only by pruning the shoots in winter to within a few inches from where they started the previous spring.

Kerria Japonica is a very old favourite in cottage gardens. There are single and double varieties. It is a profuse bloomer, being covered in April with rosettes of showy golden flowers.

The Quercus rubra, aurea, and coccinea are Oaks of very beautiful foliage, both in spring and autumn. But for brilliancy of colouring, combined with the delicacy of the finely cut foliage, there are few hardy trees that can rival the newer sorts of Japanese Maple. They are of low growth, and invaluable for gardens of limited extent. 
In peat districts, or in gardens where peat can be had at a reasonable cost, there are no shrubs so well worth cultivating as the Hybrid Rhododendron. They are now grown with almost endless shades of colouring, and at a tithe of the price of former days; but they hate limestone like poison, and it is but labour in vain to plant them in any soil but peaty turf. Similar treatment may be given to the Ghent Azalea. The blooms come out before the leaves, and they have every variety of tintscarlet, pink, yellow, gold, and white.

Lavender and Rosemary stand on the borderland between shrubs and flowers; the latter is redolent of pure camphor.

The Mexican Orange-flower (Choisya ternata) is conspicuously beautiful in May and June. When grown in a sheltered corner, with occasional protection of fir-boughs in severe weather, it will make itself at home, and is very easily propagated by layers or cuttings.

The Desfontania are charming evergreens with leaves resembling Holly.

The Pittosphorum Maii is the New Zealand Evergreen Oak with slender dark stems.

The Glastonbury Thorn (Cratogus Oxyacantha proecox) has a strange habit of precocious development of leaf and bloom. Its name is suggested by an old legend associated with the monks of Glastonbury.

There would be much greater satisfaction found in most gardens, if the rule were followed to attempt growing only those shrubs that are likely to thrive. After a little 
experience of climate and aspect and soil, it will be easy to decide on what we can grow satisfactorily, and what we cannot.

I have already alluded to the beautiful Golden Ivy, which, when planted against a pier or over an old block, stands out in striking relief against its more sombre neighbour-its first leaves come out perfectly greenbut as the season advances the colour deepens into a rich gamboge. I have seen Silver Ivy completely covering the stem and branches of a huge old fruit tree, without apparently much injury to the tree, which never looked so beautiful before, even in the month of May. In this case, I am bound to say, there had been no annual clipping.

It seems as if we had only reached the fringe of our subject, and yet this chapter is already too long. When we see from our windows bare empty beds spoiling the landscape for a large part of the year while waiting for their summer furniture, one often thinks what a garden might be made, not of exotic mosaics, but of beds bright with things beautiful all the year round-Heaths, and Azaleas, and Andromeda, and Evergreen Barberry, and Star-bush, and Alpine Cotoneaster.

Fabiana imbricata might well be mistaken for a Heath; in the early summer it is covered with small trumpet-like white flowers.

On more distant banks and rough places in the background our own native Furze should not be forgotten. There is no season in the year when it will not bloom 
The Brooms* and Guelder Rose, and Weigelia rosea, and Buddleia or Mock Orange are all hardy and beautiful. The Mediterranean Heath is a grand flowering plant, and fragrant, but it needs a sheltered aspect. In similar places Hydrangeas will thrive, and few things make a more effective group.

The hardy Daphnes are beautiful flowering shrubs; the best known is the Mezereon, which blossoms before the winter is over. $D$. Cneorum is a dwarf plant best fitted for the rock garden. It is deliciously fragrant, and thrives best when embedded in rocks and stones.

Of late the Lilacs have become enriched by many lovely varieties, but even the old sorts are beautiful They should be planted on open sunny spots, and kept so pruned that they may the better send up bold and luxuriant trusses of flowers.

The Judas Tree will grow freely from seed, and is well worth growing both for its leaves and blooms.

The Smoke Plant, or Venetian Sumach (Rhus cotinus), a very striking shrub from Southern Europe, gets its name from the smoke-like clusters that come when the plant has finished flowering, and which remain in evidence for weeks in autumn.

Aralia Sieboldi is equally suitable for the flower garden and shrubbery. I have grown it in an exposed spot for twenty years, but it thrives best in the shade, and may be either planted in groups or as single

* The Genista monosperma is a very lovely White Broom, and most fragrant. It is not quite hardy, and requires the shelter of a wall on a sunny border. 
specimens. One cannot imagine why it is so seldom seen in gardens.

Arundo Donax, the Great Reed of Southern Europe, is a noble plant in a warm, rich, deep soil. It loves shelter, and needs to have a mound of coal ashes or cocoa-nut fibre thrown over the roots in winter. Some years ago I brought home a small rootlet from the Jordan Valley, which has ever since grown fairly well in the garden, but in a neighbouring conservatory it has attained to very great perfection, growing to the height of more than 30 feet.

One of the sweetest of May flowers is the early Dutch Honeysuckle; it likes a warm corner, and should be cut back hard as soon as it has made its summer growth; it may be increased by summer layering.

Epimediums are very attractive little plants, with wiry stems and graceful leaves; pinnatum is said to be the best. The old Sweet Briar and the familiar Sweet Verbena are not grown in as many gardens as they should be. The Verbena only needs a warm aspect under shelter of a wall to make it quite hardy.

When the frost does injure them, the spoilt branches should not be cut in until late in the following spring. The larger stems are hollow, and when cut back the water collects in them and either rots or freezes the roots.

The plan is to cover Verbena roots in November with dry ashes; they will then grow more vigorously each year.

Verbena cuttings strike readily in sand under a bell glass on the greenhouse stage. 


\section{CHAPTER $\mathrm{X}$ \\ SHRUBS AND AUTUMN TINTS}

WHEN planting our lawns we should think not only of the special flowering habits of our favourite ornamental trees, but should give some attention also to the frequently overlooked effects of their bright and varied autumnal colouring. We should try and introduce into our gardens some of the strange charms which we enjoy in a winter's walk through country lanes, or plantations of Oak or Beech, where the woods and hedgerows are ablaze with the many hues of life and death, and where the lichens and stems of trees afford an endless variety of delicately graduated colour.

In our damp climate artists must look in vain for the cheerful influences, for the warmth of colouring with which an Indian summer satisfies Canadian painters; and yet if gardeners would only group their trees and shrubs with some special regard to their autumnal effects, one additional charm, and that by no means the least important, might be added to many a well-designed lawn.

The bare walls of some ungainly houses might easily be covered with Ampelopsis, the Virginian Vine, which in autumn is a vision of glory, and the old-fashioned Pyracanthas, trained to cover a basement story, should be bright with sprays of crimson berries from September to Christmas. 
It is interesting to notice how the season of autumn seems specially to combine what is beautiful and useful -fruits that are "pleasant to the eye and good for food." Autumn is not merely the season of harvest for man, but for the lower creatures. All the bright berries on the Mountain Ash and Hawthorn which satisfy one's sense of beauty in our autumn rambles help also to satisfy our feathered friends when hard frosts have spoilt their sport in other directions.

The flowers which most abound at the approach of winter are the blossoms of the Ivy. We can scarcely imagine anything more lovely than a group of old forest tree roots, with their great prongs turned upwards, all covered with a luxuriant growth of Golden or Silver Ivy, interspersed with sprays of the Muhlenbeckia. The bees busy themselves as soon as ever the Ivy first begins to bloom, and when they have gone to sleep the berries will have formed on all these Ivy stems, and will provide a winter store for many a day to come for such of the birds as have vegetarian instincts.

It is strange how seldom one meets a well-grown plant of Elceagnus in a shrubbery, and yet it is perfectly lovely both in summer and autumn.

Olearia (Daisy Tree), formerly known as Eurybia, a large family from Australia and New Zealand. It is very closely allied to the Aster, whose home is America. These trees are not yet perfectly acclimatised, and need some care and a warm aspect. Insignis, Haasti, and Nitida are all beautiful. 
Then there is the Sumach, and the Berberis in all its varieties, Fortunei being probably amongst the best. There are also the Cotoneasters, which so readily lend themselves to covering a low wall or an old stump, a mass for weeks together of red and green; and the noble spikes of the Pampas Grass-not to speak of the tinted bark of the Golden and Crimson Willow (Salix Vitellina) after the leaves have fallen; and then there is the quaint little Cape Gooseberry or Red Winter Cherry (Physalis Alkekengi), a curious South European plant, bearing a bright orangered bladder-like calyx enclosing cherry-like fruits; and the Epimedium, and Tellima grandiflora rubra, a most desirable plant of the Saxifrage order, suited either for winter decoration on the rock garden, or for being used as a foil for plucked Christmas Roses.

The Ozothamnus rosmarinifolius is a little evergreen shrub from Tasmania, with small Rosemary-like leaves, and bears towards the middle of summer clusters of small white flowers, reminding one somewhat of the Daisy Tree. When a branch has been cut and placed in a dry vase in the drawing-room, it will retain its bloom and beauty for months though quite dried.

Those who have bare and ugly spaces in their stableyard, or court-yard, or byre, or anywhere, could hardly do better than plant here and there some Rose, such as Crimson Rambler-which, by the way, prefers a tree to a wall-or else a Vine or Fig-tree. With very little trouble at first, the protection of a piece of wire-netting and a judicious nail or two, they would produce a striking effect, 
and redeem the surroundings from the impression of ugliness.

The Garrya elliptica is a beautiful evergreen from California; its delicate green catkins are delightful either for cutting or for their winter effects amidst the profusion of handsome leaves. They like a south wall best, and the most attractive catkins are borne by the male plant.

Lonicera Standishi and fragrantissima (Bush Honeysuckles), each of these flowers in winter, and is very fragrant.

The Canoe Birch (Betula papyrifera) is a beautiful tree, more silvery even than the native sort.

The Strawberry Trees (Arbutus Unedo and A. Croomei) are at their best in autumn and winter; the fruits are as tempting to look upon as strawberries.

Leycesteria formosa is a very attractive flowering shrub from the Himalayas, which seems to thrive best in the climate of Ireland. The flowers are white, tinged with purple, and late in the year bear clusters of purple berries.

When one makes a list of true winter flowers it is surprising to find what a number of things are available, if those many trees and shrubs which have beautiful fruit and bark are taken into account.

Let me add to what I have already written in this chapter a few words as to the sort of plants that should be grown with some previous care in pots or tubs, and reserved in a shady corner for the decoration of sittingrooms, halls, porches, and window-boxes. As a rule, the 
things best fitted for indoor use are those, the leaves of which are glossy, and can therefore be sometimes washed or sponged. The Aspidistra and India-rubber plants are good illustrations; Ivy and some of the Dracœena, more especially the young plants of Cordyline, and carefullygrown specimens of the Hartstongue Fern, are excellent. The Woodwardia Fern is a fine imposing plant in a drawing-room. If its box is well placed on a pedestal, the great palm-like fronds will have room to droop gracefully all around, only requiring an occasional removal outside for a thorough syringing. Similar positions and treatment may be given to some of the hardier palms.

For hanging baskets in window or greenhouse there are few plants better fitted than Ivy-leaved Geraniums. Cape Mesembryanthemums are also pretty basket plants, and the attractive little Fuchsia procumbens, which is much more like Maidenhair Fern than a Fuchsia.

As winter comes on and drives the summer tenants of the window-boxes into warmer regions, it is not always an easy matter to find eligible shrubby plants to take their place, and it needs some forethought to provide them. By far the best method is to make a selection of bright hardy evergreens; layer them, or get them in nurseries while very small; grow them very dwarf in small pots; if some can be had which bear red berries so much the better, but varieties with well-marked variegated foliage are very suitable-such as the Striped Privet, Gold and Silver Box, Aucuba Japonica, and the Eloeagnus. Diminutive specimens 
of the Juniper, Fir, and Pine tribes might be added, and the attractive little Euonomus radicans. These should be plunged (in their pots) in the boxes, and if some early spring bulbs-such as Tulips, Hyacinths, and Dwarf Daffodils - are grouped in the spaces between, the changes of seasons need not seriously affect the aspect of the porch or window-garden.

\section{CHAPTER XI}

\section{TREATMENT OF LAWNS}

THE lawn, when well kept, is a most important feature in every garden, though it does not always find the attention which it properly demands. At its first formation the essential thing is to secure a level surface. The whole extent should be regularly broken up so that it may settle down evenly; wherever there has been a path or a hole where a tree has been dug up, the ground should be carefully rammed to avoid the danger of a subsequent settlement. The best surface for a lawn is a sandy loam. The soil ought to be thoroughly cleared of the roots of all coarse perennial weeds, and worked to a fine tilth to make ready for turfing or sowing.

The more expeditious method is to lay down turf or sods. These should be freed of weeds and cut and rolled up in strips of about I foot wide, 3 feet long, and not much more than I inch thick. The season for laying 
down turf is from September to April. The sods should be unrolled as they are laid, placing edge to edge carefully, as soon as laid the grass should be beaten flat, rolled repeatedly, and watered if the weather be dry.

Of course, when there is a large space to be covered, the cheaper plan is to sow the lawn with grass seeds; it is equally effective, though the sward takes longer to thicken.

Two chief points should be observed: first, the ground, when made quite level, should be rolled till it is perfectly firm (the neglect of this precaution is the most frequent cause of failure); this can only be done in dry weather. The seed should be evenly scattered, lightly raked in, and then rolled again. The ground can scarcely be made too firm; we may have observed how quickly grass will grow on an avenue: much more readily than it can be made to cover a recently prepared plot. The second point to be observed is to sow nothing but a really good mixture of grass seeds. The neglect of this for the sake of a short-sighted economy has often been proved to be simple folly.

March is the best season for sowing. When thus laid down, lawns require very soon to be carefully weeded. During the growing season they should, if possible, be mown once a week, occasionally rolled, and in the autumn frequently swept to clear away worm-casts.

The only effectual plan for removing daisies and other weeds is to take them out with a daisy fork, wherever they are found, in wet weather or after a shower. By dint of 
patience the most hopeless lawn may be cleared of this weed, but it will well repay the trouble spent on it.

A top dressing of soot or rotted manure applied in the early spring will strengthen the grasses, and will often hinder the objectionable tendency to grow moss.

\section{CHAPTER XII}

\section{CULTURE OF VEGETABLES*}

"SURE it will do well enough," is, unfortunately, the motto of too many owners of gardens which might easily be made productive and profitable. If it referred to the alluvial prairie-land of Manitoba such a theory might possibly pass unchallenged, for it is said the ground in those regions needs only to be scratched, not tilled; but even there the primeval earth will not produce more than half what may be raised on an average well-tilled farm at home.

Succession of Crops. - The old rule still holds, "In the sweat of thy face shalt thou eat bread." One of the root evils of our small farming is the vicious practice of growing a plot of potatoes in the same field for years together, until the land will produce almost nothing No amount of manuring will fit such ground for the same plants until a system of rotation of cropping has been followed. Not merely do the new crops draw new qualities (the chemical plant food they must live on) from the soil, but, as in the

* For Scotch gardens, the dates in this Chapter are perhaps several weeks too early. 
case of the clover crop, they attract nitrates from the very atmosphere, and thereby enrich, rather than impoverish, the ground.

The potato will not take from the soil any of the food necessary for the cabbage tribe, they can therefore follow the potato. Bearing this in mind at the outset, it is well to consult beforehand our convenience in other respectsremembering that after early potatoes any of the cabbage tribe may be planted, and this besides ensures a second crop in the same season. Again, all tap-rooted vegetables, such as parsnips and carrots, for which it is wrong to manure at the time of sowing, should be succeeded by unlike kinds which require dung at the time of plantingas celery, potatoes, and the cabbage tribe. And with a view to such arrangement some forethought is necessary, and the whole garden should be placed under review some time before the year's operations are to begin.

One not infrequently observes the vacant ground in a cottager's garden, which has borne the crops of the previous year, still undug in early spring, and in the same weedy, rough state it had been left the year before. It always reminds one of the Wise Man's vivid description of such a garden, in the Book of Proverbs. No wise man now will treat his plot of ground in this way.

Preparation of the Ground.-During the months of November and December, when a large proportion of the garden is lying fallow, it is necessary that the ground should be prepared for its future crops-e.g. for the main 
crops of onions, peas, carrots, parsnips, and beans of all kinds. The best method is to treat the ground to "bastard-trenching," as gardeners call it. Open a trench one pace wide, one spit (together with the loose shovellings) deep, and carry the soil taken out to the end, where it is intended to finish the work. Then dig the bottom spit in the trench, shovelling in first the dung with which the ground is to be manured, and then the surface soil of the next trench; then fill up the first trench with the top spit of the second (taking care that it is thrown on in a ridge, not level); then dig the bottom of the second trench as before, and so on, until the piece of ground is finished. For all crops this plan will more than repay any additional labour involved, and as the roots will certainly grow much deeper, the crops will be generally independent of dry seasons. In the case of very light, sandy soil, this operation had best be left until spring, or else the winter's rain may filter away some of the fertilising ingredients of the manure.

In case, however, this trenching has not been done, the ground should be thrown up in ridges, in a rough, lumpy state during the winter, so that the action of the atmosphere and frost may leave it, when thawed, in a pulverised condition, ready, when spring comes, to be levelled, and to receive without delay its intended crop.

In ground set apart for onions and carrots it is a good practice, when the first levelling takes place, to give a liberal dressing of soot below, fresh slaked lime on the surface and some salt, and afterwards, in the case of 
heavy ground, it is well when sowing to fill in the seed drills with some compost made up of fine fresh clay and burnt earth.

Under no circumstances should ground be trodden upon or worked when it is in a moist state. Garden plots, where this rule is broken, are generally more fitted for making bricks than for growing vegetables.

Peas and Beans.-Amongst the first vegetables which may be sown in the garden are beans and peas. A sowing of each may be made towards the middle of November, in a sheltered position. Sow thick, and give 2 inches of cover. Early Mazagan Bean and American Wonder Pea are, perhaps, the best, with a succession of peas in each of the following months of Dr Maclean, Telegraph, American Wonder, and Stratagem.

It used to be the practice to sow peas in a plot by themselves, but experience teaches that two rows at a good distance apart will yield as much as three near together, cropping between them with early potatoes, celery, cauliflowers, or dwarf kidney beans; and when the peas or beans have been pulled, their places can always be filled with one of the later crops. Open the drills wide at the bottom, and spread the seed regularly, always making the soil firm before sowing.

Onions.-About the middle of March, or earlier if the weather permit, is the best time for sowing onions. The ground having been prepared and manured in the late autumn, all that will be needful in March is the levelling down of the ridges. Sowing in drills is better than 
broadcast. Draw the drills an inch deep, 6 or 8 apart, missing a drill when 7 have been drawn, so as to form an alley. After sowing and covering, tread it in, or roll. If this cannot be done without binding the surface, it will be better to put off the sowing. The best sorts are Strassburg, Reading, James' Long-Keeping, Trebons, Globe Tripoli.

Lettuce.-A few seeds of lettuce may be scattered thinly amongst the onions, and if a few plants of Cos Lettuce, which have been raised in frames, can be had from a neighbour, they may be pricked out on a warm border, and each fortnight or so a small sowing made for succession. All the Year Round is a useful cabbage variety.

Parsnips.-About the same time-in the early weeks of March-parsnips should be sown, and later on, carrots on the same plot and in same way. The drills may be made an inch and a half deep and a foot apart. Three or four may be dropped in the drills, 6 or 8 inches apart, afterwards thinning them out. The Hollow Crown and Student are the best.

Carrots.-Early Horn Carrots may be sown in succession broadcast, in a warm border, during the first open weather, and later, for the main crop, James' Intermediate and Long Surrey.

It will hasten germination if all these seeds are well mixed with moist rabbit sand, and kept in boxes in the potting-shed for a week before sowing them. 
Broccoli.-As early as may be in March a few pinches of Walcheren Broccoli should be sown, and before the Ist April some of the later kinds, such as Snow's Winter White, Grange's Autumn, Purple Sprouting, and Ledsham's Latest of All for later successions.

Cabbage.-In the course of the same month, on a warm border (or earlier in boxes under glass), Cabbage may be sown. Early York, Enfield Market. Cattel's Eclipse, Daniel's Defiance are amongst the best.

Cauliflowers.-Also put in seed for a succession of Early London and Late Frankfort Cauliflowers, covering the seed lightly and evenly with about half an inch of fine mould.

Leeks.-On the first favourable opportunity in March sow some Musselburgh Leek on a piece of a sunny border, covering lightly, and beating down with the back of the shovel. By the middle of May the young plants may be removed. Choose well-prepared ground, and plant in drills 12 inches apart, and about 9 inches in the row. A good method of planting is this:-Make a wide hole with a large dibbler for each plant, about 4 inches deep, into each hole drop a plant, and fix by pouring water from the mouth of a watering-pot into the holes. Do not fill in with soil until later, but dip the roots into some puddle before planting. Manure-water further on will promote a large growth.

Parsley.-By far the best time for sowing parsley (fern-leaved) is the month of July; it will be practically 
perennial, and very little of it will run to seed during the following year. It should be thinned to 6 inches. The soil should be rich, deep, and well-drained. It is slow in germinating.

Potatoes.-The vegetable most common, and at the same time most carelessly treated, is the potato. It should be remembered the potato is not a root, and cannot, therefore, get food for itself, nor can it germinate until it has produced roots and shoots; it cannot grow until the ground is comparatively warm. There is nothing gained, therefore, by planting very early. The object may best be obtained by spreading the earlier kinds, such as Beauty of Hebron or Myatt's Ashleaf, on the floor of the potting-shed or under the stage of the greenhouse, and so inducing the eyes to sprout, so that much of the growth may proceed without danger, and when favourable weather arrives, and the ground is warm and dry, they may be planted without fear of checks.

Kidney tubers do not bear the knife. The later kinds should be cut, and all but the vigorous, healthy buds rubbed off, and planted in furrows of ridged-up ground (previously trenched), I 8 inches apart, the tubers 12 inches. In light soils it may be well to lay the manure above the tubers, covering in with the fine mould between the furrows. Main Crop, Beauty of Bute, Magnum Bonum, and Reading Russet are good sorts for later sowing.

At the opening meeting of a Potato Exhibition in Ireland two or three years ago Lord Cadogan, in a speech 
redolent of the soil, assured his audience that on his return to England he would have his cook instructed in the Irish method of cooking the potato. There may possibly be other cooks besides his Excellency's who would need the instruction. I am able to give it here on very high authority. When the tubers have been thoroughly washed, a thin ring or circle should be peeled round the circumference of each. All should then be placed in a saucepan of cold water and allowed to come quickly to a boil : boiled on briskly until the skins show some signs of bursting, when all but about an eggcupful of the water should be poured off, after which let them steam with lid tightly shut until they are thoroughly done.

When preparing them for cooking avoid leaving the tubers for any length of time in cold water. New potatoes should be put at once into boiling water.

Spinach should be sown occasionally in succession throughout the season, thinly, and in small portions, the latest sowing for winter use about the second week in August. Winter Prickly is most satisfactory for all seasons.

Turnips.-The same practice may be followed with turnips. Snowball (early); Six Weeks and Golden Ball in succession.

Salsify and Beet should be sown early in April, in ground prepared in the same way as suggested for carrots, and thinned carefully to 8 inches apart.

In October or November all these root crops should 
be carefully lifted, and, when dry, stored in sand or dry soil, or put into an opened trench and covered over with litter and earth outside. In preparing beet for baking, it must not be trimmed or cut, or even pricked with a fork, or it will bleed-only washed clean. White's Black or Dell's Crimson are the best beet for shape and colour.

Borecole and Sprouts.-Curled Greens or Borecole, as well as Brussels Sprouts, may be sown as early in April as the weather permits.

Kidney Beans.-Scarlet Runner Beans and Kidney Beans gain nothing by early sowing; the last days of April or the first in May are quite time enough.

The ground for these beans should never be manured at the time of sowing. Sow in successions, say, of a fortnight, in drills 18 inches or 2 feet apart, and 2 inches deep, the seed 2 or 3 inches separate. The small-seeded White Haricots, as ripe seed, are excellent food in winter, and much more nourishing than potatoes.

Scarlet Runners are most valuable for screening ugly corners by judiciously training them on poles, or letting them cover a trellis or porch.

Asparagus.-It has been always a question with me whether an ordinary gardener should venture on the culture of this favourite vegetable. The results are so very uncertain and so frequently disappointing. I have known it to sow itself on a gravel walk, and to flourish there, while it often fails in carefully prepared beds. 
Probably the best plan would be to excavate three spits deep, throw in a quantity of coarse gravelly stuff, or lime rubbish, then a layer of stable litter, upon that another deep layer of fresh sods from the field and rich cow dung, crowning all with sandy loam, on which to sow in April the best seed in drills, one foot apart (Cannovers Colossal or Purple Argenteuil), thinning out to twelve inches. A bed thus treated, carefully weeded, and the surface stirred each autumn and spring, will produce buds in the fourth or fifth year, and last for a lifetime.

Rhubarb.-One corner of every garden ought to be devoted to the growth of rhubarb.

A few plants of Victoria or Monarch, or Myatts Linnaus and Mitchell's Royal Albert, should be obtained from a friend, or bought in the nursery, and planted 3 or 4 feet apart every way. If the ground has been well prepared and manured, it will grow like a weed. In the late autumn the crowns should be covered with an inverted hamper or flower-pot, or by a few stakes driven round, and stable litter thrown over, so as to keep out light and blanch the stalks; this will make the Rhubarb not only of better flavour and come earlier to perfection, but scarcely half the quantity of sugar will be needed in the cooking.

Seakale.-One of the most welcome and seasonable of all vegetables, coming in when the rest are very scarce, is one of those most easily managed. Seakale is readily grown on a north border, which is little used for other crops. Small crowns may be bought in the seed-shops 
[CH.

and planted in February or early in March, or seeds may be sown in a patch of ground about the same time. After some of the seedlings have been planted out in rows to strengthen for the year, they may be raised and placed thickly in large pots or boxes in November, and treated as rhubarb for forcing any time during winter and spring. The remainder should, at the same time, be permanently settled in the north border, which has been previously prepared by bastard-trenching, in which a large quantity of sand has been mixed with the manure. Plant them in triangular groups of three, six inches apart, and a couple or three feet from group to group. When the first winter frost has made the leaves drop off, the crowns should be covered to the depth of fifteen inches with spent bark, or hops, or coal ashes, through which they will grow almost to the surface in their natural season; or they may have placed over them large pots, or boxes, or hampers turned upside down, and these covered with heaps of old leaves, or long, warm dung from the stable, when it is desired to hasten the crop. The crowns when being cut should be cut well below the young growth, so as to keep the plants in the ground. They will last in this way many years, as dwarf healthy plants. Care should be taken to cut away all the crowns but two or three, and not to allow them ever to flower.

Celery.-Early in the season, the end of February or the beginning of March, sow Celery in a shallow box filled with light compost; cover lightly, and place in a hot-bed or cucumber turf frame, sowing rather thin. The best 
sorts are Leicester Red, Standard Bearer, and Incomparable Dwarf White. Early in May the young plants should be pricked out in a warm, sheltered position to strengthen. The plan is to select a perfectly hard surface, such as an unused path; upon this spread a thin layer of rotten dung 2 inches deep, and over this another inch or so of compost, and prick in the plants, 3 inches apart every way. They root sest in the dung, are easier kept moist, and the hard ground underneath hinders them forming tap roots. When removing them to plant in trenches they can be scooped out with a trowel, and when once well watered will hardly feel the moving. After pricking them out in the nursery bed, they should be shaded from the sun with a mat, or some branches of evergreens. When the plants are strong and the weather showery, they should have their final move.

Open a shallow trench 15 inches wide, into this dig some well-rotted manure, stretch a line along the bottom, and plant a row on each side of the line alternately 6 or 8 inches apart. The trenches may be rather more than 3 feet apart. As the plants mature in August, they must be carefully earthed up from time to time after a previous watering, either natural or artificial. The outer stems should be well matured before earthing up, as the only object is to blanch it, which takes but a few weeks. Only a little earth should be given at a time, and none should be allowed to get within the stems or near the heart.

Cucumbers, Tomatoes, Marrows, should be sown 
under glass in March, re-potted in a few weeks, and kept in a frame until they are strong plants. Cucumbers, as a rule, must have the protection of glass, but Marrows only require a cap-glass for shelter at night from late frosts. They may be planted on any well-manured mound, and cut when they are 6 or 8 inches in length.

If Tomatoes can be raised early and pushed forward in pots until frosts are gone, they may then be planted in a sunny aspect, or against a south wall, staked, carefully disbudded as they grow to maturity, and mulched with liquid manure; they will, in ordinarily good summers, bear a very fair crop, but their proper place in a northern climate is under glass.

A lady who plants out her Tomatoes each summer has lately complained that a large proportion of each year's crop is lost from repeated attacks of a disease which appears first as a black spot, and eventually spreads over half the plant.

If such plants have been already established in the ground, a sprinkling of sulphur at the earlier stages might destroy the fungus, or treatment similar to that so successfully used with the potato fungus (see chap. vi. part i.) might be tried, but it is not by any means an easy matter to exterminate such a growth.

To secure an efficacious preventive of mildew and of all sorts of fungoid growth, we cannot do better than write for a sample bag of "Veltha" and a copy of his pamphlet, to Mr Wm. Wood, Wood Green, London, N. Directions will accompany the mixture, which must, however, be dug into the soil previous to planting. 


\section{CHAPTER XIII}

\section{GROWING FRUIT AND PRUNING TREES}

ONE of the first necessities for fruit-growing is that the ground should be thoroughly drained and trenched. Without this it is impossible there should be any adequate return for one's labour, but this being granted, there are still a good many matters to be considered, and it is with a view to be helpful to those who are as yet without personal experience that I propose to give the results of many years both of success and failure, for these are alike precious to a thoughtful amateur.

And, at the outset, let me suggest that all should endeavour to ascertain what fruits will and what will not thrive in their district. A marked feature of modern farming and gardening, both in Canada and in the States, is the establishment in the several provinces, of Experimental Farms, presided over by capable experts, who make it their business to ascertain, by actual experiment, the sorts of farm crops and fruits best fitted for that particular soil and climate. Each year practical and helpful reports are drawn up and circulated, so that the farmers for whose benefit all this is done have only themselves to blame if they come short of success.

If we have not the advantage of such valuable institutions, we may, at least, find individuals amongst our acquaintance on whose intelligence we may depend, 
and let us certainly ask their advice, and act upon their experience.

It is desirable that fruit trees should be planted so far as possible on their own ground, where there can be no excuse for their roots being disturbed by the spade, and where the earth can be mulched and kept free from rank vegetation while the fruit is setting and growing. No fruit can succeed if its delicate, fibrous surface roots are interfered with: these should rather be encouraged and strengthened as they endeavour to raise themselves towards the sunlight, and just in proportion as they are matured will fruit spurs be found above.

Where it is possible, planting should be completed early, certainly before the end of November (except for strawberries, which should be got in by August), and it would be difficult to exaggerate the importance of doing this work properly. If the trees arrive from the nursery in wet, sticky weather, it is best to lay them in and cover up the roots with soil for some days, or even weeks, until the ground is in fair order. If the roots are jagged or torn, the injured parts should be cut off with a sharp knife, and all downward tap roots shortened back.

It is a good rule not to place the young trees lower in the ground than when they were growing in the nursery; in wet or heavy land it is best to plant almost on the surface, and to mound up the earth to 3 or 4 inches over the roots, carefully fanning out the young fibres all around, throwing in loose and fresh soil, and firmly treading round the stem as each shovelful is added, then put 
d strong stake to the tree, and let the stake be so fastened that the stem cannot chafe itself against it.

For the first couple of years very little pruning will be necessary, and nobody should use the knife until he has learned something of the art. The most that inexperienced people should attempt is to thin out in November any weak spray wood, removing one of all branches that cross each other, and keeping the heads of the trees open in the centre. As a rule, no branch which it is evident must eventually be taken away, should be allowed to remain in a young tree, for every tree suffers materially by the amputation of branches when they are large.

When the trees have groryn sufficiently high, the top shoots of the main branches may be pruned each year or cut back to a strong side shoot. The experienced fruitgrower aims at keeping his trees so open that he may be able to put in his hat between any of the principal stems.

When an established tree is found to be growing too vigorously, making only wood, and showing no signs of fruit spurs, it would be well to try root-pruning or lifting.

I like the plan of digging a trench round the tree the previous year, 20 inches deep and 24 from the stem, cutting away most of the great roots which merely anchor the tree to the soil, and carefully preserving the finer ones, by means of which the plant is chiefly supplied with food. It may be found on examination that there is a great tap root beneath, which ought to be removed. Then fill in the trench with coarse 
rubbish, cover over the roots with fresh mould, and secure the tree with cords and stakes.

Pears.-There is no more deservedly popular fruit than the Pear, and no country in which its flavour is so excellent as our own. For many reasons, chiefly perhaps on account of its earlier blooms, the Pear is not nearly so hardy or so suitable for all districts as the apple.

The soil best fitted for pear trees is that which is more nearly loam than sand, with a dry sub-soil. It is useless to plant them in light, poor, cold, or wet ground.

The most suitable for garden culture are those grafted on the Quince stock, which gives them a moderately compact habit.

They should be pruned with the object of repressing all redundant and crowded growths, and of promoting fruit spurs.

When in June the young side shoots have made six o: eight leaves, they should be pinched back to four, and should these spurs bud out again, they should be nipped to one leaf.

The leading shoots of the tree may be allowed to grow and draw up sap to the end of the summer. When the crop is evidently too large, the fruit should be judiciously thinned as the season advances.

Apples.-The best soil for Apples is deep, strong, adhesive loam on a dry sub-soil. The Kentish growers prefer the side of a hill to the low level ground. Pyramids 
or Dwarf bushes are the most satisfactory, and the same sort of treatment as suggested for pears, in the matter of summer pinching back, applies to apples.

As the trees grow, the heads should be kept well balanced, open in the centre to allow in light and air, and all the branches kept well apart.

Plums will grow in almost any garden soil. They require very much the same treatment as apples and pears as to pruning and summer nipping back of the bud growths.

Peaches, Apricots, and Nectarines, owing to our uncertain springs, are not satisfactory fruits, except against some favoured sunny wall or under glass. They need above all things warmth and sun. Their borders must have a dry sub-soil, must not be too deep, too damp, or too rich, and they ought not to be disturbed by the spade.

The most important point about their growth is to keep up a succession of young wood all over the tree. When grown in the open air, the blossom should be protected with a net until the fruit is set.

Cherries come to maturity quickly, and, compared with other fruit trees, they are short-lived. They like best a rather deep, mellow, sandy soil. The Cherry is an easy tree to prune, as the branches never grow very strong, and a judicious pinching back in summer leaves little to be done later on. Aphides should be watched 
for, and nets thrown over the trees when possible to keep away the birds. When protected in this way the May Duke will last from June to August, Late Duke to the end of September, and Morellos far into October.

Figs can be satisfactorily grown only in a warm, sheltered situation. As a rule, they thrive best against a wall, in a light garden soil, with an artificial sub-soil of lime rubbish. An occasional root-pruning helps to the formation of short, compact, fruit-bearing stems.

During the growing season, all superfluous shoots should be cut away, so as to expose the wood to sun and air.

When the fruit is as large as a cherry, the ends of the shoots may be nipped off.

It is well in planting Strawberries to see that the collar or neck is only just below the ground, and that the roots are carefully spread out on all sides, leaving 2 feet between each drill,* and the plants 2 feet apart in the drill. When not required for fresh planting, the runners

* In theory the spaces between the plants should never be dug, only the surface occasionally cleared with the hoe, and well mulched to supply the upper roots with abundance of nutriment. In practice, however, an experienced gardener will find it good to vary the treatment. He will carefully dig with the fork between the plants in early spring, remove the earth, fan out the tangled network of roots with his hands wittingly (removing any tap-root from a suspiciously vigorous plant), cover them over with the richest available mulching, replace the soil, and tread it down very firmly. Needless to say such an operation requires very careful handling, and must not, on any account, be intrusted to a novice. 
should be cut off as they appear, so as to throw all the strength into the main crown of the plant. The leaves ought not to be cut off, only the lower withered ones trimmed, the ground hoed, and all the surface strewn with stable litter; the nutritive part of this will be carried to the roots by the winter rains; the straw makes a clean ground for the fruit to rest on, while it tends to prevent evaporation in dry seasons. Irrigation is desirable at such times. Fresh beds should be made in succession every third or fourth year. Of the earlier sorts, Royal Sovereign, Leader, and President are not to be surpassed. Next in succession Sir J. Paxton will be found a great cropper, and the Elton Pine a fine late kind.

Raspberries are easily grown. Fay's Prolific, Carter's Prolific, or Bunyard's Superlative are well worth planting, only care must be taken that the ground has been previously cultivated (e.g. with a crop of potatoes), so that no particle of such a pest as bindweed may be left, for once they are planted raspberries must not be disturbed by the spade.

In the early summer thin out the young growths by pulling up the superfluous ones. The old canes should be cut out as soon as they have done fruiting and a mulching of manure laid over the roots.

Currants need very simple autumn pruning. The Red and White should have the side shoots of the summer's new growth shortened back to a couple of eyes, and the main leaders to five or six eyes, more or less, as 
the bush is required to increase or not in size, taking care that the centre is kept as open as possible.

On the other hand, Black Currants should be treated differently. The old wood with them should, as far as possible, be removed, and the young summer growth left their full length, only cutting out the growth from the centre. Red and White Currants bear chiefly on the old wood, Black on the new.

With the Gooseberry the same rule applies, to a certain extent. Keep the centre open like a bowl, cut away the low branches which touch the ground when laden with berries. Cut away all cross stems, leave as much of the young white wood as possible, and avoid the mistake (into which so many gardeners fall) of treating their gooseberry bushes as if they were Red Currants!

Gooseberries lend themselves to being placed along the edges of vegetable borders, where they may be easily reached from the paths, and they need in no wise interfere with the culture of the vegetables.

In ordering currants and gooseberries ask for plants with stems 12 inches long, and cut away suckers whenever they appear.

For young trees of all sorts the ordinary welltrenched soil of the garden is quite rich enough without the addition of manure. 'The chief aim for the first few years should be the laying the foundation of a good tree. The boughs should be kept well apart, so that sun 
and air may get into every part and ripen the wood, thus forming a good basis for future abundant crops. When growing and in good health the manuring should be applied (to the surface) only when they are bearing their fruit after it is well set, thus enabling trees to bring the year's fruit to prefection by supplying the necessary additional strength, and at the same time helping the formation of fresh blossom-buds for the next year.

The list of Apples, Pears, Cherries, and Plums which are here appended, is chiefly selected from that prepared by forty leading experts, at the request of R.H.S. of England, for most of which I can speak from personal knowledge :-

Cooking Apples.-Blenheim Orange, Bramley's Seedling, Tower of Glamis, Ecklinville Seedling, Lane's Prince Albert, New Hawthornden, Pott's Seedling, Warner's King.

Eating Apples.-Cox's Orange Pippin, Irish Peach, Lady Sudeley, King of the Pippins, Duchess of Oldenburg, Sturmer Pippin, Worcester Pearmain.

Cooking Pears.-Catillac, Verulam.

Eating Pears.-Louis Bonne of Jersey, Williams' Bon Chrétien, Marie Louise.

Eating Cherries.-May Duke, Kent Biggarreau, Early Rivers (Black), and Elton White Heart.

Cooking Cherries.-Kentish, Morello.

Cooking Plums.-Cox's Emperor, Gisborne's, River's Monarch, Victoria, Czar. 
Eating Plums.-Belgian Purple, Green Gage, Denniston's Superb, Jefferson's, Kirkes' Coes' Golden Drop.

It may not be out of place here to note that no fruit should be gathered for storing before it has come to maturity-in growth and size-not necesarily in ripeness. An apple or pear, when fit for gathering, will always leave the tree upon a gentle pressure, the fruit stalk parting from the twig without any signs of violence. They are best gathered on those autumn days when leaves begin to fall. The fading of the leaf and the maturity of the fruit keep pace with each other.

The storing of apples and pears is a difficulty with many. When late fruit leave the tree easily they should be carefully gathered and handled, each kind kept separately. The best place in which to keep fruit is a cellar or dry room not affected by weather. The Codlins, or other cooking apples likely to shrivel should be laid carefully in small heaps and covered with straw. For the more valuable and choice late apples and pears, the following plan has been recommended:Dry some fine sand, and make it hot, so as to destroy any vegetable matter, then procure some large crocks, throw in some sand when cool alternately with each layer of fruit, filling up the spaces until the vessels are full, then stow them away out of the reach of frost and damp. For the main crop it is enough to lay them on shelves made of thin, unpainted battens, and kept perfectly clean by an annual scrubbing. 


\section{PART III}

\section{CHAPTER I}

HEARTSEASE, VIOLAS, AND VIOLETS

THERE is probably no other family of hardy flowers which has given our gardens anything more valuable for their quaint beauty and their delicious fragrance than the numerous race which includes Pansies, and the great variety of sweet-scented Violets, with which most of us have been familiar all our lives, and with which our earliest floral recollections have probably been associated.

Indigenous plants like these, which through long generations have been improved by careful culture and selection, and brought to a very high state of excellence, are much more satisfactory objects for our care than uncertain exotics, which often require a combination of favourable circumstances, the failure of any one of which brings disappointment and loss.

A few very simple and elementary suggestions as to the old family tree and its separate stems and branches may be helpful to some of my readers. It $\underset{139}{\operatorname{may}}$ be 
convenient to consider it after the manner of preachers under three heads - the Pansy, the Viola, and the Violet.

It is correct in these days to speak of the Pansy and the Viola as distinct flowers, but it is not always easy to satisfy oneself as to the differences, nor is the pedigree of the Heartsease or Garden Pansy by any means readily traced. Florists are inclined to agree in thinking it has come from the native British Viola Tricolor.

There are two distinct types of the Pansy or Heartsease. (a) There is the Show Pansy, the true old English plant, which has been improved generation after generation by careful culture. Of this type there are the White Grounds, with the upper petals purple or maroon and the lower white, with similar toned edgings. Then there are the Yellow Grounds, with the same tints and yellow ground; and the Selfs, which are of three distinct colours, white, yellow, and maroon, some being almost black. The Selfs should have clear decided colours, and should have a black, well-defined blotch under the eye.

(b) The other type of Pansy is the Belgian or Fancy. This is now the more popular flower, and well deserves its popularity. When first introduced, about forty years ago, by William Dean, who is still devoted to its culture, there was a great flutter and ill-concealed contempt bestowed upon the garish novelties by the old Scotch florists of the day. 
The Viola or Tufted Pansy, so familiar now in every garden, is really a hybrid between the Show Pansy and the Viola cornuta (which came into fashion as a bedding plant more than thirty years ago), a perennial with pretty pale blue flowers, paler and larger than the Czar Violet. It is a strong, wiry plant, not easily disturbed, and its progeny has much of the perennial toughness of the parent stock. The term "tufted" is used to distinguish plants of a spreading habit, like Pinks and Alpine Violets, from plants with simple erect stems, like the Stock. The Belgian Pansies, for example, do not spread at the root as the tufted Pansies do. Plants of a "tufted" habit are often a mass of delicate rootlets even above the ground, so that they are easily increased. This is the reason the older Pansies often die after flowering, while those crossed with the Alpine (cornuta) remain like true perennials, and are easily increased.

The Violas are much better adapted for bedding out than either the Show or the Belgian Pansies. Pansies and Violas like a deep, rich, and cool moist soil. They are best suited to a northern climate, and prefer the shady side of the garden to the full sunshine. It is best to make cuttings of them every year or so. They may be struck in the open ground in summer in a half shady place, and well watered in dry weather. All sorts, including Violets, are readily raised from seed sown in spring or early summer, and seedlings, as a rule, do not suffer from winter frosts when well established. 
Sweet Violets may be grown in almost any soil, but they thrive best on free sandy loam. A somewhat shaded place which has produced early potatoes is almost an ideal spot in which to plant them out of their nursery beds. In the suburbs of Paris, and of late years in some districts of the County of Cork, the cultivation of Violets is largely carried on, and in such favoured places Violet farms of 3 or 4 acres produce very considerable incomes to the fair and enterprising farmer.

Violets require a certain kind of shelter-not of a wall, but rather a hedge-row, through which they get currents of pure air ; but when the soil is deep and rich they will bear a considerable amount of sunshine. By planting them at different times, and in different positions, a succession of bloom may be ensured.

The most satisfactory of all the varieties is the Czar-a very robust and sweet Violet. And one much less known, but quite as good, is a sort of double Czar, of a dwarfspreading habit. Some of the more recent introductions are La France, Princess of Wales, and the vigorous Californian strains, such as Admiral Avellan and Luxenne. Then there are the beautiful double violets Marie Louise, a vast improvement on the Neapolitan-a double mauve, not quite hardy-and the double white Comte de Brazza, or Swanley white. These latter are best grown in sod frames, with the occasional protection of a glass light during frosty weather. Treated in this way, or in pots in a cold greenhouse, they will bloom all through winter. 
The old plants should be torn to pieces in March, April, or May, retaining all healthy pieces which have some fibrous roots; replant in good, deeply-dug, and well manured soil ( 16 inches apart for the larger sorts, and 12 inches for the double and smaller leaf kinds), with their roots well down, so that they may not suffer in dry weather. If at all times the runners are kept cut in, the beds may, with advantage, be retained for the second season, and the crop will be scarcely inferior to that of the first year.

\section{CHAPTER II}

\section{SCILLAS AND GENTIANS}

IT has been often observed what a rare, and perhaps for this reason, attractive feature good blue flowers are in every garden. Scillas are particularly welcome for their spring colouring. In some rock borders the beautiful Chionodoxa Lucillice (the Glory of the Snow) will cover whole patches of several square feet, having sown itself during previous dry summers. All the Squill family thrive well with us, and ought to be cultivated much more widely in our rock gardens.

In April and May the Gentians are in full bloom. Few more beautiful objects can be imagined than a group of $G$. acaulis in the early part of the day, when its intensely blue, erect bells open to the morning sun. 
Its only rival is its own near relative, $G$. verna, which is not always easy to transplant or to grow, when removed from its native haunts in Switzerland, or from the grass cliffs over Galway Bay. It does grow, however, in great luxuriance in confinement, and is worth almost any trouble involved in procuring the right soil and aspect and treatment, if it only succeeds. Gentians must always be firmly planted, and well trodden into light peat or turfy loam, and the surface covered with grit. I have sometimes found $G$. acaulis thriving much better when it had found its way on to the gravel-path, where it had actually been walked on for the greater part of the season without any injury, than in the bed from which it had strayed. The obvious reason is that it had found there both grit and firmness, and the fact suggests the advantage of making plantations of Gentian through the rough stone edgings of our garden paths, and leaving them to their own devices undisturbed for years and years.

\section{CHAPTER III}

\section{IRISES}

THE Iris family is remarkable for the number, variety, and exceeding beauty of its members. In the brilliant colouring of their flowers, and their accommodating disposition with regard to soil and situation, they are unrivalled. When their value as cut flowers, and the 
extended season of their blooming-from Christmas to August-is taken into account, it must be admitted that no collection of hardy plants can be considered complete that does not include some sections, at least, of this family.

A striking characteristic of the Iris is that the three outer segments of their flowers are reflexed or drooping, while the three inner are erect.

The Iris includes a large number of species of various habits and character, all beautiful, some brilliant.

There are two clearly distinguished groups - (a) Bulbous, which are now called Xiphions, and the larger class (b) Rhizomatous, or those with creeping stems.

The hardier Bulbous Irises include the English (Xiphioides) and Spanish (Xiphium). The English Iris comes originally from the Pyrenees. It was the Dutch, who, having bought it first in England a couple of centuries ago, miscalled it the English Iris, and one of their professors of Botany at Leiden-Clusius, a great plant collector and author-actually came to England to try and find it in its native haunts!

The Spanish Iris is smaller, earlier, much more variable, and thrives in drier and more barren spots than the so-called English bulb, which likes a damp border, and will soon die out on warm dry soils.

The Spanish are each year becoming more popular; they embrace lovely shades and combinations of yellow, white, blue, citron, orange, and lilac.

I. Persica (Xiphium Persicum) comes, of course, from 
Persia, and is, therefore, somewhat tender, but in warm, sheltered spots succeeds well enough with us. The flowers are white, tinted with pale Prussian blue, and blotched with purple.

I. reticulata (Netted Iris) is one of the loveliest of hardy flowers. While the snow is on the ground in December or January its leaves begin to push up, and the bud opens with three violet segments and a gold crest on each. When the flowers have faded the leaves grow a foot high. The species comes from Palestine and the Caucasus, and there are several varieties. They are absolutely hardy, and may be planted wherever the Crocus grows.

I. juncea (Rush-leaved Flag) is a native of Spain and North Africa. It is one of the best of the bulbous Irises, and as easily grown as the English. It has bright goldenyellow flowers and a very sweet fragrance. It thrives all the better where it can be kept dry during winter.

All the bulbous sorts need an antumn drought to ripen them, and a dry soil in winter in which to preserve the bulbs and keep them at rest, while in spring, when the leaves are pushing up, they love moderate rain.

A great point is not to meddle with the bulbs as long as the plants are doing well, and when it is necessary to transplant (when the soil is exhausted, and the bulbs too close), they ought not to be allowed to become shrivelled or dried up.

These hardy bulbs require to be planted in thoroughly drained beds, in very light, open soil, moderately enriched, 
and they should have a rather sheltered position; a thin layer of half-decayed leaves and cocoanut-fibre is a desirable protection during the severe winter months.

The Rhizomatous Irises, with creeping stems, are generally known as the Flag, sometimes as the German Iris; they are very numerous, and grow in any good garden soil, preferring a turfy loam. These non-bulbous sorts vary a good deal as regards their love of moisture. The condition that answers for the majority is comparative dryness in winter, and abundance of water in summer; unluckily, this is the reverse of what they usually get. Amongst them the flowering season extends over the greater part of the year.

Stylosa (Algerian Winter I.) flowers in mid-winter. Its blooms are almost hidden away in its grassy foliage, its silky, fragrant, sky-blue flowers are quite equal to many an orchid. It likes a light, warm soil, on a well-drained, raised, sheltered border, and to be almost smothered with stones.

Pumila (Dwarf Flag), the best of the dwarf flags, growing 4 to 8 inches, with deep violet flowers. It is well to plant in large masses, so as to form sheets of bright colour.

Ochroleuca (Yellow-banded I.) is one of the tallest of the flags, with spikes often 6 feet high. Its large flowers and luxuriant foliage make it very effective in a mixed border. 
Aurea (Golden Flag) is a tall, stately kind, and grows well amongst shrubs.

Pseudacorus (the Common Water Flag) likes a rich soil, plenty of water, and sunlight.

The beautiful Japanese Iris (Kampferi) is a distinct type of comparatively modern introduction; it is quite novel in form of flowers. The outer segments are spreading, rather than drooping, forming an almost circular flower; in some varieties six broad segments are produced instead of three. They require a sandy peat soil, and a cool, moist subsoil. In very dry weather they should be regularly watered.

It only remains to add that the most effective treatment of the Iris is to plant in clumps of greater or less extent rather than singly, and, when allowed to remain undisturbed, they become in this way more effective each succeeding year.

\section{CHAPTER IV}

\section{LILIES}

THE Lilium is a popular family of hardy bulbous flowers. No garden should be without a variety of them, but the species are so numerous that it would be impossible in one brief chapter to lay down general rules for their culture. Under glass we may have Lilies all the year 
round, in the open border we may admire them each in their season.

There are Lilies which will grow in any ordinary soil; rich, loamy soil suits best for the larger number; some want plenty of sand to keep the soil free, and there are others which require leaf mould or peat to be mixed with the ordinary soil.

L. chalcedonicum dislikes peat; tigrinum, auratum, Canadense do badly without it.

If the bulbs are healthy, manure, specially in the liquid forms, such as "Clay's Fertilizer" may be used with advantage to most sorts.

The bulbs are best planted 6 inches below the surface, which should be mulched over with short halfdecayed dung and leaves or with cocoanut fibre to protect from frost. Dr Wallace, who has given much attention to their culture, says in one of his Notes: "Lilies, so far as their roots are concerned, require a cool bottom soil, abundant moisture, and, for most kinds, a free drainage." He adds:- "Plant deep 6 to 8 inches, so that the roots may easily get down to a moist sub-soil, and so be protected from the scorching, drying influence of the sun's rays."

The early autumn is the best time for planting, so that the roots may be at work through winter. They should be put into a cool, shady border, not exhausted by roots of trees.

Valotta purpurea (The Scarborough Lily) is one of these half-hardy bulbs which ought to be more 
generally known. It is associated with Yorkshire only by the accident of a Dutch barque having been wrecked off Scarborough some years ago. The bulbs were washed ashore from the ship, and were grown freely in the neighbourhood. This is said to be the Guernsey Lily (Nerine).

It is a bright, showy plant, and blooms freely during the summer and autumn, equally well in a greenhouse as in a cottager's window. When potted it need not be shifted more than once in four years. As it is evergreen, it ought not to be dried off too much in its resting season. It needs scarcely any heat, but, while growing, a good deal of water. It is quite worth the trouble of bedding out in a cosy corner of the rock garden in May, taking up and housing the bulbs before the first hard frost.

L. candidum (the White Madonna), one of the loveliest of all the tribe, used to be seen at its best in cottage gardens, where the bulbs were left very much to themselves, and got no attention whatever. It flourishes in rich, heavy soil exposed to full sunshine. When the plants begin to die down in summer, the bulbs may be dug up with a fork, the off-sets removed, ground dug and manured with a mixture of lime-rubbish, and the larger bulbs replanted. Liquid manure in the following June helps the bloom.

L. longiflorum (White Trumpet) is amongst the most valuable of these plants. There are several varieties. Longiflorum giganteum comes from Japan. Strong bulbs 
will send up a head of from eight to ten blooms. It lends itself to forcing under glass.

L. Harrisi is the Bermuda Lily, the very same as longiflorum, only grown in a tropical climate.

L. Martagon (Turk's Cap) is so well known that it needs no description here, but the White variety, in districts where they will grow, is perhaps the most attractive of all bulbous plants. Deep soil enriched with leaf mould, without sand or manure, answers their requirements best, and as it also suits such plants as Lily of the Valley and Anemone sylvestris exactly, it has been found a good plan to carpet the ground with these which serve the double use of keeping the soil cool during the hot days of summer, and providing an endless supply of flowers in May.

Pardalinum (Panther L.) will make itself at home in these islands, and grows almost as vigorously as in its more favoured Californian home.

Testaceum (Nankeen L.) bears a flower of a delicate apricot colour, reaches a height of 7 feet, and grows freely in town gardens.

L. auratum (Golden L. of Japan) is well known as the grandest of all flowering plants. It will thrive in ordinary garden soil if it be well drained and fairly rich. It grows, perhaps, best alternately with rhododendrons in beds of fibrous peat. The rhododendrons also afford the necessary shelter from cutting winds and from the blazing mid-day sun.

Agapanthus (African L.), a lovely Cape plant, with blue and also white flowers, well fitted for the flower 
garden and vases in summer, should be stowed away during winter under the stage of the greenhouse. The fleshy roots may be stored without potting.

Amaryllis (Belladonna L.).-Under favourable circumstances, this beautiful lily may be grown in the border. It is a bulbous plant from the Cape, blooming late in summer, with flowers as large as the White Lily, in clusters of delicate silvery rose tints. It must be planted only in a warm, sunny border on the south side of a house or wall, fully 2 feet below the surface, in a good mixture of fresh loam, leaf mould, and sharp sand, with plenty of drainage and some half-rotted manure beneath. In winter the spot should be well covered with cocoanut fibre or leaves.

In the month of May, as its name implies, the Convallaria majalis (Lily of the Valley) will take a foremost place amongst the Lilies. It thrives in almost any aspect, but once established, it should not be disturbed. It never seems so happy as when it has broken bounds and found its way into the grit of the gravel walk. A top dressing of rotten manure and leaf mould at the beginning of winter is all the care it needs.

For the growing of Lilies in pots the soil should consist of three parts of turfy loam to one of leaf mould and well rotted manure, and grit enough to keep the mass porous; turfy peat may, however, take the place of manure.

The bulbs should be potted in October, the pots plunged in a cold frame and protected from frost. 
About May they should be removed to a shady place out of doors, where they may grow on until they are ready to bloom, when they can be removed to the greenhouse. Those that are most suitable for this treatment are auratum and speciosum, longiflorum and Harrisi.

\section{CHAPTER V}

\section{ANEMONES}

How much less lovely the world would be without its Anemones. Their first blooms surprise us in the early spring, before the winter has left us, and they flower on far into the summer. There are over seventy known species. Almost always the first to bloom is fulgens, the Scarlet Windflower (Pau Anemone). Though a native of the South of France and Italy, it will stand the severest frost in the open border. No spring flower can compete with it in brilliancy; it is almost dazzling in bright sunshine when it expands its petals, and contrasts in a strangely beautiful way with a group of Narcissus cernuus as its next neighbour. In fresh, well-drained soils it will grow freely, but best in a northern aspect and in a somewhat shaded situation.

It is good as a cut flower, and if plucked when just coming into bloom, will retain its beauty for fully a week in a moderately warm room.

A. nemorosa (Wood Anemone) is one of the first of 
our natives to show itself. There is a double sort not equally common, and some of lilac or purplish tints. Robinsoniana is a lovely sky-blue variety, whose origin is uncertain. There are those who think that no other Anemone can compare with it in simplicity and loveliness; it is easily grown.

The yellow, ranunculoides, though not so free-growing as the others, thrive on a warm, chalky soil.

$A$. appenina grows vigorously anywhere, in grass or on the edge of walks or under the spreading branches of forest trees.

A. silvestris (Snowdrop Anemone) should be grown on every border, with its roots amongst rocks and stones. Its drooping white buds might be mistaken for those of the Clematis montana.

A. Pulsatilla (Pasque Flower) also likes the chalk. There are few things more attractive than the purple blooms of Pulsatilla just showing through their woolly sepals on a bleak spring day.

A. japonica is the finest of all the tribe. It is to autumn what the Hellebore is to winter-a glorious plant from which to cut and come again. By growing some on a north border and others in the sun, it is easy to secure a lengthened bloom. Every bit of the root grows when divided. There are two shades of pink, but the white is best.

$\mathrm{Mr}$ Andrew Campbell, of the gardens at St Anne's, Raheny, has been fortunate in growing some singularly beautiful hybrids from this flower, one of which he has 
named Lord Ardilaun, but as yet it is very scarce, and by no means as vigorous as the parent stock.

There may be some among my readers who do not know that the welcome surprise flower of early spring, the Hepatica, is really an Anemone. It is a very deep rooter-few plants make such roots-it, therefore, thrives best upon deep alluvial borders between rocks, and specially in such places as will secure its crowns from moisture.

These plants are impatient of division, and dislike the spade. They are found in a great variety of colourdouble and single blue, double red, double and single white, and one with a pretty mauve shade. But every variety is worth cultivation, and, when planted in wide groups, they are a great addition to the herbaceous border.

The St Bridget Anemone is the outcome of Mrs Lawrenson's patient and skilful development of the old commonplace garden Windflower. Under her hands, during some decades, the plant experienced a sort of apotheosis (as the old monks would say), from being one of the common herd it has assumed an almost saintly dress. And yet this would be a description somewhat likely to mislead, for the St Bridget shades are more in harmony with the reputed colours of a Roman cardinal or the convocation robes of an Anglican primate than with the more sombre garb of the foundress of Kildare. The charm of this Irish flower is that it is absolutely hardy, so much so that it may be grown in almost any garden by almost any amateur, the only 
conditions being very rich manure and very fresh soil. It is, perhaps, in its habits, rather a field than a garden flower; like its kin, A. fulgens, it is really in its element not in the gardens but the meadows of Savoy.

There is, of course, the tendency in a flower like our Irish Anemone, which owes its beauty to careful culture, to revert, if left to itself, to its old meagre shades; and the grower must still be careful to select only the good and pure blooms for seed, if he is to avoid the liability to degeneracy.

Although they may be raised from seed at almost any time of the year, it will be found that the best season for sowing is about the middle of March, on a seed bed of well-prepared compost. The seed a day or two before sowing should be thoroughly mixed with about ten times its own volume of moist rabbit sand; this makes it possible to spread the fluffy seed evenly over the whole surface of the bed. Cover and tread lightly, and rake in well. In dry weather give water, or, better still, shade with light canvas until the seedlings are almost ready to appear. Their germination is sometimes slow.

As soon as the young plants are sufficiently strong to handle, the bed intended for their reception should be prepared by clearing away the old worn-out garden soil to the depth of 12 or 15 inches, filling in with a corresponding amount of rich dairy-yard manure, and adding 6 inches of fresh top-soil from the field. From an æsthetic point of view, a circular bed somehow seems to fit them best. Into this prepared ground transplant the seedling 
bulbs in July or August, 6 inches apart; shade carefully and water until they are established, and, under favourable conditions, they will bloom from September through a good part of winter up to April-and such blooms!

\section{CHAPTER VI}

\section{CARNATIONS}

FOR centuries the Carnation has been the most popular of our garden flowers. Parkinson, the earliest writer on garden plants, describes no less than fifty kinds which were then cultivated. We have many of them still, and though some have been lost, others quite as good have taken their place. They may be classed under four groups-Bizarres, Flakes, Selfs, and Painted Ladies. True Carnations have their colours arranged in longitudinal stripes or bars of variable width on each petal, the ground colour being white.

Bizarres (Odd or Irregular) are those in which stripes of two distinct colours occur on the white ground, and their merit rests on the purity of the ground and the clearness and evenness of the striping. Scarlet Bizarres are marked with scarlet and maroon, Crimson Bizarres have crimson and purple; Pink and Purple are marked with these two colours. 
The Flakes are Carnations which have stripes of only one colour on the white ground, and so we have Purple, and Rose, and Scarlet Flakes.

The Selfs are those showing one colour only, white, crimson, purple, etc. The old Crimson Clove is the most familiar type, but we have them now in every shade of colour.

The Painted Ladies, or, as Parkinson more happily calls them, "Dainty Ladies," have the under side of the petals white, and the upper side a beautiful lake red or purple, so laid on as to appear as if it were really painted. This variety has become so very rare that there are many gardeners who have never seen it.

The Tree Carnation is a really beautiful pot plant; the large salmon and rose-coloured Souvenir de la Malmaison is the best known of the family, and from it have come sports of very various shades of colour, so that from Malmaison and its kindred varieties almost all colours may now be obtained, from pure white to bright scarlet. One of these latter shades belongs to Yuletide, an excellent winter Tree Carnation. When planted on a border under glass; these plants will bloom all through winter and spring, when both perfume and colour will be specially welcome.

It would not be easy in a short chapter to give a list of even a few from the classes of show Carnations and Picotees. Amongst many I may notice a few really good-Albert Whale, Duchess of Fife, Kelton Rose, Hotspur, Miss Willmott, Mrs Muir, Rose Celestial, 
Mrs R. Hole, Germania, Red Braes, Salamander, John Forbes.

Amongst the border Pinks the best known and most useful is the pure white Mrs Sinkins, which has now taken the place in most gardens of the old Clove White.

The Picotee is only a seminal divergence from the true Carnation, but on account of its difference of character it may be considered a distinct plant. Picotees differ from Carnations in having their petals laced rather than striped with a distinct colour. Their sub-groups are described as - red, purple, rose, and scarlet-edged, all having white grounds, each group again having its heavy-edged and light-edged varieties.

With the heavy-edged the colour is laid on in little touches, spreading from the edge inwards, and coalescing into one line of colour more or less feathered on the inner edge-the less the better. The light-edged sorts show what is called a wire edge of colour on the white ground.

Then the Yellow Picotee is a very beautiful group.

Both Carnations and Picotees may be freely grown from seed, and new varieties are found by selecting the best seedlings.

The established varieties are easily propagated by layers and pipings or cuttings.

Layering when the shoots are sufficiently long is best. It should be done when the plants are in flower, or soon after. When rooted, they should be cut away 
from the parent, and potted or planted out in September or October, the choicer sorts potted small and kept in the cold frame for the winter.

The soil they best like is a good turfy loam as fibrous as may be; to four parts of this add one part of rotten dung and one of leaf mould, with sharp sand enough to keep it loose : a good sprinkling of old lime-rubbish is a very welcome addition.

\section{CHAPTER VII}

\section{CHRYSANTHEMUMS}

Chrysanthemums have two exceptional merits: at a season when Nature has clothed herself in grey, they produce an almost endless variety of colour, and to this may be added a wonderful readiness to adapt themselves to the most smoky surroundings. Few things are more encouraging in the experience of the owner of a town garden than a visit to the Temple Gardens, in the very heart of London, in the very depth of winter; many an amateur has gone home after such a visit with the resolution to make this flower a speciality. To be sure, the extent of one's ambition as a Chrysanthemum grower must vary with the opportunities and time at our disposal, but as smoke and soot are not against us, we may well take heart. Those who are really in earnest will be sure 
VII.] SEASON OF GROWTH AND MATURITY LIMITED I6I

to succeed in a season or two, and some few will very soon develop into experts.

The object of this chapter is rather suggestion than instruction; many books have been written on the subject. "The Standard Handbook," however, is one by Edwin Molyneux, from which even beginners may learn much, and exhibitors everything.

The first thing to be thought of is to provide oneself with healthy young plants which have been struck in the early spring (they are constantly advertised in The Garden, Gardening Illustrated, Amateur Gardening, or The Gardener), if one's friends cannot supply them from their old plants. People have often many more than they need for themselves. When the plants are obtained these should first be potted in 3-inch, and afterwards in 5-inch, finally in 7-to 9-inch pots, and never allowed to remain long enough to be pot bound; each shift should be made as soon as the roots have filled the pot. The ordinary compost for soft-wooded plants is sufficiently good for the first two pottings, but the final remove is of much importance.

It ought to be borne in mind that Chrysanthemums have a great deal to do during a very limited season of growth, they must not only grow but mature their wood in a few months. They ought, therefore, to have a more than ordinary share of nourishment, as much as they can possibly assimilate; with this object two things are of importance, the composition of the soil and the afterfeeding, and the one to a great extent with a view to the 
other. The soil, in fact, should contain in itself suitable food, but in addition it should also be looked upon as a sort of store for the stimulants which must be administered from time to time, but not until the stems and roots have far advanced towards maturity, the store itself all the while remaining sweet and well-drained. The plants greatly resent overmuch moisture, and the compost must be so contrived that while abundance of stimulants shall be supplied, the water may always percolate freely, and the pot never become water-logged. Bearing this in mind, I should advise a compost of this sort:-Three parts of fibrous sod broken into pieces as large as walnuts, the fine soil being taken out; one part stable manure without the straw ; one of half decayed leaves; one of coarse silver sand ; one of bone manure, charcoal, and wood ashes (from the stems of last year's plants) in equal parts; all these latter well mixed first, and afterwards mingled with the broken sod.

When being finally potted the plants should be very firmly fixed, and the soil rammed into the pot with a blunt stick; the growth will not be so rapid, but the plant will mature all the better. There should be more than an inch drainage covered with a piece of thin sod or the rougher part of the compost; over the drainage some soot may be thrown; it at first baffles the worms and afterwards helps to nourish the roots. At the top an inch and a half space should be left for water and top-dressing later on. It is well to place the row of plants standing on slates or boards on the side of a path running north and south, and in dry weather 
to cover them at each side with coal ashes, so that they may not be parched with the hot sun, and require watering half a dozen times in a day.

The treatment of the buds and feeding with stimulants are arts in themselves, not very easy to explain on paper (see note). Enough to say that they must be learned, and practised during the months of August, September, and October if satisfactory blooms are to be looked for. Till then, however, the more urgent work is the pressing on the growth, and when dwarf and bushy plants are wanted, they should be cut down before Midsummer Day to within $4,6,8$, or 12 inches of the soil; they will not then need much moisture at the roots for a while, only a syringing once a day to help the buds to start into growth. Without cutting back, however, the plants will break of themselves later on and bloom some weeks the sooner.

Any surplus plants and those of last year, if they remain, may be planted out in the borders, and, if not spoilt by autumn frosts, they are sure to be treasures of beauty-unfailing stores for cut flowers.

The early autumn flowering sorts of the Madame Desgrange type should certainly be distributed through the garden, as they will bloom all through September.

Let me therefore impress upon my readers the advantage of securing in early spring, and growing on vigorously through summer, strong young plants of the earlier and hardier sorts of Chrysanthemums, some of which have been already given in a previous chapter. 
Amongst the Yellow there is Soliel d'Octobre, W. $H$. Lincoln, George Wermig, Bouquet d'Or; of the Whites, Madame Desgrange, Avalanche, La Vierge, and Lady Fitzwygram; Lilacs, Emmie Frizeon, Étoile de Lyon, and Madame Marie Masse. These, and other shades of crimson bronze or gold, such as Crimson Précocité, Harvest Home, are of robust habit and very floriferous. In a well-prepared garden border they will grow freely, but wherever a plot can be planted under glass they will produce an abundant harvest up to Christmas.

The three following illustrations will assist the reader in the somewhat intricate question of buds and their selection:-

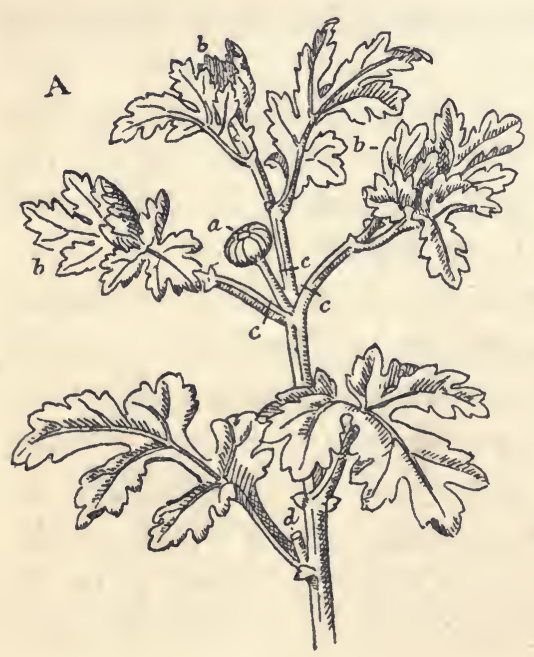

In A a large single bloom is the objectthe "Crown bud" (a) is to be "taken" i.e. chosen.

It generally appears in August in the middle of a cluster of leading shoots $(b)$; these are cut off at $(c)$ as well as those below at $(d)$.

In this way the whole strength of the plant is given to $a$. 
In B three "Crown buds" are retained (d). They are the result of an early break caused by a bud (a) forming at the leading point of the young growing plant. This growth causes other buds to start just beneath as early as June. Three are "taken" $(b)$; all the remainder $(c)$ are removed. Each of these shoots produces the "Crown bud" (d). They are "taken" by removing all the shoots which grow around each $(e)$.

If more shoots are

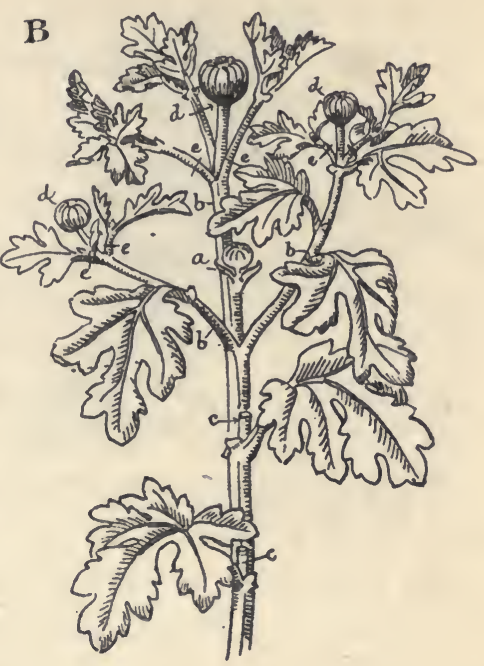
retained, there will of course be more blooms, but smaller in proportion.

$\mathrm{C}$ is an illustration of a single branch or shoot of $\mathrm{B}$. A "terminal bud" is the apex of growth on every such shoot. It is formed by hindering the bloom of the early "Crown bud" ( $a$, Fig. B.), and so enabling each of the other shoots to produce (terminal) buds. One of these shoots is here selected (Fig. C). The "terminal bud" on each branch of B is "taken" by removing all the side buds at (e). This would throw all the strength of that branch into (a) (Fig. C.). 
If smaller sprays of bloom are wanted, then the five

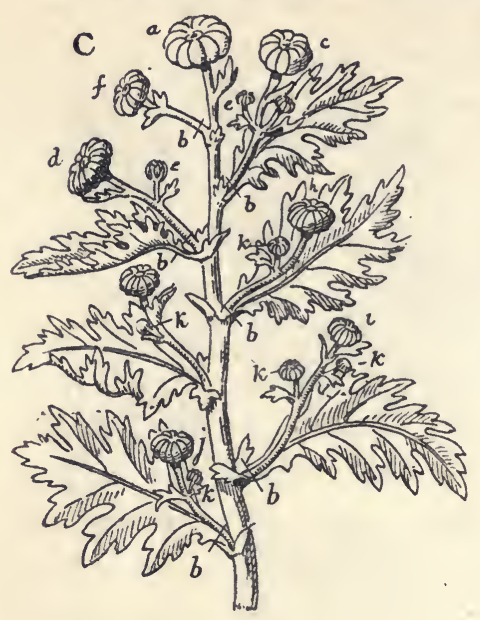
or seven larger buds should be "taken" $(a, c$, $d)$, etc., and the smaller $(e, k)$ removed.

By so regulating the buds on each branch of the plant, flowers may be produced, larger or smaller, according to taste. As a rule, "terminal buds" form in September or early October.

\section{CHAPTER VIII}

\section{CYCLAMENS AND TUBEROUS BEGONIAS}

IT is strange that the hardy Cyclamen is seldom seen amongst our winter and spring flowers. People are perhaps so much accustomed to admire the bright blooms of the Persian Cyclamen in greenhouses that they scarcely think of Cyclamens as hardy flowers, and yet there are kinds just as hardy, and just as easily grown, as our Primroses, wherever they can enjoy the shade of low bushes or rocks, and where they may nestle in security 
between the netted roots of forest trees, as they do when growing wild. They will frequently scatter their own seed, and colonise their neighbourhood. The Ivy-leafed Cyclamen is in full leaf all through the winter and early spring, and the only thing which is necessary for its successful culture is good drainage. It grows naturally among broken rocks and stones, mixed with vegetable soil and grit, but it is well to have the tuber buried under the surface, and not exposed, as Persian Cyclamens are, which grow in pots.

As to these Persians-from their seed pan to maturity, during their first year of life, they should be grown as quickly as possible. When done flowering in spring, the best plan is to shake them out of their pots and plant them in a north border in a rich mixture of fibrous earth and some sand and leaf mould. Here they will grow freely without further trouble all through the summer, and need only be potted again in September, and kept in a cold frame until the new blooms are showing themselves; they are then ready for the greenhouse.

Tuberous-rooted Begonias are welcome additions to our gardens, either as pot plants in the greenhouse or for bedding use. It is best to grow the tubers in shallow wooden boxes, or separately in good-sized thumb-pots, plunged in a cooled hot-bed, until they have become vigorous young plants, and they can then be either transferred to larger pots, or placed out in the open air in groups or beds. 
Some of the named varieties are very costly, but in colour and general effect there are not many things so easily grown, which quite equal these exceedingly attractive flowers.

\section{CHAPTER IX}

\section{CHRISTMAS ROSES}

IF the Rose is the queen of summer flowers, the Christmas Rose reigns supreme in winter. By careful observation and selection, a continuous succession of bloom may be had from October until April, and that in the open border, exposed to storm and rain and frost, when almost no other flower is to be found.

Amongst the earliest of the Hellebores are giganteus, maximus, and major; these are classed as Niger; they are of the purest white. Then, later on, between January and the end of March, the Lenten Roses or Hybrids-in various shades of red, and crimson-succeed. The one I like best is Colchicus, with its dark-veined petals and its graceful leaves. Later, still, other hybrids are in perfection, and are a welcome addition to the spring garden, even though flowers are abundant enough by that time.

The most fitting position for Hellebores is the highest level of a sloping bank, where there is a depth of 2 or 3 feet of good rich loam, well mixed with clean grit from 
the roadside, well sheltered on the east from wind, and with a partial shade on one other side, such as Rhododendrons would afford, well away from the depredations of forest tree roots.

The best time for lifting and dividing them is sometimes said to be the month of July, when they are in the most vigorous condition. I think I should prefer it earlier, whenever they have finished flowering; but they ought not to be often moved-once in ten years is enough, and in some cases not even so often, and when moved at all, they should be broken up into single crowns. In the growing season top-dressing or liquid manure is helpful to those that have been some years planted.

They may be propagated either by division or by seed, and the seed should be sown as soon as it is ripe (as it does not long retain its vitality) in pans or boxes under glass, or covered over on the border with slates or flags until nearly germinating.

\section{CHAPTER $\mathrm{X}$}

\section{WALLFLOWERS (CHEIRANTHUS)}

NoT without reason has this old favourite been given the name of Wallflower, for it is at its best when found growing on old walls, or sea cliffs, or quarries; in such places it has a tendency to form a dwarf bush, and to live and thrive and bloom for years. 
There are not many garden plants so fragrant and lovely as the old double perennial Wallflower, which our grandmothers loved so well; it is perhaps not quite hardy, and it is well to keep the stock replenished by propagating a few plants each year, by slips put in under hand-lights in sharp sandy soil. Cuttings put in in August, September, or October strike without any protection in a shady border or in boxes of sandy soil. The yellow is the more common-of a beautiful, golden shade, and very floriferous. The old dark crimson is all but extinct; its flowers are almost black, and contrast well with the brighter shades.

The German single kinds are, however, the staple garden plants for spring; and they well repay the small annual expenditure of time and money needful for their culture. The Covent Garden Blood-red is the best dark sort. Either Belvoir Castle or Golden Yellow produces great compact masses of rich orange-yellow bloom.

The double biennials have a striking variety of colours and a strong robust growth.

It is well to sow the very best seed which can be had in April or May, for the stronger and better rooted the plants are, the more likely they are to stand the hardships of the coming winter. Before being finally placed out where they are to bloom they should have been transplanted once at least, and put 6 or 8 inches apart into nursery beds; the moving destroys the tap-root and induces them to throw out surface-roots, so that they 
may be readily lifted with balls at any time, and without much interfering with their growth.

By no means so common as the ordinary Wallflower, but quite as useful and attractive as border plants, are some of the more modern hybrids. These Wallflower-like perennials are known as Erysimum. The most familiar is Erysimum ochroleucum (Cheiranthus Alpinus, or the Alpine Wallflower). It grows in spreading tufts, which in spring and summer are covered with beautiful sulphurcoloured flowers; it thrives equally well on the rock garden or in the level border, but needs to be frequently divided. Cheiranthus Marshalli bears orangecoloured blossoms, and mutabilis has variegated tints. All these perennials like dry soil during winter and plenty of water in summer; they can be readily increased by cuttings, taken off when the plants are going out of flower.

I have found it a good plan sometimes to make a sowing of Wallflowers at the end of the summer, leaving the young plants in their seed bed all winter; plant out in March, and in this way secure a satisfactory supply of flowers all through the following winter. 


\section{CHAPTER XI}

\section{PRIMROSES.}

Without Primroses a garden would be strangely bare and incomplete, and yet the family is so large and diversified that no chapter could possibly do it justice. It is said to contain more than a hundred different sorts, and it is by no means an easy task to classify them. Perhaps the most satisfactory arrangement is to be found in Mr Robinson's "English Flower Garden."

The Auricula possibly should be given the first place. It is an Alpine plant of rare beauty and fragrance. The florist's varieties are a class to themselves, and require the experience and knowledge of an expert. The border Auricula may be readily grown from seed, and will thrive in most places on the rock garden, if only there has been a liberal supply of old leaf mould or road grit thrown into the space when opened for them before planting. Wares' seed, from Tottenham, is perhaps the best that can be had.

The Chinese Primrose is of course only suited to the temperature of the cold frame and the greenhouse, and its treatment has been already considered in another chapter.*

There is a middle class too, which will yield to none in interest and utility: chiefly furnished from Japan, the Himalayas, and other districts, which have supplied our * See page 23. 
English gardens with so many plants and shrubs singularly fitted for our own insular climate.

Amongst these, Primula Japonica is one of the best, and it is not in the least tender. In moist, shady spots with deep rich loam, it will grow vigorously, with stems a couple of feet high, and with tier upon tier of beautiful crimson blossoms. It suits the rock border well, and sows itself freely. It may be sown in the cold frame in a pan as soon as gathered, and never in heat.

Primula Sikkimensis comes from the higher slopes of the mountains of India. It starts into growth by the end of April, likes a shady position; a deep, boggy place suits it best. Its flowers are very numerous, and of a pale yellow shade.

Primula rosea is also a most attractive Himalayan Primrose, perfectly hardy. Like its neighbour, it is a marshy plant, and will not stand drought. It likes a deep rich loam in a moist, shady part of the garden, and must be increased by division.

Primula Cortusoides comes from Siberia. It is also rose-coloured, and likes a sheltered corner with light and rich soil. It is one of these that loses its leaves, and, unlike Rosea, it may be easily raised from seed.

Primula amcena (Caucasian Primrose) is of a bluish lilac shade. The blossom comes out before the snow has gone, and has quite finished its bloom before our native Primroses have started theirs.

Nivalis is a very pretty Alpine dwarf, snowy white. 
As in the case of some others of the family, I have observed it growing as freely as a cabbage on one side of a rock, and on the other side, only a few inches away, it has dwindled and died.

In this respect it is a type of many another plant, and should teach us to shift our favourites and try them in various positions and soils. For these questions of soil and aspect are perhaps the most urgent of all points in gardening.

Of all the members of this family there are none so attractive and satisfactory to the amateur as our native Primrose and its varieties. One class, the Primrose proper, takes its origin from the flower which grows wild everywhere on our banks and in our hedgerows. Another, the Polyanthus, comes from the oxlip or cowslip. The one sends up a number of separate flowers, each on its own stem; the other produces one distinct stem, and on it grows many flowers. Cultivation in each case has produced a variety of new developments in size, and colour, and beauty of foliage.

Perhaps the most notable result of the cultivation of the polyanthus has been the Munstead or bunch-flowered, raised by Miss Jekyll.

As to the Oxlip, when a good strain of seed has been found, there will be no difficulty in raising some very perfect and beautiful forms and shades of colouring. Every sowing will produce a host of charming flowers, and frequently something altogether novel. For rich inlaid colouring and profusion of bloom, there is nothing 
to surpass the Polyanthus form of the Primrose. The old-fashioned Gold-laced Polyanthus especially is a gem. The best seed may be had from Mr Dean of Ealing. They are not often seen now, but they are as readily grown as any other, and will come as a surprise to many amateurs, who are only familiar with their name.

The best time for sowing the primrose is either immediately the seed is ripe or in the following March. It should be sown in boxes placed in the cold frame, and when the young plants are big enough to handle, they should be pricked out into other boxes or nursery beds. These again should be planted out in June in beds or groups, and they will grow on without hindrance, and bloom the following spring. When the bloom is over, towards the end of May, it is time to divide and replant, as they will never be the same after the first year unless divided.

The old Double Primroses, which used to be familiar in every garden, are now again prized as they deserve. Unlike the single, these may be left undisturbed for years when they have once established themselves. The best known are the Double-white, Red, Crimson, Lilac, and Sulphur.

The rich Crimson Pompadour is very scarce, and not easy to cultivate, except in a favourable aspect, and to discover this, local experiments must be made. If this be not found, it is quite worth while wintering the plants in small pots in a cold frame. A slightly shaded and 
sheltered position, with light rich soil of old manure and leaf mould, suits them best. Rotten leaves or cocoanut fibre spread over them in summer will keep them cool and promote their growth.

\section{CHAPTER XII}

\section{ANNUALS, BIENNIALS, AND PERENNIALS}

IN the minds of many people Annuals belong to a class of flowers which are so easy of culture that no trouble need be taken with them. Few gardeners give their annuals a fair chance; they sow them in a haphazard way, forget an early thinning or a careful transplanting, and so the plants, which find so little room and get such scant care, bring nothing but disappointment.

Annuals are plants which grow up from seed, flower, ripen, and die in one year.

They may be grouped into three classes. Hardy, which are sown as a rule in the ground they are to bloom in.

Half-hardy, sown in a slight hot-bed, and pricked out into the nursery before being planted out.

Tender, raised in pots and treated as greenhouse plants of the hardy class.

Some hardy annuals are best sown in September and October; the plants not only flower much sooner, but are stronger and more beautiful. Sweet Pea, Silene, Saponaria, 
Nemophila, Cornflower, Larkspur, and Poppy, treated in this way, will come into bloom just at the season when, except spring bulbs, few other things are to be found.

When they are to be sown in spring it may be best to wait until some genial weather has come in April, then no time should be lost in scattering over some wellprepared border the Shirley. Poppy, Phacelia, Candytuft, Gaillardia, Eschscholtzia, and Mignonette, and as the young seedlings grow they should by degrees be steadily thinned, so that each plant may have room to develop.

Half-hardy annuals require more trouble and culture; sown in boxes in a frame that has some heat still in it, supplied with air when growing, and before being shifted hardened for a while in a cold frame, and then pricked out 2 to 4 inches apart into a well-prepared bed composed of a mixture of thoroughly rotted dung and fibrous earth laid 4 inches deep on the hard ground: watered, shaded, and guarded from slugs until they have filled their compost with roots, when they may be cut out with a trowel and removed to their borders. Amongst the half-hardy annuals may be included China Aster, Ten-Week Stock, Zinnia, Sunflower, Marguerite Carnation, Marigold, Summer Chrysanthemum, Salpiglossis, Coreopsis, Portulaca, Phlox Drummondii, Ricinus (Castor Oil), Sphenogyne, Petunia, and Canary Creeper.*

* Another climber admirably suited for greenhouse use is the Maurandya, an annual. It is sufficiently hardy to thrive in the open air in summer, and quickly covers trellises, fences, and pillars. It is easily raised from seed in heat. The flowers are violet, rosy, purple, and white. 
$[\mathrm{CH}$.

Biennials live as half-developed plants through one winter. They should be sown in summer and pricked out as soon as large enough, so that they may be strong plants before being transplanted in autumn. The two moves act as a kind of check to their growth, and tend to make them dwarf and bushy.

The different kinds of Stock-Intermediate, East Lothian, and Brompton, should be sown in spring for autumn use; in June, July, and August for blooming the following summer. The White Lothian and Princess Alice are beautiful pure strains of White, and are equally good for pot culture and border.

Wallflowers are usually sown in May and transplanted once or twice before winter.

About the same time we should sow Perennials, e.g. Larkspurs, Snapdragons (Antirrhinum), Aquilegias, and Penstemons, Evening Primroses (Enothera), Sweet Williams (Dianthus barbatus), and Campanulas.

The same precautions are needful for these biennials and perennials as for the half-hardy annuals, only that, as they are sown in early summer, they have no need for glass at any stage of their growth. However, each plant should be treated as a separate item, and not merely as one of a handful.

If Sweet Peas have not been raised in autumn, they should be sown in January in the open ground, previously well manured, or on peat sods in the frame, and planted out in lines or clumps rather thinly. $\mathrm{Mr}$ Eckford and the American florists have produced some marvellous 
colours, and these new varieties, e.g. "Lottie Eckford," "Blanche Burpee," "Prima Donna," "Queen Victoria "are grown to best advantage in groups of separate tints. Half a dozen plants in a group, well grown, protected from slugs, and judiciously staked, are more likely to succeed than a crowd, and will remain much longer in bloom.

\section{CHAPTER XIII}

\section{FRAGRANT PLANTS}

"The smell of violets, hidden in the green, Brought back into my empty soul and frame The time when I remember to have been Joyful and free from blame."

IN the garden as nowhere else in the world the senses find delight, sight perhaps most of all, but taste and sinell in only lesser degrees, and one of the most welcome revivals of late years has been the wider culture of fragrant flowers, and the growing love for them. Some of the most permanent sensuous impressions of our early days are those distinctly associated with the scent of plants.

Some sweet-smelling plants are generous of their fragrance, and give it not only spontaneously but lavishly, and for this reason the scents of Hyacinths and Lilies are sometimes found rather disagreeable adjuncts of a room. The border is their proper place, where they may mingle their sweetness with the Tulip and Daffodil, 
Alpine Auricula, and Musk, and Double Rocket, and Sweet Pea, and Mignonette.

It was Lord Bacon who said: "Because the breath of flowers is far sweeter in the air than in the hand, therefore nothing is more fit for that delight than to know what be the flowers and plants that do best perfume the air."

We associate with our early years impressions in the shrubbery from the Lilac, the Mock Orange (Buddleia Globosa), Chimonanthus Fragrans, the sweetest of winter flowers, Sweet Briar, Double Gorse, Honeysuckle, Broom, and Thorn; in the meadows, impressions from Cowslips, Wood Hyacinths, Meadow Sweet, and Marsh Marigold. They may well be envied who carry with them through life recollections of the fragrance rising from a sunny bank of Heather in the later summer, or a whiff from the Clover field, or the Pine trees on the avenue, or the sweet breath of the young Larch on an April night. Perhaps of all plants, whether in the greenhouse or outside, the sweet-scented Verbena is the oldest favourite.

Plants and trees such as these give off their sweetness freely, but there are some of which the scent can only be perceived on coming very near, or by touching them.

"Herbs, though scentless when entire, perfume the air when bruised." Of these the most familiar are Lavender, Myrtle, Rosemary, Mexican Orange Flower, Sweet Bay, Juniper, Escallonia Macrantha, and the delicious Bog Myrtle. 
Groups of such things planted on the outlying part of one's garden, spaces between them being filled with patches of low-growing Thyme and Sweet Woodruff, will surely afford altogether new attractions to many when they find themselves brushing against living masses of strange sweetness.

The Night-scented Stock (Mathiola Bicornis), an annual not particularly attractive in the daytime, makes its presence felt at sundown; it should be sown in the early part of April in different parts of the garden, so that its delicious fragrance may be widely diffused.

Amongst other sweet border flowers are the familiar Lily of the Valley, Chinese Pæonies, Snapdragons, Sweet William, Tobacco, some Salvias, the Musk Hyacinth, and Pansy.

"Gold-dusted Snapdragon,

Sweet William with his homely cottage smell,

And Stocks in fragrant flow;

Roses that down the alleys shine afar,

And open, jasmine-muffled lattices,

And groups under the dreaming garden trees,

And the full moon, and white evening star."

Then there are some aromatic things, such as Tansy, Chamomile, or the Eucalyptus.*

The scents of wild Roses are as various and tender as their colours, and those of Scotch Briars have a delicacy

* This interesting and strongly aromatic tree will only stand the English winter in the most favoured parts of Devon and Cornwall, though in some places in Ireland it has attained to a great size. The leaves have been found to possess a singularly effective healing quality when applied to old sores. 
peculiar to themselves. Hybrid Perpetual Roses are said to have three distinct types of perfume, and there are at least as many in the Teas. One lovely Rose, Baroness Rothschild, has no perfume.

In the greenhouse the sweetest leaf is that of the pineapple-scented Salvia, and the Diosma, when rubbed, has a surprisingly welcome smell.

\section{CHAPTER XIV}

CORDYLINE AUSTRALIS

IT is strange in how few gardens one finds a trace of the most attractive and graceful of ornamental plants, the Cordyline Australis. The reason probably is, that as it is known to be so nearly related to the aristocratic family of the Dracœnas (which as a rule, are greenhouse and stove plants) it is not supposed to favour the more plebeian atmosphere of a lawn or herbaceous border. Even so great an authority as $\mathrm{Mr}$ Robinson, in "The English Flower Garden," has strangely fallen in with the popular notion, when he tells us that it is only in the mildest parts of England and Ireland that Cordyline can be grown in the open air. This may account for the curious fact that it is rarely seen in the London parks, where rare and beautiful plants find in such variety a welcome home. In almost every part of Ireland it may be grown as readily as the evergreen 


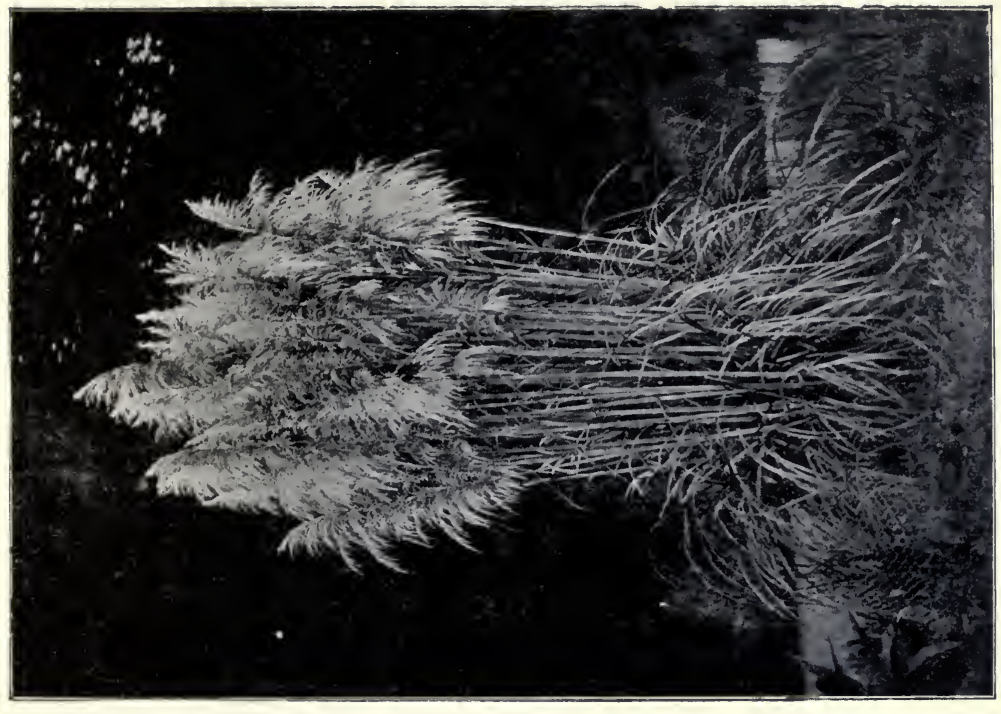

6.

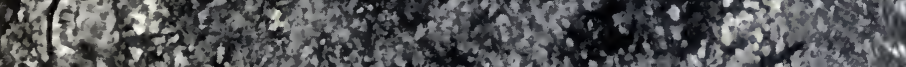

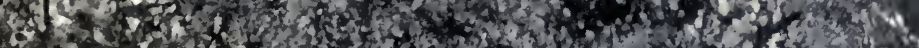

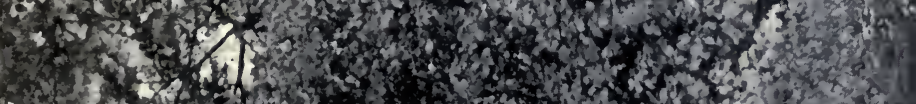

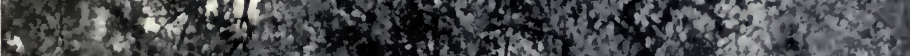

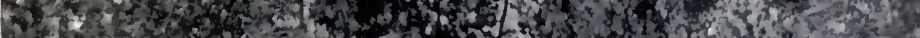

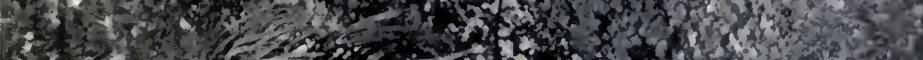
3
$F$

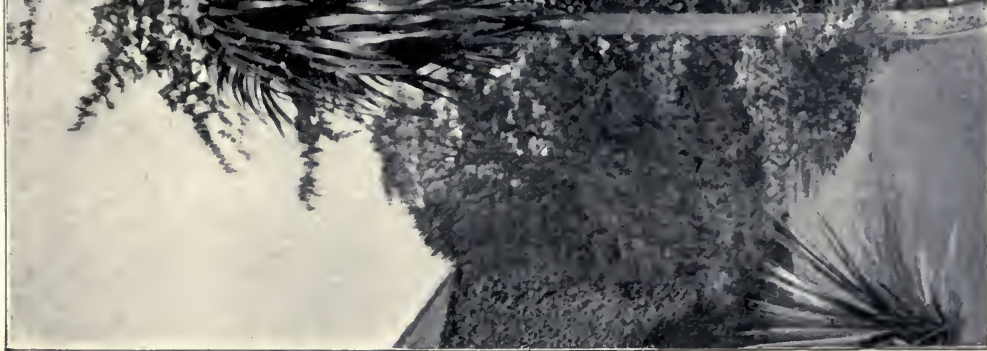




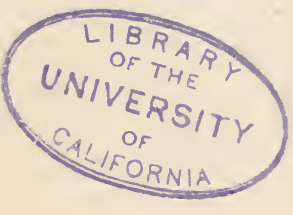


Oak, and as an ornamental plant it is far superior. Where it does well in the garden or pleasure ground it surpasses any Yucca in distinctness and grace. The only real danger to which it is liable is from snow falling into the crown and lying between the tender upper leaves, which are then exposed to the action of frost and rain ; but this may easily be avoided by tying these upper leaves up to a point in severe weather, and in this way forming a natural thatch. But even when the leader has been lost, the beauty of the plant is not much spoiled, though its appearance is altered, as it then sends out laterals and suckers all round.

One of the earliest planted, and perhaps the most prolific of the Cordylines in these islands is that growing in $\mathrm{Mr}$ Walpole's beautiful garden at Mount Ussher, Co. Wicklow. The stem, which is like that of an Ash, runs up to about Io feet; the head, which is much divided, produces every season lovely flower spikes, studded with white bell-shaped flowers. The fertility of this old tree has been amply proved by the many fine specimens that have been raised from its seed, and which are now growing in Trinity College Gardens, as well as at Howth, Sutton, and Raheny.

It is readily increased both from seed and suckers, as well as from pieces taken from the stem. If a plant is cut down close to the ground there spring up very soon a great number of young shoots, any of which can be taken off as cuttings, and will strike freely. 


\section{CHAPTER XV}

WATER-LILIES (NYMPHAEA)

How often do we see an ungainly pond disfiguring the neighbourhood of some villa or country house, which with but a very little skill and contrivance might be made positively beautiful and attractive? All that is needful is to replace the squalid duck-weed with a few plants of our native Water-lilies, and to add to the collection, where we can, some of the Eastern and North American varieties, with their soft and lovely colours. The new hybrid kinds will be found to prolong their bloom for months after our native sorts have ceased to flower, so that the attractions of a water garden may easily be sustained all through the year, from May until October. Hardy water flowers are not really difficult to manage. The plants when procured may be fixed in soil, encased in a wooden box $36 \times 15 \times 8$ inches, and sunk to the bottom, where the roots will often lengthen out into the sandy mud around. The best time for planting is spring, and plants put in in April or May often bloom during the same summer.

The two things which Water-lilies require in the British Isles are, Ist, full exposure to the sun, and 2nd, such conditions of water as will ensure a comparatively high temperature; for this reason running water is, if possible, to be avoided, and the tank should be kept pure 


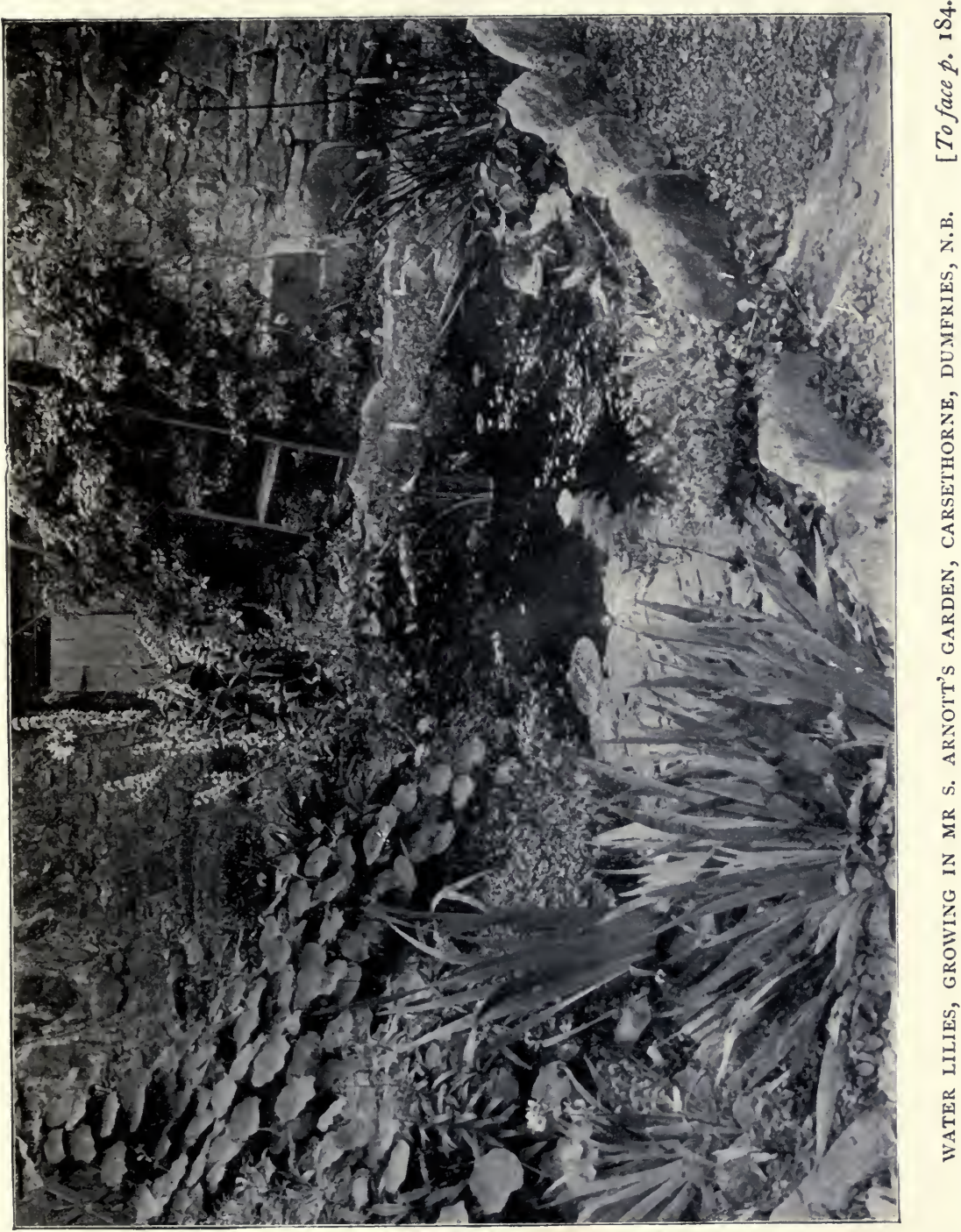



by an annual clearing out. Planting in boxes facilitates such an arrangement. Where there is no stream or pond available a broad tub may be sunk 3 feet or so in the ground, or better still, a cement or concrete tank constructed, half filled with soil and the rest with water. It is well always, if possible, to arrange that there shall be 12 or 18 inches of water to cover the crowns in winter, so that they shall be safe from frost.

The white Water-lily (Nymphea Alba) is a hardy native, and blooms in May and June. There are several varieties, and there is also a pretty pink form called Rosea. N. Tuberosa is a North American sort, with fleshy tuberous masses of roots; it blossoms during the later summer and autumn.

Another North American plant is the sweet Waterlily $(N$. Odorata); there are several varieties, with lovely shades of yellow and carmine. N. Pygmea is the smallest of the Water-lilies, and comes from Siberia and China; it is the earliest to flower, and continues longest in bloom. Of late years Monsieur Marliac has raised some very lovely hardy sorts-hybrids-(some are gems of beauty, the leaves and blossoms equally graceful and attractive); many of them are quite within the limits of the average gardener's means.

It is well worth our while to give some attention to this beautiful family of plants whenever we visit the gardens at Kew, Glasnevin, or Ball's Bridge ; and certainly in a small way some of us may make a beginning by cultivating such Water-lilies as can be easily obtained. 


\section{PART IV}

\section{K A LENDAR}

\section{GARDENING IN JANUARY}

Note-It will be necessary for my readers to make due allowance for the variations of climate in the different parts of these Islands, e.g. seeds may be sown and plants exposed in the South of England, and in other favoured localities, fully a month in advance of the time it would be prudent to venture on such work in the neighbourhood of Glasgow. Local experience alone can be our guide in such matters.

DOTHING has such a tendency to spoil the comfort of gardening as to find that we are some weeks behind time in spring work; in a month such as January, therefore, the most useful tasks are those of preparation and anticipation. We are practically at the mercy of the weather, and should endeavour to adapt ourselves to our circumstances. If the weeks should be dry, all spare plots ought to be rough-dug and trenched,* so as to expose the earth to the sweetening and pulverising action of the wind and frost, and well-manured, ready for spring sowing. It is worse than useless to work ground when it is saturated with rain or hardened by frost.

Pruning $\dagger$ operations and planting may be carried on 186

* See pages I4, II8.

† See page 130, et seq. 
still. Broad Windsor Beans and "Sangster's No. I" Peas, may be sown rather thick, but only in open weather; under similar conditions, towards the end of the month, Cabbages, where they can be had, may be planted for earliest use.

Protect Globe Artichokes with litter; lay manure and salt over Asparagus beds, but do not dig them. Where it can be found, there is no better manure than sea-weed.

In a sunny border an early planting of Kidney Potatoes may be put in. This sort should never be cut, but planted whole.

Spinach can be sown in a sheltered border in succession, though it is risky. That grown in autumn should be kept clear of weeds and withered stalks.

Where there is an early hot-bed, a first sowing of Lettuce, Cucumbers, and Tomatoes is desirable.

In the greenhouse the temperature ought to be kept as equabie as possible-not lower than $50^{\circ}$ at night, not higher than $60^{\circ}$ in the day-with judicious admission of air; avoidance of damp is of even more importance than of frost.

Pelargoniums, Chinese Primulas, and some of the early bulbs will render the house full of interest.

Dahlia roots, laid into the surface mould of the hotbed, will soon sprout, and give a good supply of early cuttings.

If any Hyacinths, Narcissus, Anemones, or Tulips should be still unplanted, put them in on some fine dry day. 
Should the digging of borders not have been finished early in December it will be better to put it off until the bulbs are showing above ground. The operation must then be performed rapidly to avoid the exposure of the tender roots.

\section{GARDENING IN FEBRUARY}

IT was an American who once observed, with quite as much truth as wit, that in these islands we have no climate, only samples. This remark applies peculiarly to the weather in our month of February; nobody can ever safely forecast it; we can but hope that the winter is pretty well gone, and that our preparations for spring may be carried on with greater activity and more confidence than during the two previous months, and so, weather permitting, earnest digging, liberal manuring, and scrupulous cleaning are the only obvious tasks we must set ourselves for the coming weeks.

Those who practise early sowing and aim at early production, must be prepared to afford some protection to their crops by means of litter, spruce-branches, mats, and such like devices, as circumstances require. In almost all respects the notes for January work still hold good. Early Potatoes* may be planted when the ground is dry and the weather mild. To secure a satisfactory early crop the border should be prepared by the addition of such warm, nourishing stuff as is to be got from the charring of all 
the light rubbish, prunings, hedge-clippings, etc., which may be raked together from the yards and outhouses, and burnt up with a heap of dried weeds and earth. Such a plan is also very conducive to tidiness. When planting, lay the mixture in the open drills, so that the roots may find a congenial soil at their first start. Ground prepared in this way will grow all seeds and tubers to perfection, and afford the least shelter to the worms and slugs which infest neglected ground.

It is during this month that preparations should be completed for making a hot-bed. The best material is fresh stable manure with a liberal mixture of the autumn leaves. To make sure of a steady, moderate, and lasting heat, the manure and leaves should be mixed, forked over, and thrown into heaps every few days for a week or so before it is wanted, and if very dry, sprinkled now and then from the rose of a watering-pot; the whole mass will then get into a uniform degree of fermentation. A rectangular bed should then be built, I foot larger each way than the frame to be used, carefully shaking out and spreading each forkful, and repeatedly treading down the manure, so as to make the bed as uniform as possible in solidity, composition, and moisture. For general purposes a bed about 3 feet deep that will settle down to 2 feet will be best. When the bed is finished the frame and sash may be put on, and some fresh manure banked round the outside to the very top. Let the sash be left partly open for a couple of days to allow the rank heat to pass off. Light, dry, friable compost may 
then be thrown in and levelled, and as soon as the temperature subsides to $90^{\circ}$, seed boxes and pans, previously prepared, may be plunged into the compost. The great essentials are-first, a uniform degree of heat and moisture, which can be obtained by a cautious admission of outside air; next, watchful and judicious shading at night and whenever during the day the sun is strong, an avoidance of draughts, and afterwards a careful hardening off of the young plants (by gradual exposure to the air and diminishing the supply of water) before transferring them at the next stage to the cold frame or greenhouse. The details of management must, however, be learned by degrees, but they will easily be acquired by careful attention to details and consultation with those who have learned by their own experience rather than from books.

One of the very first essentials in gardening is the proper application of water. In hot and dry weather growing plants should be watered daily, sometimes oftener -one good soaking is more beneficial than many sprinklings; often the soil must be loosened to enable the water to penetrate and not run away on the surface. As a rule, the best time for watering is the evening; when it is possible, rain water should be used, and what is drawn from a well or pipe should stand for some hours exposed to the action of air and sun; it should be of about the same temperature as the air surrounding the plant, and plants in bloom ought never to be showered overhead. 


\section{GARDENING IN MARCH}

THIS is the great season for the garden work. Almost every kind of seed may be sown in the month of March. Of course the weather is our master, and it is mere waste of time to fight against it. Every advantage should be taken of fine intervals, for a great deal of our success in the growing of Onions, Parsnips, and Carrots depends on their being sown early and whilst the ground is in a dry state; yet it is better to wait to the end of the month, or even till the next, than to sow on damp, pasty soil.

An important subject in every garden to be considered this month is the proper rotation of crops. The result of raising the same sorts of vegetables for many years in succession on the same ground, is to exhaust it so that no amount of manuring will avail. After Early Potatoes any of the Cabbage tribe may be planted. All tap-rooted vegetables, such as Carrots and Parsnips, which are not to be manured at the time of planting, ought to be succeeded by sorts which require dung at the time of planting,* as Celery, Potatoes, and Cabbages. It is a good practice to dress onion and carrot ground with soot, or fresh lime, or salt.

Where the ground has been ridged, the advantage of this system over flat digging will now appear-it can be levelled and sown after even a few days of dry weather. 
Sowings should now be made of Peas of any description, Beans large and small, Cabbages for autumn and winter, Carrots, Parsnips, early Turnips, Onions, Lettuces, Brussels Sprouts, Cauliflowers, Broccoli, Spinach, Celery, and Beet.

Plantations of Asparagus may be made, also the small tubers of Jerusalem Artichokes should be put in on a sunny, open spot, with deep soil and plenty of room.

When the ground is in good order towards the end of the month, hardy annuals * may be sown where they are to flower. Of tall growth-single and double Sunflowers. Of medium height - Shirley, Mikado, and White-Swan Poppies, Lupins, Cornflower, including the Yellow Sweet Sultan, and branching Larkspurs. Of dwarf annuals-Silene Compacta, Nemophila, Calendula Meteor, Eschscholtzias, Godetias. Stocks-Ten Week for summer; East Lothian for autumn. Varieties of Mignonette, and Tropcolum Canariensis.

Old Chrysanthemums may now be divided and planted out in a rich border. They may be taken up and potted towards the end of August for flowering in November. Cuttings struck in winter may now be planted outside, or potted and kept in frames until well rooted. 


\section{GARDENING IN APRIL}

IN April birds and gardeners are very busy.

It often happens that from hurry or unfavourable weather, much of last month's work remains undone; if so, it should be no longer delayed. Carrots, Parsnips, Onions, Lettuce, Cauliflowers, Broccoli, Celery, and Beet should all now be under ground. Peas and Beans and Spinach may be sown for succession twice in April ; early Cauliflowers, Cabbage, Celery, Lettuce, transplanted; plantations made of Asparagus and Artichokes. Seakale and Rhubarb may still be sown and planted, and French Beans* sown in the open, or planted out from their seed-boxes. Tomatoes, Gourds, and Marrows sown or re-potted, so as to be ready for planting in the open border early in May.

This is a month in which growth makes rapid progress, so that every spare moment should be used to the best advantage.

Never allow the weeds to flower, and never let the hoe rust during fine weather; its diligent use not only destroys weeds, but wondrously encourages the growth of crops. Insects, if neglected, multiply extraordinarily. They should be scrunched the moment they appear. The greenfly $\dagger$ may be killed with quassia water, $2 \mathrm{oz}$. of the chips to a gallon, boiled in a muslin bag; dusting with tobacco powder also is good.

$$
\text { * See page } 124 \text {. }
$$


During the opening days of April the main sowing of hardy annuals should be made; in the closing week half-hardy kinds may be put in. But the more satisfactory way is to raise all but the very hardy annuals in pans and boxes under glass, with some bottom heat, moving them into a cooler frame and pricking out into nursery beds. Stocks and Asters may be treated in this way.

Cuttings may be made of Fuchsias, Heliotropes, Salvias, Verbenas, Petunias, and sweet-scented Geraniums, in this way-plant them firmly in pots, half-filled with sandy loam, and plunged in a gentle heat, covering the pot with a pane of glass to exclude the air; or it may be plunged in a larger pot, and kept in a sitting-room, wiping the glass occasionally. Shoots of Tea or China Roses, or sweet-scented Verbena taken off close to the old wood, 3 or 4 inches long, put in carefully, will strike freely, and make good plants before the end of the summer.

The old roots of Dahlias may yet be laid into the hot-bed, and covered with light soil. As soon as the young shoots are 3 inches long, they may be cut off with some of the old tuber, put into small pots, and plunged in the same hot-bed; or the tubers may be started under a south wall, or in a box, and divided into as many pieces as there are shoots, before finally planting them in the border.

Mignonette for pot culture may be sown in thumb-pots, thinned out to two or three plants, and repotted (never 
transplanted) in rich compost, and nipped in to keep them dwarf. It may also be sown thinly in window boxes, and in the open border.

Window plants should be repotted. Box edgings (where such exist) should be clipped, and the surface of flower borders hoed.

This is the time to make up the nursery reserve corner. Such things as herbaceous Phloxes, early outdoor Chrysanthemums and Michaelmas Daisies may be taken up, separated, planted in rows, left to grow until July, and then placed in bold masses where they are to flower. Phloxes may be moved with advantage when just coming into flower, and Michaelmas Daisies flower better and earlier by this method than when left undisturbed.

One seldom meets now with the beautiful old sweetsmelling Double-white Rocket (Hesperis); when left to itself it generally disappears, it will flourish, however, if treated as a Violet, broken up some time after flowering, the divisions and cuttings planted in a shady place in the nursery, and re-planted in the borders in early winter. The trouble is more apparent than real.

\section{GARDENING IN MAY}

"No one can expect everything to be equally successful every season; an unfortunate sowing, a dry fortnight, a late frost, or a cold wind, are answerable for a good deal 
in any garden. All the same, the best gardeners have the fewest failures."

This is Mrs Earle's, experience, and it is mine, and its truth is never more evident than when during these weeks a gardener takes stock of his spring sowings outside, and of the propagation frame where seedlings have been battling their way against all sorts of odds for weeks past.

The half-hardy things and summer annuals should have been already transferred from their seed pans, pricked out, and hardened off in cold frames. Towards the middle of this month they may be planted out of doors-either morning or evening in showery weather is the best time for putting them out. A careful lookout is necessary against predatory slugs, and a sprinkling of lime or soot often repeated is a helpful precaution.

In dry weather watering becomes necessary for many plants in the open ground, but it should not be given unless absolutely required, as the benefit from artificial watering does not last. When necessary, however, water should be applied continuously until a change of weather, and much more abundantly than is usually given.

In the case of Strawberries* or newly-planted trees, mulching with short straw or grass prevents the rapid passage of moisture from the soil.

Peas, Lettuce, and Spinach may be sown twice during the month, also some Turnips for July use.

Sow Cauliflowers for October. Broccoli also for a * See page 134 . 
second succession in the first and third weeks; they will then flower from December to April.

Transplant Lettuces, Cabbages, Cauliflowers, and Savoys; prick out Celery. Harden off Tomatoes and plant them against walls and palings.

In cutting Asparagus, care should be taken not to injure the crown or neighbouring shoots in their various stages of growth under the surface. In the case of three or four year old plants, when several shoots rise from each crown, it is well not to cut all the large ones; at least one vigorous growth should be spared to supply the returning sap to the growing root, and, finally, it is bad economy to sow or plant any other crop in the beds.

Cut off the flowering stalks of Rhubarb and Seakale.

Remove suckers or strong growths from the middle of Gooseberry and Currant bushes.

Thin out Raspberry suckers to four or six of the strongest to each stool.

When the runners of Strawberries are not required for propagation, cut them off as they appear; they draw strength from the plants; if the weather is dry, the beds should be watered regularly.

Wallflowers ought to be sown about the end of the month, in boxes or border, for autumn transplanting and spring flowering; in a few weeks they will be fit for pricking out in the nursery bed. The Dark Red and Dwarf Yellow (Belvoir Castle) are most effective. Oldfashioned Double Wallflowers must be propagated by cuttings. 
Roses and creepers against walls should never be allowed to become entangled before they are trained. This is specially true of the Clematis-by the way, it will be remembered that $C$. Jackmanni and all that group may be very closely pruned in the winter and early spring, even down to the ground; but $C$. Montana and Banksian Rose never until after flowering.

About the middle of the month Dahlias may be planted out; a fresh loamy soil suits them best. The Cactusflowered are very charming. When showing flower buds they should be disbudded like Chrysanthemums.

\section{GARDENING IN JUNE}

THERE is a welcome respite from hard work in this leafy month of June, and more time for enjoying the fruit of our labours. If the weather has been moist the weeds will now grow apace, and should be given no quarter; if, on the other hand, there has been drought, then watering out of doors will be indispensable for newly-planted vegetables and flowers. A mere sprinkling does more harm than good-it attracts the roots to the surface where the sun dries them up. One abundant watering is preferable to two or three slight showers from the rose of the water-pot. After being watered the ground becomes hard on the surface, and should be loosened with the hoe. 
Very little sowing is necessary, but a good deal may be done in the way of planting. The crops of Carrots, ${ }^{*}$ Parsnips, Beet, and Onions should be thinned; Broccoli, Cauliflowers, and Cabbages pricked out into seed-beds.

A full crop of the most approved kinds of Turnips should be sown for the winter. Where room can be found for Garden Swedes, put them in drills 18 inches apart, and thin out to 9 or 12 inches. They keep better than all vegetables, lasting into the following summer.

Scarlet Geraniums (Zonal Pelargonium) should be removed from the greenhouse, and planted out in their summer quarters. Some of the smaller and better plants may be reserved, re-potted, and kept growing through the season in a cold frame, to flower in the house during autumn and winter, all flower-buds being for the present picked off as they appear.

Chrysanthemums should now have their final shift. This is the time for looking after the Freesia Bulbs which have been laid aside in their pots to dry on the shelf of the greenhouse. The secret of success with these bulbs is very simple. When the bloom is over the plants should still be vigorously grown on, and supplied with water until they naturally fade away. Then comes the time for laying them on their sides, and letting them bake in the sun-until the day for next season's potting-when they are at once transferred to their new quarters without having been left an hour out of the earth. The larger bulbs should be selected 
and planted in a strong, loamy compost, the pots being placed in a cold frame, getting very little water until they begin to show a green leaf. The grass is brittle and often needs some support.

All spring-flowering shrubs should now be gone over and judiciously pruned, more or less severely, according to their growth. Lilacs, Laburnums, Weigelias, and Pyrus Japonica are all the better for having a good deal of their wood cut away; but when this is done too late, it is likely to injure next season's bloom.

\section{GARDENING IN JULY}

THE gradual declension of the sun since Midsummer Day should suggest to the gardener the need of preparing for next year's crops. Every available space in the kitchen garden should be cleared and prepared for sowings and plantings now to be made.

A last crop of Peas and Beans and Kidney Beans (Canadian Wonder) may be sown early in the month; the first crops of Beans, when the last pulling has been made, may be cut down within 3 inches from the ground, they will probably sprout and produce a few good dishes in October.

The main crop of winter greens should be put in as soon as the young plants are fit-Borecole, Brussels Sprouts, Savoys, Cauliflowers, Broccoli, and Cabbage. 
Any favourite sort of Cabbage-such as Enfield Market or Nonpareil-should be sown about the middle or end of the month, for the principal spring or summer crops, the seed sown broadcast and thin on a well-prepared bed. It must be kept watered in dry weather and shaded until the seeds grow.

Some more Cabbage Lettuce may be sown for succession in winter and spring. In dry weather it needs watering, and the ground stirring about it while growing.

This is the best time of the year to sow Parsley; it will practically last into the second year without running to seed.

Late in the month a full winter crop of Prickly Spinach should be put in.

As the early Potatoes are dug, some White and Yellow Turnips may be put in their place each week through the month.

First Celery crops may be earthed.

Plantations from runners of really good Strawberries, layered now, and planted out when well rooted in showery weather, will be likely to bear a crop the following year.

Red and White Currant bushes tied up now in coarse muslin will have their berries preserved from birds and insects well into September-a season when fruit is less plentiful.

Alströmerias are not always easy to establish in gardens with heavy soil; perhaps the best chance for them is 
to pick the seeds from really good flowers and sow them immediately. They should be sown in the open where they are to bloom, they seldom bear transplanting. I have, however, somewhere seen this plan suggested-when they have flowered, treat them as Lily of the Valley; dig out square pieces, filling in the vacant spaces with fresh earth, and dropping in the squares cut out somewhere else without shaking off the earth that clings to them.

This is the month for sowing perennials-Columbines Delphiniums (Larkspurs), Gaillardias, Antirrhinums (Snapdragons), Stocks-as well as some of the better annuals, for planting out in autumn to bloom in early spring.

English and Spanish Irises will be the better if taken up now, the former replanted at once, the latter dried and planted in September. The Spanish like a dry place in full sun; the English do best in half shade, and like moisture.

Carnations should be layered before the end of the month. A layer has been defined as "a cutting not wholly separated from the parent plant until it has put out roots for its own support."

Early in the month both Pinks (e.g. Mrs Sinkins) and Carnations may be propagated by pipings, which make healthier and stronger plants than layers, though not so certain to strike.

Thin out the weaker branches of Dahlias, disbud, and tie to two or three stakes.

Roses may be budded while the bark rises freely. 


\section{GARDENING IN AUGUST}

THIS is the best month of the year for the gardener to take a holiday, not because there is no work to be done, but because it can be done almost equally well in July or September.

All weeds should be cleared away before they have ripened their seed. The weather generally favours the application of the hoe, which ought to be kept in constant use. Trees and shrubs planted within the year need to be watered freely during weeks of drought.

While people are away from home young French Beans or Scarlet Runners often grow more quickly than they can be used. When this is so they should be carefully picked two or three times a week, before they begin to grow coarse and old. As they are brought in they should be laid by in large earthenware pans-alternately a handful of beans with a handful of salt, until the pan is full. Preserved in this way, they may be eaten all through the winter. When wanted they can be taken out, well soaked, and then boiled in the usual way. Beans so treated will be found to have a much better flavour than any tinned vegetable.

In the early part of the month Cabbage seed for the main spring crop should be sown thinly, so as to have strong plants; the bed should be kept moist by shading if the weather is dry. Towards the end of the month some of the earlier sowings will probably be 
strong enough for transplanting in drills about a foot apart.

The last crop of Broccoli may now be planted out.

Early Horn Carrots, if sown in a small patch on a warm border, are likely to stand the winter, and prove very useful in spring.

Where a cold frame or turf pit is likely to be available for the protection of tender plants through the winter, a sowing of Cauliflowers is now desirable. Sow them thinly, in a warm aspect, on well-prepared soil.

Earth up early Celery after the roots have been well moistened by rain or watering. Do not add much earth at a time, and take care that none enters the heart. The outer stems should be well matured before earthing; the only object of the operation is to blanch it, which process takes but three or four weeks.

Early Leeks also should be earthed up if they have not been planted deep.

A few small sowings of prickly Winter Spinach and All the Year Round Lettuce may yet be made with some hope of success.

Raspberry Canes which have ripened off their fruit ought to be cut away so as to strengthen next season's wood.

New plantations of Strawberries may yet be made from the earliest runners of the best sorts, such as Royal Sovereign, Laxton's Latest, etc. All other runners should now be cut away.

In view of the September bloom, Hybrid Perpetual 
and Tea Roses should have the soil around them loosened from time to time with the hoe during drought. Water, where it may be had, should be given in abundance, but there is nothing like a mulching of farm-yard manure.

Chrysanthemums, whether in pot or border, may now have their tops removed at various heights, so that the flowers may range above each other, and have many flowering branches instead of one. Some of the most vigorous of the top shoots, if they be planted in thumb-pots as cuttings and plunged, will make capital dwarf specimens.

Choice Zonal Pelargoniums and Fuchsias, intended for the window or for winter bloom in the greenhouse, should be repotted, their growth pushed on, their flowers nipped off.*

Bulb catalogues ought to be studied and orders given for Hyacinths, Tulips, Daffodils, and so forth. The early orders probably secure the best bulbs. Our own bulbs, too, should be looked over to make sure they are not suffering from mould or damp.

Dahlias must be tied not too tightly to their stakes, and superfluous buds and stems removed, earwigs trapped in moss loosely placed in a small pot inverted on the stake. A good alternative is to insert a short length of hollow bean-stalk amongst the branches, examining it every morning, and blowing the creatures into a basin of boiling water.

The Carnations layered $\dagger$ last month will take six * See page 23. + See pages 44, 159. 
weeks to root; they should then be taken off, one or three put into a pot, and placed in a shady corner, to be established before winter. See that the drainage is good, as they resent damp more than frost.

GARDENING IN SEPTEMBER

SHORTENING days and cool nights are a bar to germination; there is, therefore, practically no sowing to be done. Cabbages may still be planted out from the seed beds; late Turnips, and Spinach thinned; Celery earthed; Onions dried and tied up in ropes or hanks, and hung in a dry, airy place.

All weeds should be kept down to prevent their seeding, decaying stems of peas and flowers burnt.

Gooseberries, Currants, and Raspberries may be manured this month with advantage.

The waning beauty of the flower borders suggests the need of keeping the plants that remain in good condition, and clearing away the unsightly remains of summer flowers.

Roses should be kept trim for their autumn blooms.

Seeds of Sweet Pea and other such things should be collected, dried, and labelled.

The weather must now be watched, and any choice half-hardy plants growing in the borders potted and placed in the window or greenhouse, so that they may 
escape frost and fill their pots with roots before winter.

It is time to prepare patches and beds for such bulbs as Lilies, Hyacinths, Tulips, Crocus, Snowdrop, and Chionodoxa (Glory of the Snow), so that when they arrive no time may be lost in getting them in.

New herbaceous things, specially those that bloom early, may be planted.

Cuttings of Roses-Tea, China, or Hybrid Perpetualmay be put in until the middle of October in drills, with a little light, sandy soil round the cuttings and treading them very firmly with the foot. Many Roses do better on their own roots than on Dog Briars or Stocks* of any kind. Next to July, September is the best month for budding.

Dahlias should be attended to, earwigs trapped (see August), and faded flowers removed.

Chrysanthemums disbudded and their shoots tied. As the flower-buds mature, they should be fed every few days with liquid manure, soot water, or artificial manure, varying the mixture every ten days.

Read over Nursery Catalogues, and fill up the order sheets.

$$
\text { * See page } 79 .
$$




\section{GARDENING IN OCTOBER}

THIS month's work consists chiefly in harvesting vegetable roots, Apples and Pears, planting bulbs, and sheltering tender plants. Parsnips and Carrots should be taken up when their tops have turned, to be packed in sand in a dry place. Care is needful to avoid hurting the roots when being lifted. It is just as well to leave some of the Parsnips in the ground, protecting with litter in frost.

Lettuce may be planted out in some sheltered place, in a bright, dry border.

In dry weather the main crop, Potatoes, should be dug, stored away in a cool, dry cellar, or pitted out of doors with a lining of straw, the tubers having been left a few hours lying on the ground to dry.

Towards the end of the month begin to prune Gooseberries and Currants, also prune Shrubs-do not clip them.

Trench all ground that has been cleared of crops.

Plant Roses, Shrubs, and Fruit Trees, having given your order last month.*

The Wallflowers (Red and Yellow) sown in early summer and pricked out in nursery beds, should now be planted in beds and groups to ensure an early bloom. Likewise, Primroses and Polyanthus, Alyssum, Candytuft, Aubretia, Foxgloves, Canterbury Bells, Early Tulips, Snowdrops, Hardy Cyclamens, Hepatica, and Winter Aconite-all this with a view to bright borders next spring.

$$
\text { * See page I } 30 .
$$


The longer Chrysanthemums in pots can be kept out of doors the better. But all the arrangements for their reception should have been made, so that on the approach of real frost they may be brought in on half an hour's notice.

This is, perhaps, the best season to lay in the raw material for composts. It will be well to secure a store of good turf from an old pasture-it should be built into a square stack, and covered above with a few large slates or a piece of corrugated iron. A couple of barrows full of byre dung should be carefully stacked in a corner of the shed; like the conventional old port of our fathers' days, it improves by keeping.

Such bulbs as Tulips, Hyacinths, Narcissus Tazzeta, etc., meant for flowering in the window garden, should now be potted. Let the soil be dry, and the bulbs put in firmly, and just deep enough in the pot to admit of the bulb itself, not the neck, being covered. Let them be plunged in a warm, dry place, and covered 6 inches deep with sand or coal ashes, until the pots have been filled with roots.

My list of late Tulips includes Bouton d'Or, Elegans Billietiana, Golden Eagle, Picotee, Maiden's Blush, Retroflexa, and Greigii. 
THERE is little to be done in these winter months in the way of sowing or planting, but when the weather permits, the ground should be prepared for future operations. The earth should be thrown up in ridges, so as to expose it fully to the weather, and to the healthy influence of frost. This will have better results in mellowing the soil than one-half additional manure.

If the weather be frosty and the ground hard, it is well to carry manure to the plots which are to receive it.

Let Cauliflower plants in frames have air. The old decaying leaves of Rhubarb and Seakale should be cleared away, and the crowns covered with litter, sand, or coal ashes.

Mazagan Beans and American Wonder or "Sangster No. I" Pea may be sown for a first crop on light ground and sunny borders.

Spinach sown in August, that has been properly thinned to 9 inches apart, will continue to grow through winter and spring. Cabbages may still be planted in November for the spring crop. Brussels Sprouts and Savoys should have their dead leaves removed and the ground cleared.

Currants and Gooseberries may still be planted or pruned while the weather is mild and dry. Neither prune nor transplant in frost. 
As the storms and nipping frosts begin to spoil the beauty of the flower borders, compensation will be found in keeping these neat by cutting away all decaying foliage, and top-dressing the ground with fresh and rich composta mixture of rotten dung, fresh earth, sand, and leaf mould. Dahlias should either have a thick covering of coal ashes or peat thrown over them, or, better still, they may be taken up on a fine day, their labels carefully fixed on them, and their colours, height, and quality entered in a note-book; let them dry gradually, and then be stored in sand beyond the reach of damp and frost. They are well worth all the trouble.

Plant out Hyacinths and Tulips in groups, 4 to 6 inches deep and 6 apart; surround them with sand, which acts as drainage, and preserves the coats of the bulbs from decay.

Pick from plants in greenhouse, pit, or window, dead or mouldy leaves; give water sparingly, if at all. Keep the temperature of the greenhouse as near as possible to $50^{\circ}$. When the outside air is up to $45^{\circ}$, let in plenty at middle day, avoiding draughts. The more fresh air the better, provided it be warm and genial-the less the better if it be moist and raw. 


\section{A SHORT LIST OF REFERENCE BOOKS ON GARDENING FOR STUDENTS}

"The English Flower Garden." By W. Robinson. I5s. "The Vegetable Garden." By Vilmorin-Andrieux. I 5 s. "Wood and Garden." By Miss Jexyll. 1os. 6d. net. "Home and Garden." By Miss Jekyll. ros. 6d. net. "Cottage Gardener's Dictionary" (last Edition revised). 9s. "Treasury of Botany." By Lindley AND MOORE (latest Edition in 2 vols). 9s. net.

One of the best of Reference Books on General Botany ever published.

"Domestic Floriculture." By F. W. Burbidge. 7s. 6d. "Popular History of British Ferns." By Thomas Moore. 5 s. "A Fern Book for Everybody." By M. C. Cooke. Is. "Epitome of Gardening." By Moore and Masters. 6s. "Manual of Horticulture." By J. Wright. is. "Chrysanthemums and their Culture." By Edwin Molyneux. Is.

"The Cottager's Calendar of Gardening Operations." By Gardeners' Chronicle. 3d. 


\section{SPECIMEN EXAMINATION PAPERS}

I.

r. Write a short account of the best way to treat Lilies, and give the names of some of the most important kinds.

2. Distinguish groups of Irises. Explain their culture. Name some of the more familiar.

3. Give a description of an effective spring border.

4. Write a note on-

(a) The Christmas Rose.

(b) Snowdrop.

(c) Violet.

5. Explain the process of planting and growing spring bulbs.

6. Write down in a few words the more important points connected with a greenhouse.

7. How should Chinese Primulas be treated?

8. Give a list of your twelve favourite shrubs.

\section{II.}

I. Name three distinct varieties of the Common Polypody.

2. Give directions on paper for the planting of an Apple, noting three or four important points.

3. How should you set about the pruning of a Gooseberry? 
4. What symptoms should make you decide on root-pruning a tree?

5. Describe the process.

6. To what family does the Mahonia belong?

(a) Describe the Muhlenbeckia.

(b) Aucuba Japonica.

7. What do you consider the most effective summer bulbous plants?

8. Write an order for a dozen flowering shrubs.

9. Write a list of the autumn flowers you should choose for your herbaceous border.

\section{III.}

I. Of what departments do you consider an average villa garden should consist?

2. Enumerate six autumn flowers.

3. Enumerate six Dutch roots.

4. Enumerate six evergreen shrubs.

5. Enumerate six winter flowers.

6. Give the English and the Latin names of the Milkflower.

7. Describe the three parts of a Fern.

8. Explain "Rhizome." 


\section{IV.}

I. Explain to your gardener on paper-

(a) Your method of growing Ten Week Stocks or Asters.

(b) Of striking Rose cuttings.

(c) Of budding a Maréchal Niel Rose on a Dog Briar.

(d) Of layering a Carnation.

2. Describe the process of grafting, and state, the benefits to be derived from it.

3. What should you expect to find in a well-furnished potting shed?

4. Put down lists of herbaceous plants or bulbs such as would furnish a small herbaceous border with plants in bloom between March and June, giving-

(a) Six varieties each of white, red, and yellow plants.

(b) Three varieties of blue and pink.

(c) A few of most suitable edging plants.

5. Sketch a plan of your border showing how you would distribute your plants.

6. How should you set to work to make and use a hot-bed for spring propagating?

7. Describe your method of pruning Banksian Roses, and Clematis Montana, so as to ensure their bloom.

8. Write down a list of the best known British Ferns. 
I. Give the scientific names of-

(a) The Trinity Flower.

(b) Snowflake.

(c) Mexican Orange.

(d) Evening Primrose.

2. Name two or three types of Phlox.

$\begin{array}{llll}" & \text { " } & & \text { Gentian. } \\ & \text { " } & & \text { Poppy. }\end{array}$

3. To what genus do the following belong?-
(I) Houseleek.
(2) London Pride.
(3) Periwinkle.

4. Explain briefly the process of budding a Rose.

5. Give directions for pruning a Black and Red Currant bush.

6. Give a short list of your favourite hardy Annuals.

7. Enumerate the Filmy Ferns.

8. Write a brief note on the Heartsease.

\section{VI.}

I. Explain briefly the classification of British Ferns.

2. To what groups of Ferns do the following belong?-
(a) Osmunda.
(b) Limestone Polypody.
(c) Killarney. 
3. Name some varieties of the Polypody.

4. Write a short note on the culture of the Wallfower.

5. Give the scientific name of-
(a) The Ivy Vine.
(b) Cape Gooseberry.
(c) Winter Gladiolus.
(d) New Zealand Flax.

Give season of bloom of-
(a) Clematis fammula.
(b) Clematis vitalba.

7. How should the Dahlia be treated in autumn and spring?

8. How are such herbaceous plants as the Aster and Pyrethrum uligunosum propagated?

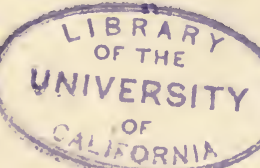





\section{N D E X}

Adiantum capillus Veneris, 89

Ailantus, 97

Almonds, 104

Alpines, 76

Alpine borders, 73

Alpine fern, 85

Alströmeria, 55

Alyssum, 56

Ampelopsis, 8, 94, 109

Anemones, 53, 153

Annuals, 176

Antirrhinum, 55

Aphis, see Greenfly

Apple, 103, 132 storing of, 138

Apricots, 133

Aquilegia, $5^{6}$

Aralia Sieboldi, 107

Arbutus, Croomei, II 2

$$
\text { Unedo, I } 12
$$

Aristolochia Sipho, 97

Arunao Donax, 107

Asparagus, 124

Aspect, 7 I, 174

Aster, 56

Aubretia, 56, 72

Aucuba, 101, 113

Auricula, 172

Autumn flowers, 55

Azara, 97
Bamboo, 102

Metake, 102

gracilis, 102

palmata, 102

Beans, 119

Kidney, 124

Beech fern, 87

Beet, 123

Begonia, Tuberous-rootea, 24, 31, 167

Bell flower, 57

Berberis, 94, 1 I I

stenophylla, 94

Fortunei, 111

Betula papyrifera, 112

Biennials, 178

Birds, 33

Blanching of rhubarb, 125

Celery, 126

Seakale, 125

Blechnum, 87

Bleeding Heart, $5^{8}$

Bocconia cordata, 57

Books of Reference, 212

Borecole, 124

Briar, Sweet, 108, 180

$$
\text { Dog, 4I, } 207
$$

Broccoli, I2I

Broom, 106

Budding, 4I

Buddleia, 106 
Buds-Chrysanthemums, 163

Bulbs, Dutch, 47, 209

Bush Honeysuckle, II 2

Cabbage, 121

Cactus, 22

Campanula, 57

Canker, 37

Cannovers Colossal or Purple Ar. genteatil, 125

Canoe Birch, II 2

Cape Gooseberry, II I

Cape Hyacinth, 60

Carnations, 45, 157, 202

Carrots, 120

Caterpillar, 34

Cauliflowers, I2I

Celery, I26

Ceterach officinarum, 88

Chamorops Fortunei, I02

Cheiranthus, 169

Cherries, I33

Chimonanthus fragrans, 94

Chinese Primula, 23, 172

$$
\text { sowing of, } 3 \mathrm{I}
$$

Choisya ternata, 105

Christmas Roses, 71, 168

Chrysanthemum, 25, 160

Cinquefoil, 65

Clay, Io

Clematis, 93

montana, 95

Jackmani, 95

lanus inosa, 95

Climbers, 93

Clipping ivy, 99

Colchicum, 49, 168

Cold frame, 26, 29

Columbine, 56

Composts, 4, 16, 162, 209
Cone flower, 66

Convolvulus, 97

Cordyline Australis, 102, II 3, I82

Cotoneaster, 93, II I microphylla, 97

Cratagus, 104 Oxyacantha pracox, 105

Crocosmia, 68

Cucumber, 127

Currants, 135

Cuttings, propagation of, 28 making of, 45 planting out, 192

Cyclamen, 166 sowing of, $3 \mathbf{I}$

Cydonia Japonica, 94

Daisy Tree, I Iо

Dahlias, 194, 198, 205, 21 I

Daffodil, 52, 72

Daphne, 107

Mezereon, 107

Cneorum, 107

Day Lily, 6I

Delphinium, 58

Desfontania, 105

Dianthus barbatas, 57

Dicentra, 58

Dielytra spectabilis, 58

Digitalis, $5^{8}$

Digging, I3

Doronicum, 59

Dracana, 102

Draining, 12

Dress, 7

Dutch bulbs, 47

Edelzweiss, 76

Elder, Golden-leaved, 104

Eloeagnus, IIO, II3 
Epimedium, 108, 1 II

Erigeron, 59

Erinus Alpinus, 59

Eryngium, 59

Escalonia macrantha, 94

Eucalyptus, I8I

Euonomus radicans, $\mathrm{I} 14$

Eurybia, 110

Evening Primrose, 63

Examination Papers, 213

Fabiana imbricata, 106

Farms, Experimental, I 29

Ferns, 75, 113

classification of, 86

transplanting of, 90

Ferneries, construction of, 90

Figs, II I, I34

Flags, 146

Flame Flower, 6I

Fleabane, 59

Food of plants, 15

Forsythia suspensa, 94 viridisissima, 94

Fortunes Palm, 102

Foxglove, $5^{8}$

Fragrant plants, 179

Freesia Bulbs, treatment of, 199

Fritillaria, 53

Fruit, growing, 129

gathering of, 138

Fuchsia procumbens, II 3

loam for, 5

Fungus, 35, 128

Gaillardia, 59

Galtonia candicans, 60

Garrya elliptica, II 2

Genista monosperma, 106
Gentians, 72, 143

Geraniums, Ivy-leavea, II 3

Scarlet, 199

Germination, $3^{8}$

Gladiolus, 60

Globe-flower, 68

Gooseberry, 136

Grafting, 42

Grass, Lawn, II 5

Pampas, 102

Molinia altissima, 102

Green Briar, 98

Greenfly, 35, 133, 193

Greenhouse, I8, 187, 2 I I

Ground, preparation of, II7

Guelder Rose, 106

Gunnera, 6o

Hairbell, 57

Half-hardy plants, I7

annuals, 177

Hanging baskets, II 3

Hartstongue fern, 88

Heartsease, 140

Helianthus, 60

Hellebore, 168

$$
\text { Lent, 51, } 168
$$

Hemerocallis, 6r

Herbaceous borders, 69

Holly, ror

Honeysuckle, Dutch, 108

Hop, 97

Hot-bed, 27

how to make, I 89

House Leek, 67

Hyacinth, 54

Hydrangea, 107 climbing, 100

Hymenophyllum Wilsoni, 89

Tunbridgense, 89 
Inarching, 44

India-rubber plant, II 3

Insects, 193

Ipomoa, 97

Iris, 144

English, 145

Spanish, 145

German, 147

replanting of, 202

Ivy, 72, IIO, II 3 climbing, 93, 98

Golden, 105

Silver, 106

Ixia, 67

Jasmine, 94

Judas tree, 107

runiper, II4

Kalendar, 186

Kerria Japonica, 104

Killarney Fern, 89

Kniphofia, 6I

Labels, 7

Larkspur, 58

Lastrea Thelypteris, 87

Laurels, Ior

Portugal, ror

Laurestinus, IOI

Lavender, 105

Lawn Shrubs, 100

Lawns, treatment of, $\mathrm{II}_{4}$

Layering, 44

Leeks, I 2 I

Leopard's Bane, 59

Lettuce, I20

Leucojum, 6I

Leycesteria formosa, 112

Lilac, 107
Lilies, 72, 148

Lily of the Nile, 65

Lithospermum prostratum, 62

Loam, Io

Lobelia, 62

Lonicera, II 2

Lupine, 62

Lychnis, 62

Magnolia, 94

Maidenhair Fern, 89

Manures, 15,187

Marrow, Vegetable, 127

Marsh Fern, 87

Maurandya, 97, 177

Meconopsis, 64

Medlars, 104

Melia azadarach, 97

Mesembryanthemum, Cape, II 3

Mexican Orange-flower, 105

Mice, 33

Michaelmas Daisy, 56

Mignonette, I77, 194

in pots, 29

in beds, 40

Mildew, 35

Mimulus, 62

Mock Orange, 106

Molinia altissima, I02

Monkey-fozver, 62

Montbretia, 68

Mountain Ash, IIo

Muhlenbeckia complexa, 98, I10

Mullein, 68

Myrsiphyllum asparagoides, 98

Narcissus, 5I

Nasturtium, 95

Nectarines, 133

Nemophila, 40, 192 
New Zealand Flax, 102

Nymphaa, 184

Oak Fern, 85,87

Enothera, 63

Olearia, I Io

Onion, II 9

Onoclea sensibilis, 88

Ornithogalum, 63

Osmunda, 87

Ozothamnus rosmarinitolius, II I

Prony, 63

Pansy, 140

Tufted, I4I

Pampas Grass, 102, III

Papaver, 64

Parsley, I2I

Parsley Fern, 87

Parsnip, 120

Passion flower, 94

Peaches, 133

Pears, 132

Peas, II 9

Pelargonium, Zonal, 23, 205

Penstemon, 64

Perennials, 178 sowing, 202

Periwinkle, 68

Peruvian Lily, 55

Phlox, 64

Phormium tenax, 102

Phyllereas, IoI

Physalis Alkekengi, II I

Picotee, I 59

Pines, diminutive, II4

Pinks, 159

Pittosphorum Maii, 105

P'lanting shrubs, IOI fruit trees, 130
Ploughing, 13

Plum, 133

Plume Poppy, 57

Polyanthus, 174

Polygonatum, 65

Polypody, 75

Welsh, 87

Cornish, 87

Polystichum, 87

Poppy, 64

Poppywort, 64

Potato, I 22

disease, 37

rotation, II 7

method of cooking, 123

time for planting, 188

Potentilla, 65

Potting, 6

Prickly Rhubarb, 60

Prickly Shield Fern, 87

Primroses, 172

Prince of Wales' Plume, 88

Propagating pit, 27

Pruning trees, 129

roots, 131

currants, 135

gooseberries, 136

time for, 186,200

Purple Rock Cress, 56

Pyracanthas, 95, 109

Pyrethrum, 65

$$
\text { uliginosum, } 65
$$

Quercus rubra, 104

aurea, 104

coccinea, 104

Quince, 104

Raspberries, 135

Reed, Great, 107 
Rhododendrons, Hybrid, 104

Rhubarb, 125

blanching, I 25

Rhus cotinus, 107

Richardia Athiopica, 65

Rock borders, 69

Rockery, building of, 73

Rock Madwort, 56

Rodgersia podophylla, 66

Roses, 77

Tea, 77

Noisette, 77

Climbing Ramblers, 78

Hybrid Perpetuals, 78

propagating of, 79, 207, I I I

for market, 25

Rosemary, 105

Rotation of crops, I 16, 191

R'udbeckia, 66

Rush Lily, 54

Salix Vitellina, II 1

Salsify, '123

Salvia, 66

Sand, Io

Sanguinaria Canadcnsis, 54

Saxifraga, 66, 72 sarmentosa, 66

Scale fern, 88

Schizophragma hydrangeoides, 100

Schizostylis coccinea, 67

Scillas, 143

Scolopendrium fern, 4, 88

Sea Holly, 59

Seakale, 125

Sedum, 67

Seed, sowing of, 39

Sempervivum, 67

Shading glass, 21

Shrubs, 109
Shrubs, for house, 112

Siberian Crab, 103

Sisyrinchium, 54

Slugs, 33

Smilax, 98

Smoke Plant, 107

Snapdragon, 55

Snowdrop, 50

Snowflake, 51, 6I

Soil, 9

its composition, 10

Solomon's Seal, 65

Sowing, 192 reasons of failure in, 40

Sparaxis, 67

Spinach, 123

Spleenwort fern, 88

Spring Garden, The, 47

Sprouts, Brussels, 124

Star of Bethlehem, 63

St Bridget Anemone, 155

Sternbergia, 67

Stock, 178

Stone crop, 67

Storing fruit, 138

Stoves, heating, 19

Strazberry, 134

Strawberry tree, II 2

Struthiopteris germanica, 88

Sumach, I I I

Summer flowers, 55

Sunflozver, 60

Sweet Peas, 176, I78

Sweet William, 57

Tellima grandiflora rubra, II I

Thorns, I04

Glastonbury, 105

Todeas, 89

Tomato, 26, 127 
Tools, 8

Trenching, I3

$$
\begin{aligned}
& \text { bastard, } 118 \\
& \text { time for, } 186
\end{aligned}
$$

Trichomanes radicans, 89

Irillium, 54

Tritoma, 61,

Iritonia, 68

Trollius, 68

Tropaolum, 95

$$
\begin{aligned}
& \text { speciosum, } 96 \\
& \text { tricolor, } 97 \\
& \text { polyphyllum, } 96
\end{aligned}
$$

Tulip, 25, 48, 53, 209

Turf, laying down, 114

Turnip, 123, 199

Vegetables, culture of, II 6

Venetian Sumach, 107

- Verbascum, 68

Verbena, 108, 194
Vinca, 68

Viola, 14I

Violets, I42

Virginian Vine, 109

Vitis Coignetia, 94

Wallfower, 169, I78, 197

Wall Garden, 74

Watering, 19, 190, 196, 198

Water-lilies, 184

Weeds, 32

Weigelia rosea, 106

Willow, Golden, I II

Window boxes, I12, I1 3, 195

Winter Daffodil, 67

Wire baskets, 20, 113

Wireworms, 34

Wistaria Sinensis, 94

Yucca, 102

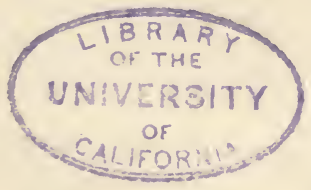

PRINTED AT THE EDINBURGH YRESS, 9 AND II YOUNG STREET. 


\section{TWO BOOKS ON \\ ENGLISH COUNTRY LIFE}

\section{A Cotswold Village}

OR, COUNTRY LIFE AND PURSUITS IN GLOUCESTERSHIRE By J. ARTHUR GIBBS New and Cheaper Edition

With Portrait and many Illustrations Large Crown 8vo. 6s.

The New Forest

ITS TRADITIONS, INHABITANTS, AND CUSTOMS By ROSE DE CRESPIGNY AND HORACE HUTCHINSON With a Photogravure Frontispiece and other Illustrations, and a Map Crown 8vo. 7s. 6d. 


\section{WORKS BY CHARLES DARWIN \\ (A SELECTION)}

JOURNAL OF A NATURALIST DURING A VOYAGE ROUND THE WORLD IN H.M.S. "BEAGLE." With Portrait. Popular Edition. 3s. $6 d$. Also with 100 Illustrations. Medium 8vo. 2 I $s$.

VARIATION OF ANIMALS AND. PLANTS UNDER DOMESTICATION. Woodcuts. 2 vols. I5s.

VARIOUS CONTRIVANCES BY WHICH ORCHIDS ARE FERTILIZED BY INSECTS. Woodcuts. $7 s .6 d$.

MOVEMENTS AND HABITS OF CLIMBING PLANTS. Woodcuts. $6 s$.

INSECTIVOROUS PLANTS. Woodcuts. $9 s$.

CROSS AND SELF-FERTILIZATION IN THE VEGETABLE KINGDOM. 9 s.

DIFFERENT FORMS OF FLOWERS ON PLANTS OF THE SAME SPECIES. 7s. $6 d$.

FORMATION OF VEGETABLE MOULD THROUGH THE ACTION OF WORMS. Illustrations. $6 s$. 


\section{WORKS ON BOTANY, Etc.}

GREENHOUSE AND STOVE PLANTS, FLOWERING AND FINE-LEAVED, PALMS, FERNS, AND LYCOPODIUM, with Full Details of the Propagation and Cultivation of 500 Families of Plants, embracing all the best kinds in Cultivation, suitable for growing in the Greenhouse, Intermediate House, and Stove. By Thomas BaINES. 8vo. I2s.

CHAPTERS IN MODERN BOTANY. By PATRICK GedDes, Professor of Botany, University College, Dundee. With Illustrations. Crown 8vo. 3s. $6 d$.

THE REALM OF NATURE: A MANUAL OF PHYSIOGRAPHY. By Dr Hugh RoBert Mill, Librarian to the Royal Geographical Society. With I9 Coloured Maps and 68 Illustrations. Crown 8vo. 5 s.

AN INTRODUCTION TO MODERN GEOLOGY. By R. D. Roberts, sometime Fellow of Clare College, Cambridge; Fellow of University College, London. With Coloured Maps and Illustrations. Crown 8vo. $5 s$.

RECORDS OF A NATURALIST ON THE AMAZONS, DURING ELEVEN YEARS' ADVENTURE AND TRAVEL. By H. W. BATES, F.R.S. With a Memoir by Edward Clodd. With Portrait, Coloured Plates, Illustrations, and Map. Medium 8vo. I8s.

LONDON : JOHN MURRAY, ALBEMARLE STREET, W. 



\section{DAY USE \\ RETURN TO DESK FROM WHICH BORROWED \\ LOAN DEPT.}

This book is due on the last date stamped below, or on the date to which renewed. Renewals only: Tel. No. 642.3405

Renewals may be made 4 days prior to date due. Renewed books are subject to immediate recall.

\section{JAN2 0197224}

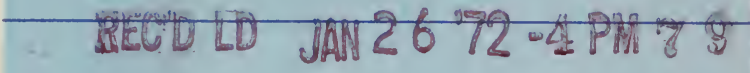




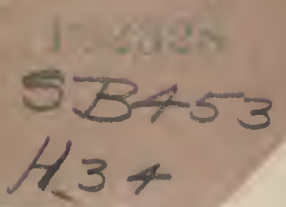




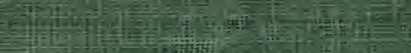

1.

ition

12.

Hif

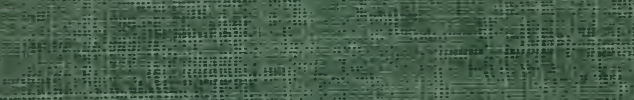

(4)

(16)

(5)

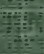

tive $=5$

(1)

1)

(1)

(1)

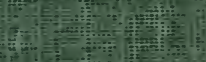

H.

Witio:

a.

sit. 